\title{
1 Ensovibep, a novel trispecific DARPin candidate that protects against
}

\section{SARS-CoV-2 variants}

3 Sylvia Rothenberger ${ }^{1,2,{ }^{*}}$, Daniel L. Hurdiss ${ }^{4,5,{ }^{*}}$, Marcel Walser ${ }^{3,{ }^{*}}$, Francesca Malvezzi ${ }^{3,{ }^{*}}$, Jennifer Mayor ${ }^{1,2}$, Sarah Ryter ${ }^{1}$, Hector Moreno ${ }^{2}$, Nicole Liechti ${ }^{1}$, Andreas Bosshart ${ }^{3}$, Chloe Iss ${ }^{3}$, Valérie Calabro ${ }^{3}$, Andreas Cornelius $^{3}$, Tanja Hospodarsch ${ }^{3}$, Alexandra Neculcea ${ }^{3}$, Thamar Looser ${ }^{3}$, Anja Schlegel $^{3}$, Simon Fontaine ${ }^{3}$, Denis Villemagne ${ }^{3}$, Maria Paladino ${ }^{3}, Y_{\text {Vvonne Kaufmann }}^{3}$, Doris Schaible ${ }^{3}$, Iris Schlegel ${ }^{3}$, Dieter Schiegg ${ }^{3}$, Christof Zitt ${ }^{3}$, Gabriel Sigrist ${ }^{3}$, Marcel Straumann ${ }^{3}$, Julia Wolter ${ }^{3}$, Marco Comby ${ }^{3}$, Julia M. Adler ${ }^{9}$, Kathrin Eschke $^{9}$, Mariana Nascimento ${ }^{9}$, Azza Abdelgawad ${ }^{9}$, Achim D. Gruber $^{10}$, Judith Bushe ${ }^{10}$, Olivia Kershaw ${ }^{10}$, Heyrhyoung Lyoo ${ }^{4}$, Chunyan Wang ${ }^{4}$, Wentao Li ${ }^{4}$, leva Drulyte ${ }^{6}$, Wenjuan Dư ${ }^{4}$, H. Kaspar Binz ${ }^{7}$, Rachel Herrup ${ }^{8}$, Sabrina Lusvarghi ${ }^{8}$, Sabari Nath Neerukonda ${ }^{8}$, Russell Vassell ${ }^{8}$, Wei Wang ${ }^{8}$, Susanne Mangold ${ }^{3}$, Ramanathan ${ }^{13}$, Seth Lewis ${ }^{3}$, Randall Watson ${ }^{3}$, Micha A. Haeuptle ${ }^{3}$, Alexander Zürcher ${ }^{3}$, Keith M. Dawson ${ }^{3}$, Daniel Steiner ${ }^{3}$, Carol D. Weiss ${ }^{8}$, Patrick Amstutz ${ }^{3}$, Frank J.M. van Kuppeveld ${ }^{4}$, Michael T. Stumpp ${ }^{3,14, * *}$, Berend-Jan Bosch ${ }^{4, * *}$, Olivier Engler ${ }^{1, * *}$, Jakob Trimpert ${ }^{9, * *}$

* These first authors contributed equally to this work

** These senior authors contributed equally to this work

${ }^{1}$ Spiez Laboratory, Austrasse, 3700 Spiez, Switzerland

${ }^{2}$ Institute of Microbiology, University Hospital Center and University of Lausanne, Rue du Bugnon 48, 1011 Lausanne, Switzerland

${ }^{3}$ Molecular Partners AG, Wagistrasse 14, 8952 Zurich-Schlieren, Switzerland

${ }^{4}$ Department Biomolecular Health Sciences, Division Infectious Diseases \& Immunology - Virology section, Faculty of Veterinary Medicine, Utrecht University, 3584 CL, Utrecht, The Netherlands.

${ }^{5}$ Cryo-Electron Microscopy, Bijvoet Center for Biomolecular Research, Department of Chemistry, Faculty of Science, Utrecht University, Padualaan 8, 3584 CH Utrecht, The Netherlands

${ }^{6}$ Materials and Structural Analysis, Thermo Fisher Scientific, Eindhoven, 5651 GG, The Netherlands.

${ }^{7}$ Binz Biotech Consulting, Lüssirainstrasse 52, 6300 Zug

${ }^{8}$ Laboratory of Immunoregulation, Division of Viral Products, Center for Biologics Evaluation and Research, U.S. Food and Drug Administration, Silver Spring, Maryland, USA

${ }^{9}$ Freie Universität Berlin, Institut für Virologie, Robert-von Ostertag-Straße 7-13, 14163 Berlin, Germany Germany

${ }^{11}$ Novartis Institutes for BioMedical Research, PK Sciences, Cambridge, MA, USA 
35

36

37

38

39

40

41

42

43

45

46

47 Conflict of interests: authors from Molecular Partners own performance share units and/or stock of the 48
${ }^{13}$ Novartis Pharma AG, Basel, Switzerland

${ }^{14}$ To whom correspondence should be addressed:

Michael T. Stumpp

+4144755 7700

info@molecularpartners.com
Keywords: SARS-CoV-2, COVID-19, coronavirus, mutations, emerging variants, antiviral therapy, ensovibep, MP0420, DARPin drug, ankyrin repeat protein, DARPin, multispecific, K417N, K417T, L452R E484K, N501Y, B.1.1.7, B.1.1.529, B.1.351, P.1, B.1.429, B.1.526, B.1.617, B.1.618, B.1.621, AY.1, alpha, beta, gamma, delta, mu, omicron, Roborovski dwarf hamster company. H.K.B. owns stock of the company. I.D. is an employee of Thermo Fisher Scientific. C.G.K.; K.K.B. and K.R. are employees of Novartis. The other authors declare no competing interests. 


\section{Abstract}

51 SARS-CoV-2 has infected millions of people globally and continues to undergo evolution. Emerging variants can be partially resistant to vaccine induced and therapeutic antibodies, emphasizing the urgent need for accessible, broad-spectrum therapeutics. Here, we report a comprehensive study of ensovibep, the first trispecific clinical DARPin candidate, that can simultaneously engage all three units of the spike protein trimer to potently inhibit ACE2 interaction, as revealed by structural analyses. The cooperative binding of the individual modules enables ensovibep to retain inhibitory potency against all frequent SARS-CoV-2 variants, including Omicron, as of December 2021. Moreover, viral passaging experiments show that ensovibep, when used as a single agent, can prevent development of escape mutations comparably to a cocktail of monoclonal antibodies (mAb). Finally, we demonstrate that the very high in vitro antiviral potency also translates into significant therapeutic protection and reduction

61 of pathogenesis in Roborovski dwarf hamsters infected with either the SARS-CoV-2 wild-type or the 62 Alpha variant. In this model, ensovibep prevents fatality and provides substantial protection equivalent 63 to the standard of care mAb cocktail. These results support further clinical evaluation and indicate that ensovibep could be a valuable alternative to mAb cocktails and other treatments for COVID-19. 
65

66

67

68

69

70

71

72

\section{Introduction}

The extent of the COVID-19 pandemic allowed SARS-CoV-2 to quickly undergo adaptive evolution. The main mutations localize to the spike protein, a metastable prefusion trimer on the viral membrane that mediates virus entry into the host cell. The spike protein comprises multiple functional subunits: S1, which includes the N-terminal domain (NTD) and the receptor binding domain (RBD), responsible for interaction with the angiotensin-converting enzyme 2 (ACE2) host receptor ${ }^{1-4}$, and the S2 subunit, which is responsible for virus-host cell membrane fusion via extensive, irreversible conformational changes $^{5-8}$. In the first months of the pandemic, a single mutation, D614G, located in the S2 domain, became prevalent. This mutation impairs premature conformational change of the spike protein, thus increasing the number of infectious viral particles and therefore overall viral infectivity ${ }^{9}$. By November 2021, more viral lineages have been identified and designated as Variants of Interest (VOIs) or Variants of Concern (VOCs) based on their associated increased risk to public health. These were first isolated in the UK (Alpha, B.1.1.7 lineage), South Africa (Beta, B.1.351), Brazil (Gamma, P.1), South California (Epsilon, B.1.429), Nigeria (Eta, B.1.525), New York, (lota, B.1.526), Peru (Lambda, C.37), Japan (R.1), India (Kappa, B.1.617.1 and Delta, B.1.617.2), Uganda (A.23.1), and, more recently, in Colombia (Mu, B.1.621), the UK (Delta Plus, AY.1), as well as Africa (Omicron, B.1.1.529) ${ }^{10-22}$.

Many of these variants harbor mutations in the RBD domain of the spike protein, mainly in the ACE2 binding site (K417T/N, N439K, L452R, E484K/Q, N501Y). Since this region is also highly immunogenic, these mutations have been linked to a dual effect: either increasing the affinity to the human ACE2 receptor (N439K, N501Y) and therefore transmissibility, and/or facilitating immune escape of the virus (K417T/N, L452R, E484K/Q) 10,11,15-17,23-25. In particular, the E484K substitution has been shown to play a key role in attenuating the potency gain and resistance to the majority of antibodies, according to a study analyzing clinical-stage therapeutic antibodies ${ }^{12}$.

Fighting the COVID-19 pandemic requires a coordinated global effort to maximize the benefits of vaccinations and therapeutics ${ }^{1}$. The presence of an unvaccinated portion of the population and the evolution of escape mutants highlights the medical need for globally accessible therapeutics ${ }^{26}$. Neutralizing mAbs are a critically important therapeutic approach against COVID-19. To circumvent their loss of potency due to viral mutational escape, antibody cocktails were generated to provide increased protection against variants ${ }^{27-29}$.

We have applied the DARPin platform ${ }^{30}$, which allows fast generation and cost-effective production of biological therapeutics, to generate ensovibep, an anti-SARS-CoV-2 multispecific DARPin antiviral clinical candidate ${ }^{31,32}$. DARPins are an emerging class of novel therapeutics that are actively being developed in ophthalmology and oncology ${ }^{33,34}$. They are structurally fully differentiated from antibodies 
98

99

100

101

102

103

104

105

106

107

108

109

110

111

112

113

114

115

116

117

118

119

120

121

122

123

and consist of a single chain of linked DARPin binding domains. In the case of ensovibep, the molecule comprises two human serum albumin binding DARPin domains for systemic half-life extension ${ }^{35}(\mathrm{H} 1$ and $\mathrm{H} 2$ ) and three spike protein RBD-binding DARPin domains at the C-terminus (R1, R2 and R3). The relatively small size of ensovibep ( $85 \mathrm{kDa}$ ), in conjunction with high thermal stability ${ }^{31}$, high production yields ${ }^{31}$ and demonstrated high protection against viral escape mutations and variants makes this molecule an attractive alternative to other treatments.

Using structural analysis, we provide an explanation for ensovibep-mediated neutralization of the SARSCoV-2 spike protein. The three distinct DARPin domains can simultaneously target the receptor binding ridge on each RBD of the spike trimer, locking the spike in an open-conformation and occluding the ACE2 binding site. Thanks to the cooperative binding of this novel trispecific design, ensovibep confers very high protection against a panel of relevant spike mutants as well as all frequent SARS-CoV-2 variants identified around the globe to date. We show in a viral passaging experiment that the protection provided by ensovibep against development of viral escape mutants is equivalent to that of a well characterized and clinically evaluated monoclonal antibody cocktail27,36,37.

Following our in vitro characterization, we demonstrate high in vivo efficacy in a therapeutic Roborovski dwarf hamster model of COVID-19. Here ensovibep protects against severe disease induced by either wild-type or the Alpha variant SARS-CoV-2. The Roborovski dwarf hamster is highly susceptible to SARSCoV-2 infection and develops strong lung pathology, with most animals reaching a defined humane endpoint within two to five days after infection ${ }^{38}$. In the presented study, ensovibep protects the animals to an extent equivalent to a standard-of-care mAb cocktail. For both therapeutic agents, a significant reduction of fulminant disease, as well as significantly reduced viral loads and attenuated lung pathology was observed.

In brief, the trispecific design of ensovibep provides great protection against all currently known SARSCoV-2 variants with the potential to protect against emerging variants in the future. Our findings strongly support the progressing clinical development of ensovibep as a potential therapeutic for COVID-19. 
124

\section{Results}

\section{Structural basis for ensovibep-mediated neutralization of the SARS-CoV-2 spike}

Ensovibep comprises of five covalently linked DARPin domains. Three of them (R1, R2 and R3) bind the RBD of SARS-CoV-2 with picomolar affinity (Supplementary Figure 1 ) and two of them ( $\mathrm{H} 1-\mathrm{H} 2)$ bind to human serum albumin (HSA), extending the systemic half-life (Figure 1A). To understand how ensovibep binds to the SARS-CoV-2 spike (S), we selected one of the three RBD-targeting DARPin domains of ensovibep for cryo-EM analysis in complex with the trimeric S-ectodomain. The RBD-binding domains are from the same sequence family and are thus expected to target a common epitope (Figure 1B). Upon incubation of the trimeric spike protein with the monovalent DARPin R2 for 15 seconds prior to vitrification, 3D classification revealed that $65 \%$ of the S-ectodomains were in the closed conformation, $20 \%$ had two RBDs in the open conformation and $15 \%$ had all three RBDs in the open conformation (Supplementary Figure 2A, B). For the open RBD classes, additional density, consistent with the size of the monovalent DARPin molecule, was present on the RBD receptor binding ridge (RBR). When the incubation time was increased to 60 seconds, $66 \%$ of S-ectodomains had three monovalent DARPin molecule-bound RBDs in the open conformation (Supplementary Figure 2C). Interestingly, 18\% of the S-ectodomains had two DARPin-bound RBDs in the open conformation and one trapped in a partially closed conformation (Supplementary Figure 2C and 3A-B). These results demonstrate that monovalent DARPin domain binding prevents closure of the RBD through a previously described ratcheting mechanism ${ }^{39}$. 3D refinement of the fully open class, from the 60 second incubated sample, produced a 4.2 A global resolution map (Figure 1C and Supplementary Figure 2D-F). Following focused refinement of the RBD region, the quality of the map was sufficient to unambiguously assign the pose of the monovalent DARPin domain, which binds perpendicular to the RBD receptor binding motif (RBM), with its $\mathrm{N}$-terminus orientated toward the spike three-fold symmetry axis (Figure 1C). The concave DARPin binding surface covers the RBD and would prevent ACE2 binding through steric hindrance (Figure 1D). Guided by the cryo-EM data, molecular docking experiments were performed between the RBD of SARS-COV-2 and DARPin R2.

The top scoring model indicated that the interface area is $\sim 700 \AA^{2}$ and that key epitope residues are F456, Y473, F486, N487 and Y489, which form an interface of hydrophobic interactions and hydrogenbonds with the DARPin domain (Figure 1E-F). Because the three DARPin domains share a similar paratope composition and architecture, we were able to conceptually model the entire ensovibep molecule bound to the fully open S-ectodomain (Figure 1G). This demonstrated that the linkers would permit simultaneous binding of all three DARPin modules, allowing very high avidity of ensovibep (Supplementary Figure 1), and that the half-life extension modules have sufficient space to bind HSA 
(not shown). Taken together, these data suggest that ensovibep inhibits SARS-CoV-2 by blocking ACE2 binding and promoting the premature conversion of spike to the post-fusion state. This mechanism of inhibition through receptor functional mimicry was observed for a number of SARS-CoV-2 neutralizing antibodies $^{39,40}$.

\section{Ensovibep is highly potent against globally identified SARS-CoV-2 variants as well as the most frequent}

\section{spike protein point mutations}

In order to assess the neutralizing potencies of ensovibep against the initial SARS-CoV-2 (Wuhan) and emerging variants, we used vesicular stomatitis virus (VSV)-based as well as lentivirus-based pseudoviruses carrying the SARS-CoV-2 wild-type or mutant spike protein at their surface. In addition, we tested the authentic SARS-CoV-2 variants for the Wuhan reference and for lineages B.1.1.7, B.1.351 and P.1. Ensovibep is able to neutralize the reference wild type strain with an $I C_{50}$ of $\sim 1 \mathrm{ng} / \mathrm{mL}$, when either the authentic SARS-CoV-2 or the pseudovirus is used (Figure 2A). Remarkably, the high neutralization efficacy is retained in all the frequent variants circulating to date, which display a diverse set of mutations over the entire length of the spike protein (Figure 2A and 2B; Supplementary Table 2; Supplementary Figure 4). In particular, ensovibep can neutralize the variants of concern (VOC) and variants of interest (VOI) of the lineage B.1.1.7/Alpha (69-70 del, del145, E484K, N501Y, A570D, D614G, $\mathrm{P} 681 \mathrm{H}, \mathrm{T716I}, \mathrm{S982A}, \mathrm{D} 1118 \mathrm{H}$ and with the addition of E484K or S494P), lineage B.1.351/Beta (L18F, D80A, D215G, Del242-244, R246I, K417N, E484K, N501Y, D614G, A701V), lineage P.1/Gamma (L18F, T20N, P26S, D138Y, R190S, K417T, E484K, N501Y, D614G, H655Y, T1027I, V1176F), B.1.617.2/Delta (T19R, G142D, del156-157, R158G, L452R, T478K, D614G, P681R, D950N) and AY.2/Delta Plus (T19R, G142D, del156-157, R158G, K417N, L452R, T478K, D614G, P681R, D950N), Lambda (C.37; G75V, T76I, del246-252, D253N, L452Q, F490S, D614G, T859N), Mu (B.1.621; T95I, Y144S, Y145N, R346K, E484K, N501Y, D614G, P681H, D950N) and Omicron (B.1.1.529; A67V, $\Delta 69-70$, T95I, G142D, $\Delta 143-145, \Delta 211$, L212I, ins214EPE, G339D, S371L, S373P, S375F, K417N, N440K, G446S, S477N, T478K, E484A, Q493K/R, G496S, Q498R, N501Y, Y505H, T547K, D614G, H655Y, N679K, P681H, N764K, D796Y, N856K, Q954H, N969K, L981F). The neutralization potencies of ensovibep remain within 10-fold difference from the reference virus (Wuhan or D614G variant) with $\mathrm{IC}_{50}$ values in the low single-digit $\mathrm{ng} / \mathrm{mL}$ range, even against those variants that have been shown to be, to a large extent, refractory to vaccine- or infectionrelated antibody neutralization, such as Beta, Gamma, Delta, Delta Plus, and the newly evolved Omicron variant. ${ }^{25,41-43}$ When testing the neutralizing potency in a VSV-based pseudotype assay, containing more than 30 substitutions of the Omicron spike protein, ensovibep maintained neutralization at low single digit $\mathrm{ng} / \mathrm{mL} I \mathrm{C}_{50}$ values without loss in potency, when compared to the wild type. In contrast, many of the tested clinically relevant monoclonal antibodies and antibody cocktails demonstrated a major loss in neutralization (Figure 2D). 
191

192

193

194

195

196

197

198

199

200

201

202

203

204

205

206

207

208

209

210

211

212

213

214

215

216

217

218

219

220

221

222

Using the VSV- and lentivirus-based pseudovirus neutralization assays, we also evaluated the influence of single mutations on the neutralization potency of ensovibep, of the monovalent DARPin molecules and of the mAbs REGN10933 and REGN10987, as a reference within the same experiment. The panel included mutations present on variants of interest/concern, appearing frequently, or located within the binding epitope of ensovibep. Most notably, ensovibep protected well against all point mutations tested, in contrast to the single monoclonal antibodies, with the only exception of substitution F486V, which affects all three monovalent DARPin RBD binders incorporated in ensovibep (Figure 2C). A major impact of this mutation is not surprising, as our structural analysis and modelling identifies F486 as a core interacting residue for the three related but distinct RBD binders ${ }^{31}$ (Figure 1B,F). Consequently, the mutation F486V destabilizes the binding of the entire tri-specific ensovibep molecule to the spike protein. However, F486 is also a critical residue for the interaction between the RBD of SARS-CoV-2 and human ACE2 and its mutation leads to a $\sim 8.5$-fold reduction of the binding affinity as well as a $\sim 17$-fold reduction of the ability of ACE2 to reduce the infection of a VSV-based pseudovirus carrying the F486L mutation (Supplementary Figure 6). The functional importance of F486 is reflected by a low frequency of naturally occurring substitutions at this site (Figure 2C; Supplementary Table 3; Supplementary Figure 4) where the selective pressure on the virus favors a phenylalanine, thus maintaining the key anchoring element for ensovibep binding. A reduction of the potency of ensovibep from one-digit to double-digit $\mathrm{ng} / \mathrm{mL} \mathrm{IC} 50$ was also observed for mutation $\mathrm{N} 234 \mathrm{Q}$. This residue is located outside of the RBD binding region of ensovibep. This minor effect of substitution N234Q could be related to the loss of the conserved glycosylation site at this position, favoring the kinetics of the down conformation of the RBD domain and thus reducing binding of ensovibep as well as ACE2 to the RBD, which only bind the RBD up confirmation. ${ }^{44}$

It is interesting to note that ensovibep retains potency against spike proteins carrying mutations at locations where the single DARPin domains partially lose activity, such as E484K and Q493K/R. We hypothesize that the cooperative binding in combination with the complementarity of the three independent RBD-binding DARPin modules provides resistance to mutation escape. Taken together, our analysis demonstrates that the trispecific design of ensovibep enables very high potencies against spike proteins carrying the most frequently observed mutations as well as mutations known to impact the binding of neutralizing antibodies.

\section{Passaging of SARS-CoV-2 under therapeutic pressure of DARPin antivirals and monoclonal antibodies}

Previous studies have shown that SARS-CoV-2 escape mutants may arise under selective pressure of a therapy ${ }^{29,45}$. Using a viral passaging model, we compared the risk of mutational escape from therapeutic 
pressure of ensovibep compared to that of its monovalent R2 module, the mAbs REGN10933 and REGN10987, singly and as a 1:1 mixture, as well as the mAb S309.

In order to generate a stringent therapeutic pressure, a relatively high viral load of $1.5 \times 10^{6} \mathrm{pfu}$ of an authentic French SARS-CoV-2 WT isolate (with the following differences to the Wuhan wild-type spike protein: V367F; E990A) was serially passaged in the presence of increasing concentrations of DARPin molecules and antibodies (Figure 3A,B). Resistant escape variants were further selected by passaging the supernatant of cultures showing significant virus-induced cytopathic effect (CPE) under the selection pressure of the highest therapeutic concentration onto fresh cells while maintaining the selective pressure of increasing concentrations of therapeutic antivirals (Supplementary Figure 5). After the first incubation cycle of four days (passage 1), ensovibep, DARPin R2, REGN10933 and the antibody mixture conferred protection at the same concentration of $0.4 \mu \mathrm{g} / \mathrm{mL}$. S309 was less efficient, requiring a higher concentration $(10 \mu \mathrm{g} / \mathrm{mL})$ for protection and REGN10987 was not protective up to the highest tested concentration of $50 \mu \mathrm{g} / \mathrm{mL}$. Under continuous selective pressure through passage 2 to 4 , DARPin R2 and the individual mAbs S309 and REGN10933 lost the capacity to protect cells, which manifested in complete CPE up to $50 \mathrm{\mu g} / \mathrm{mL}$. In contrast, ensovibep and the cocktail of two mAbs remained effective and protected cells from CPE throughout the four passages (Figure 3A).

To identify putative escape mutations in the spike protein upon therapeutic pressure of the DARPins, RNA was extracted and deep-sequenced from the supernatant of wells with the greatest selective pressure showing a significant cytopathic effect in each passage (Figure 3B). Mutations were found near the spike protein cleavage site (H655Y, N679_R685del, R682W, R682Q), which are likely related to adaptations to the experimental cell system and thus would not account for escape mutations due to the therapeutic pressure of the DARPin ${ }^{36,37}$, as well as a potential escape mutation, F486L, which was found for the monovalent DARPin R2 but not for ensovibep, up to passaging round four. Still, supporting this finding, mutations in F486 were shown to influence also the potency of ensovibep, when analyzed separately.

\section{In vivo antiviral efficacy of ensovibep in a COVID-19 SARS-CoV-2 Roborovski dwarf hamster model}

To test the in vivo efficacy of ensovibep in treating SARS-CoV-2 infection, we employed the Roborovski dwarf hamster, a species susceptible to severe COVID-19 like illness ${ }^{46}$. Unlike the more commonly used Syrian golden hamster ${ }^{47}$, this species is prone to develop a lethal course of disease, notably without the extrapulmonary disease manifestations observed in highly susceptible transgenic mice ${ }^{48}$. We used this particular animal model to judge the in vivo efficacy of ensovibep and to compare it to the REGN10933 \& REGN10987 antibody mixture. Moreover, evaluation of the virological and histopathological outcome of infection enabled comparison across a variety of important parameters of infection. 
We first aimed to determine in vivo protection conferred by ensovibep against a SARS-CoV-2 wild type reference strain (BetaCoV/Germany/BavPat1/2020). In an initial series of experiments, we determined both dose and time dependency of treatment efficacy based on clinical and virological parameters. In absence of venous access in dwarf hamsters, we choose intraperitoneal (i.p.) treatment for delivery of ensovibep. It is important to note, that the course of disease in Roborovski dwarf hamsters is rapid, with first animals developing severe disease and reaching termination criteria within 48 hours of infection. For this reason, we considered 24 hours post-infection (p.i.) the latest possible intervention time point. Both dose and time of ensovibep administration (relative to time of infection) were found to positively affect the outcome of infection. Specifically, the use of ensovibep resulted in markedly reduced virus loads in the respiratory tract of treated animals (Supplementary Figure 7).

From these initial results, we determined $10 \mathrm{mg} / \mathrm{kg}$ to be the optimal dose for ensovibep treatment and in further studies compared this dose with the same dose of the REGN10933 \& REGN10987 cocktail using the SARS-CoV-2 alpha (B.1.1.7) variant of a more recent isolate (BetaCoV/Germany/ChVir21652/2020) for infection of animals. We chose two treatment time points, the first at the time of infection to mimic clinical post exposure prophylaxis and the second at $24 \mathrm{~h} \mathrm{p}$.i. to mimic treatment at the onset of clinical symptoms (Figure $4 \mathrm{~A}$ ). For the post exposure prophylaxis dosed directly after infection ( 0 h p.i.), we confirmed full protection for both treatments with notable reduction of viral loads, particularly in the lungs of treated animals compared to placebo treated controls at all time points (Figure 5A). There were no obvious differences between the two agents, however, based on virological parameters, a slight trend towards lower viral load in the antibody cocktail group was observed at 5 days p.i. (Figure $5 A$ ).

In contrast to the similarities in the post exposure prophylaxis setting we observed differences between the groups treated 24 hours p.i. (Figure 4B, C). In this scenario, animals treated with ensovibep presented with improved condition at 2 days p.i. with 0/12 of the animals reaching a defined humane endpoint, while 5/12 animals were euthanized in the mAb cocktail group and 5/12 in the placebo group (Figure 5B) due to reached humane endpoints. Nevertheless, 3/10 hamsters in the ensovipeb group and an additional three hamsters in the placebo group reached defined endpoints at day 3 p.i., while no further animals in the mAb cocktail group developed severe illness after day 3 p.i. (Figure 5B). Following $24 \mathrm{~h}$ p.i. treatment, no significant differences in average body weights or temperatures were observed in any of the treatment groups (Figure 5C, Supplementary Figure 8). This is likely a result of the early termination of severely sick animals, while the healthier animals remained in the study. However, examination of these parameters on day 2 p.i. revealed significant trends towards reduced body weight loss in both treatment groups compared to the placebo and a similar trend towards higher body temperatures in the ensovibep group compared to the other groups (Figure 5C). As body 
temperature decrease is a very sensitive parameter of disease in this species ${ }^{46}$, this in particular is reflective of the improved condition in the ensovibep treated group at $24 \mathrm{~h}$ p.i., when compared to the antibody cocktail treated or the placebo treated animals. Virological readouts were not significantly different between groups treated with ensovibep and the mAb cocktail at 24 hours post-infection. Both treatments resulted in drastic reductions of viral load compared to the placebo group (Figure 5A, B). This result was more pronounced at the level of replicating virus, indicating efficient neutralization of cell-free virus in both treatment groups (Figure 5B). These trends were likewise reflected by the results of histopathological examinations of animals treated at $24 \mathrm{~h} \mathrm{p.i..} \mathrm{While} \mathrm{the} \mathrm{histological} \mathrm{outcome} \mathrm{of}$ infection was similar between both treatment groups (Figure 6), semi-quantitative assessment of SARSCoV-2 induced lesions revealed consistently higher scores for the mAb treated group compared to ensovibep. Interestingly, scores for inflammation in the mAb treated group were on average exceeding the scores obtained for the placebo group. These findings need to be interpreted knowing that 5/6 animals in the mAb treated group which had been scheduled for termination and analysis at day 3 had to be taken out of the study already on day 2 due to rapid onset of fulminant disease, which is reflected by these readouts.

To account for possible differences in exposure, we performed pharmacokinetic analysis for both treatments. These assessments identified that overall, comparable exposures were achieved in noninfected hamster following i.p. administration. It was noted that, ensovibep achieved a higher maximal serum concentration (Cmax) and a shorter systemic half-life compared to the mAb cocktail (Supplementary Figure 9).

Considering the small size of the Roborovski dwarf hamster, failure of i.p. injection due to an accidental injection into body compartments other than the peritoneum may occur. We thus screened for animals which lacked a proper drug exposure in terminal serum samples and removed data of these animals from all other analyses (Supplementary Table 4).

Whole genome sequencing using virus RNA recovered from lungs and upper respiratory tract was performed to investigate whether SARS-CoV-2 escape mutants were selected under ensovibep treatment. Viral RNA from individual animals with higher viral load compared to other animals of the same treatment group was analyzed and no escape mutations affecting the ensovibep epitope located in the RBD were discovered (Supplementary Table 5). 


\section{Discussion}

320

321

322

323

324

325

326

327

328

329

330

331

332

333

334

335

336

337

338

339

340

341

342

343

344

345

346

347

348

349

350

351

Multiple strategies are urgently needed to combat the COVID-19 pandemic. Next to preventive vaccination approaches and small molecules, mAbs are showing therapeutic promise, based on highly potent virus inhibition and encouraging animal and clinical efficacy. However, manufacturing capacities are limiting a global supply and novel emerging variants of SARS-CoV-2 are an ever-present threat, as they may escape the antibodies generated during immunization or in response to therapeutics. A number of alternative molecules are being developed to complement and partially overcome these limitations.

In the present study, we provide the structural and functional analysis of ensovibep, a trispecific DARPin designed as a potential alternative to antibodies and other therapeutics ${ }^{32,49-53}$. The structural analysis provides insights into the mode of action, which enables low picomolar neutralizing activity against the currently most frequent SARS-CoV-2 mutations as well as recently identified variants. We measured the effect of ensovibep on a panel of single spike protein mutations which have been shown to be of concern because they may be associated with increased transmissibility, disease severity, or affect neutralization of some monoclonal- or polyclonal antibodies $27,54,55$. Among all mutations tested, only F486 substitutions caused a strong decrease in ensovibep potency when compared to the wild-type or reference virus. The effect of this mutation was also noted in the viral passaging study: sequencing of mutations allowing escape from inhibition by the monovalent RBD binder ( $R 2$, incorporated in ensovibep) identified F486L (Figure 3B). These findings are in line with our structural analysis (Figure $1 F$ ) showing that F486 is one of the key binding residues for the interaction of ensovibep with the RBD. Most importantly, F486 is a critical residue for the virus itself, allowing an efficient binding to the ACE2 receptor and thus cell infection. Therefore, mutations of the phenylalanine at position 486 will decrease the affinity between the RBD and human ACE2 receptor and lower the infectivity of the virus ${ }^{17,56-58}$ (Supplementary Figure 6). We thus expect that position F486 in the SARS-CoV-2 spike protein will remain conserved to maintain efficient binding to the human ACE2 receptor or that the virus might lose fitness if mutated at this position. So far, based on the global SARS-CoV-2 database sequences published in the GISAID database (https://www.gisaid.org/hcov19-variants/; visited November 2021), mutations in position F486 occur at very low frequencies.

A small reduction of neutralization potency observed for ensovibep and its single DARPin moieties for viruses bearing the $\mathrm{N} 234 \mathrm{Q}$ mutation outside of the RBD might be explained by the impact of the mutation on the RBD conformational dynamics. An in-silico simulation study showed that this conserved glycosylation site, together with N165, might be involved in the stabilization of the RBD upconformation. Since the epitope of ensovibep is exposed only in the up-conformation, a mutation in 
one of these glycosylation sites might affect its binding equilibrium, as indicated in our neutralization assays. The $\mathrm{N} 234 \mathrm{Q}$ mutation might thus impact all protein binding scaffolds that are binding exclusively to the up-conformation of the RBD. By the same token, reduced affinity of the spike protein for the human ACE2 receptor was demonstrated elsewhere in in vitro assays ${ }^{44}$. Accordingly, mutations of the N165 and N234 amino acids have been observed only at low frequencies $(<0.02 \%)$.

Some mutations that are not predicted to be key interaction residues for the three distinct RBD binders of ensovibep (e.g., E484K or Q493K), led to a reduction in potency for one or several of the RBD-binding monovalent DARPins, while the trispecific ensovibep molecule maintained full neutralization capacity. This demonstrates that the trispecific DARPin design of ensovibep, with cooperative binding of three distinct paratopes (Supplementary Figure 1), permits high neutralizing potency, even in the case when an individual monovalent DARPin domain exhibits decreased affinity (Figure 2A). This cooperative binding of multiple paratopes is a hallmark of the trispecific nature of ensovibep and differentiates the molecule from mAb candidates to allow full neutralization of highly mutated SARS-CoV-2 variants such as Omicron, that are substantially different from the original virus that the mAb was selected against ${ }^{59}$.

The high level of protection against viral escape mutations by ensovibep demonstrated in the virus challenge studies was also clearly apparent in a viral passaging experiment. The single mAbs and the monovalent DARPin binder were rapidly overcome by escape mutants whereas ensovibep maintained potency to an extent comparable to a clinically validated mAb cocktails.

Translatability of the observed in vitro activity of ensovibep against SARS-CoV-2 was evaluated in a COVID-19 model using the highly susceptible Roborovski dwarf hamsters. Using this in vivo model, we confirmed the therapeutic benefit of ensovibep, which displayed comparable outcomes to a clinically validated antibody cocktail (REGN10933 \& REGN10987). In our comparison, we found evidence for a better performance of ensovibep in a late intervention scenario with prolonged survival of animals and reduced inflammation of the lungs. Potential reasons for this difference include differences in pharmacokinetics where ensovibep demonstrated a higher maximal concentration compared to the antibody cocktail (Supplementary Figure 9). Another possible explanation could be that ensovibep lacks an Fc-fragment when compared to antibodies stimulating pro-inflammatory immune responses mostly via their Fc-fragment. Regardless of this, we clearly demonstrate that ensovibep has great potential to prevent disease and eliminate the virus in a highly susceptible in vivo model under different treatment scenarios. The clinical translatability of these results is currently being investigated in the EMPATHY trial for the treatment of ambulatory COVID-19 patients.

In conclusion, ensovibep, has been shown to have highly potent neutralization against the currently most frequent SARS-CoV-2 variants due to its cooperative and complementary binding to a highly 
conserved epitope region on the spike RBD. In vitro and in vivo single agent efficacies closely match the performance of one of the best clinically validated mAb cocktails. In addition, the albumin binding domains of the molecule have been demonstrated to confer a plasma half-life compatible with single dose treatment. Translation of these preclinical findings into the clinic is currently under investigation and if successful, the E. coli based-manufacturing of the agent will allow rapid and large-scale production for global access to this alternative class of therapeutics as an addition to other treatment approaches for COVID-19. 
392

393

394

395

396

397

398

399

400

401

402

403

404

405

406

407

408

409

410

411

412

413

414

415

416

417

418

419

420

421

422

423

424

425

\section{Data availability}

The EM density maps for the SARS-CoV-2 spike ectodomain in complex with monovalent DARPin R2 (state 1 and state 2), have been deposited to the Electron Microscopy Data Bank under the accession codes EMD-11953 and EMD-11954, respectively. The monovalent DARPin and multivalent DARPin sequences, and pseudo-atomic models derived from molecular docking experiments, are available here, to allow the use of the data for non-commercial purposes:

https://www.guidetopharmacology.org/GRAC/LigandDisplayForward?tab=structure\&ligandld=11470

\section{Acknowledgements}

S.R. \& J.M. were supported by Swiss Federal Office for Civil Protection (Grants Nr. 353008564/Stm, 353008218/Stm, and 353008560/Stm to Olivier Engler and Stefan Kunz).

D.L.H. is funded by the European Union's Horizon 2020 research and innovation program under the Marie Skłodowska-Curie grant agreement (No 842333) and holds an EMBO non-stipendiary long-term Fellowship (ALTF 1172-2018). Cryo-EM data processing was carried out on the Dutch national e-infrastructure with the support of the SURF Cooperative.

The authors also thank Dr. Gert Zimmer for the gift of the recombinant VSV (Institute of Virology and Immunology (IVI), CH-3147 Mittelhäusern, Switzerland, Department of Infectious Diseases and Pathobiology, Vetsuisse Faculty, University of Bern, CH-3012 Bern, Switzerland).

The expression plasmid for the SARS-CoV-2 spike protein was kindly provided by Dr. Giulia Torriani and Dr. Isabella Eckerle (Department of Medicine, University of Geneva, Switzerland).

We would like to thank Dr. Sylvie van der Werf for the supply of 2019-nCoV/IDF0372/2020 (National Reference Centre for Respiratory Viruses hosted by Institut Pasteur (Paris, France)). Strain 2019nCoV/IDF0372/2020 was generously provided by Dr. X. Lescure and Pr. Y. Yazdanpanah from the Bichat Hospital.Additionally, we would like to thank William Lee, former board member of Molecular Partners - and the Virology group at Gilead Sciences for their helpful input.

We would like to thank the Centre for AIDS Reagents (National Institute for Biological Standards and Control, Herts, UK) for providing VeroE6/TMPRSS2 cells.

Lentivirus pseudotype investigations were performed independently by investigators at the US Food and Drug Administration, Center for Biologics Evaluation and Research as part of Therapeutics Research Team for the US government COVID-19 response efforts. The work was supported by US government research funds.

\section{Funding}

The work was funded by Molecular Partners AG, Switzerland, or as stated in the Acknowledgements. 
bioRxiv preprint doi: https://doi.org/10.1101/2021.0203 429164; this version posted December 17, 2021. The copyright holder for this 
A

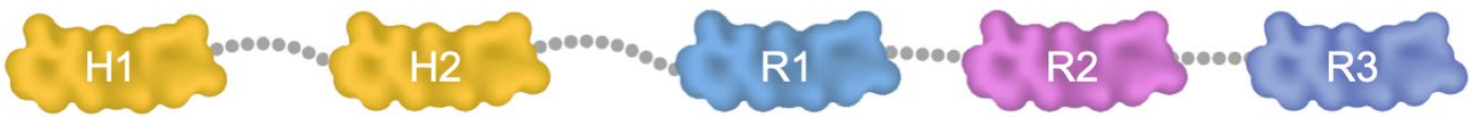

B

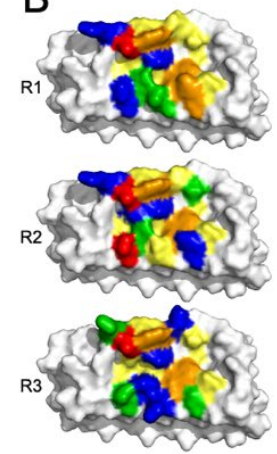

E

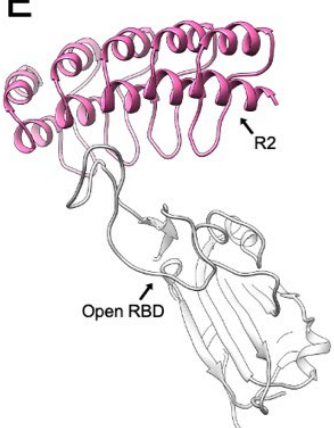

C

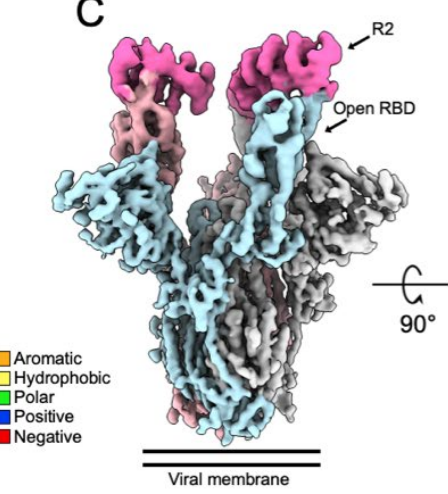

$\mathrm{F}$

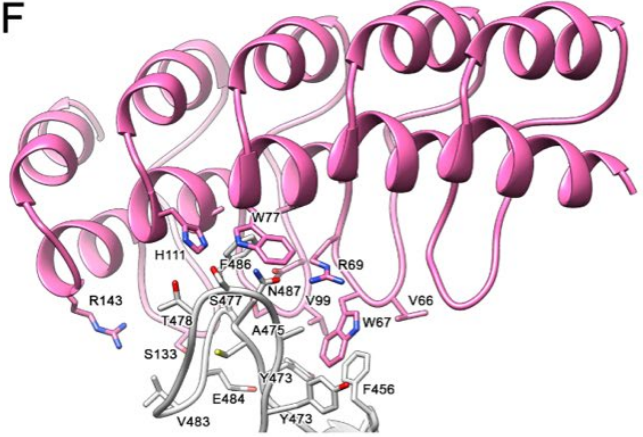

D
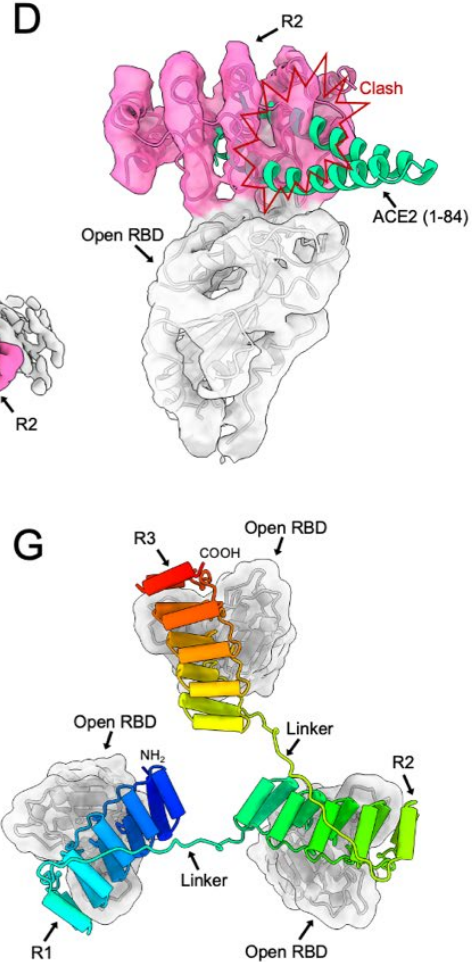

Figure 1: Structural modelling of ensovibep. A) Schematic overview of the ensovibep construct. Protein linkers are depicted as gray dashed lines and the half-life extending human serum albumin binding monovalent DARPins (H1 and H2) are colored yellow. B) Surface representations of the three monovalent DARPin molecules binding to the $R B D$, with the amino acid residues in the paratope colored according to their biophysical characteristics as indicated. C) Cryo-EM density for the SARS-CoV-2 spike ectodomain in complex with the $R B D$-targeting monovalent DARPin R2, shown as two orthogonal views. The DARPin density is colored magenta and the three spike protomers are colored light blue, grey and pale pink. D) Zoomed in view of an RBD-bound to DARPin R2 with the cryo-EM density shown semitransparent. The atomic coordinates for the fitted open RBD (PDB ID: 6XCN) and the DARPin model are overlaid. The atomic coordinates for residues 1-84 of the RBD-bound ACE2 (PDB ID: 6MOJ), colored green, is superimposed. E) Pseudo-atomic model of the monovalent $D A R P i n$ R2 in complex with the RBD, colored pink and grey, respectively. F) Zoomed in view of the interface between monovalent DARPin R2 and RBD. G) Proposed model of the three covalently linked RBD-targeting monovalent DARPin molecules of ensovibep bound to the trimeric spike protein RBD domains. The three DARPin domains are shown in a rainbow color scheme from the $N$ terminus (blue) to the $C$ terminus (red). 
bioRxiv preprint doi: https://doi org/10.1101/2021.02 03 429164; this version posted December 17, 2021. The copyright holder for this preprint (which was not certified by peer review) is the author/funder, who has granted bioRxiv a license to display the preprint in perpetuity. It is made available under aCC-BY-NC-ND 4.0 International license.

A

Neutralization assay ensovibep

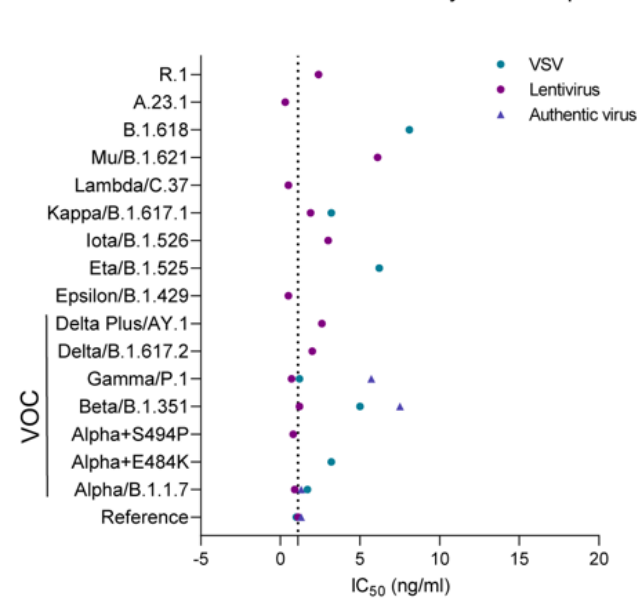

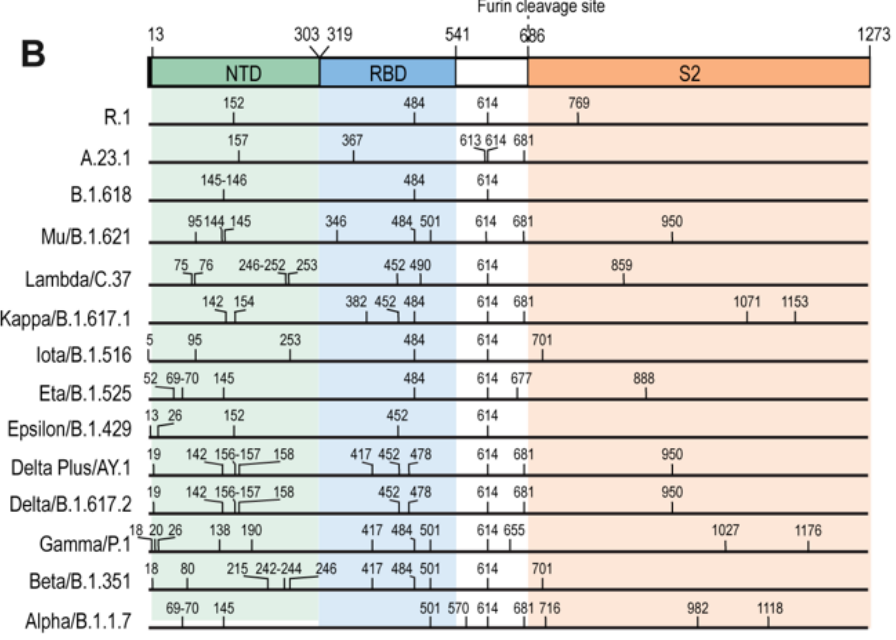

C

IC $50(\mathrm{ng} / \mathrm{ml})$

0-10 $\quad 11-20 \quad 21-50 \quad 51-100>100$

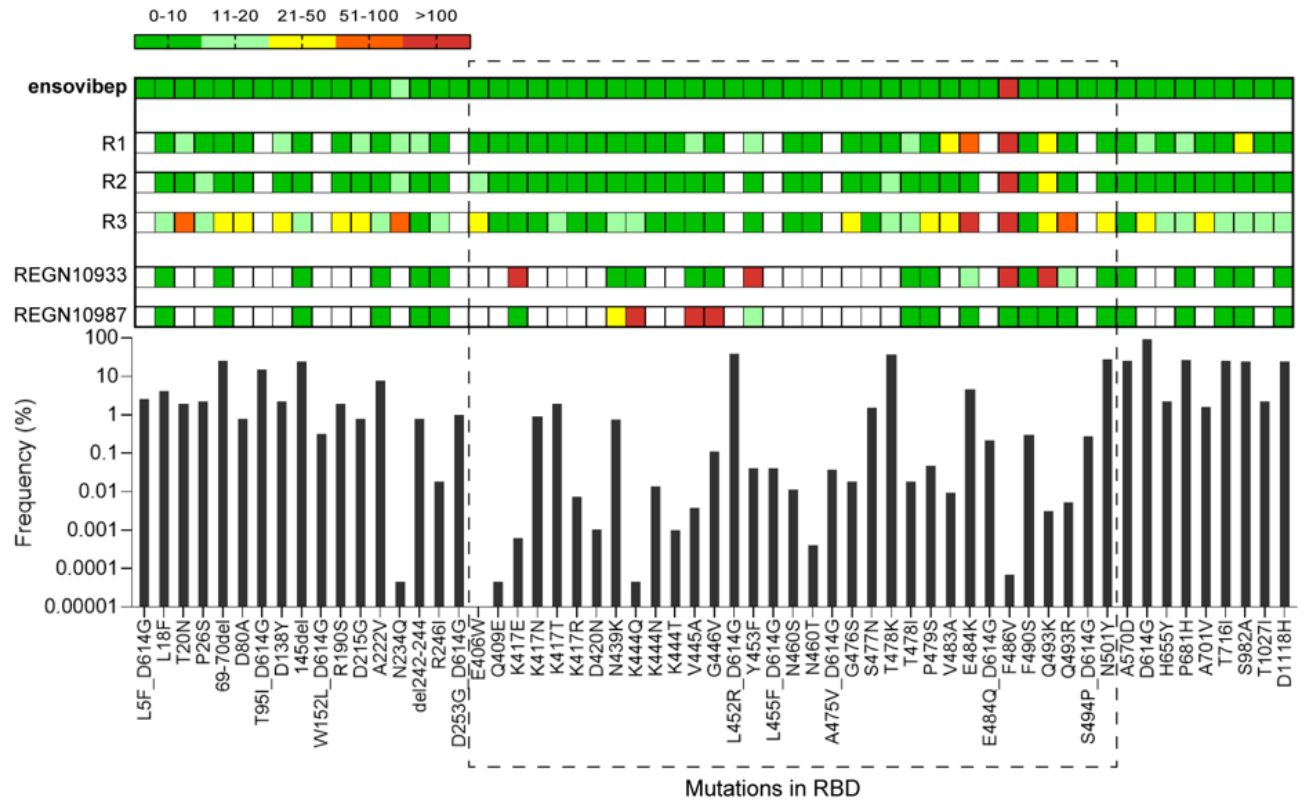


45

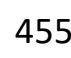

456

457

458

459

460

461

462

463

464

465

466

467

468

469

470

471

472

473

474

475

476

477

478

479
D
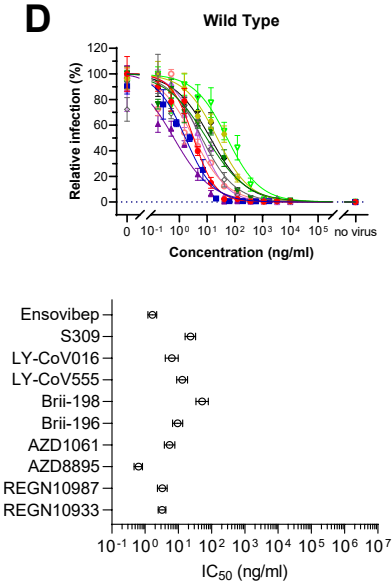
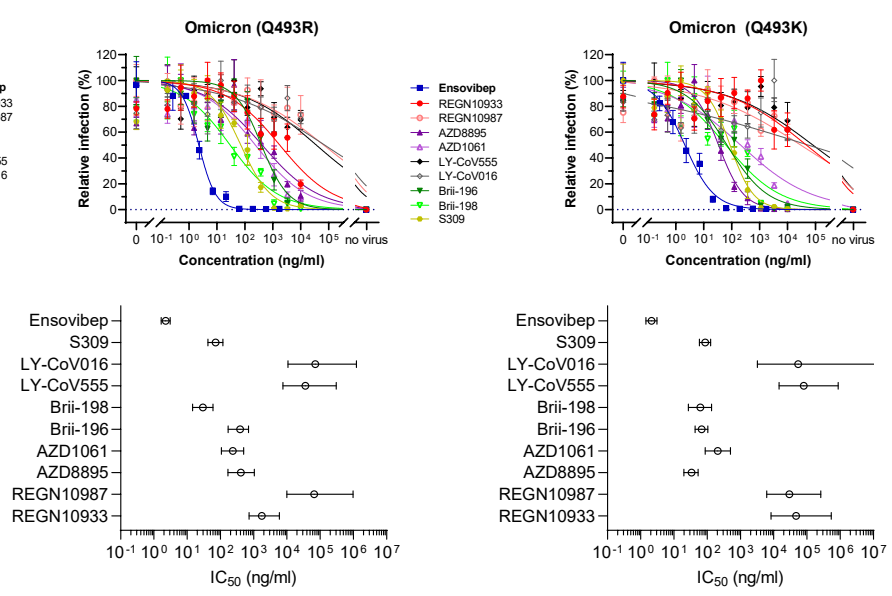

\begin{tabular}{|c|c|c|c|c|c|}
\hline \multirow[b]{2}{*}{ Compound } & \multirow{2}{*}{$\begin{array}{c}\text { Wild Type } \\
\mathrm{IC}_{50}(\mathrm{ng} / \mathrm{mL})\end{array}$} & \multicolumn{2}{|c|}{ Omicron (Q493R) ${ }^{1}$} & \multicolumn{2}{|c|}{ Omicron (Q493K) ${ }^{2}$} \\
\hline & & $\mathrm{IC}_{50}(\mathrm{ng} / \mathrm{mL})$ & fold change to wt & $1 \mathrm{C}_{50}(\mathrm{ng} / \mathrm{mL})$ & fold change to wt \\
\hline ensovibep & 1.6 & 2.2 & 1.4 & 2.1 & 1.3 \\
\hline REGN10933 & 3.2 & $>1000$ & $>100$ & $>1000$ & $>100$ \\
\hline REGN10987 & 3.3 & $>1000$ & $>100$ & $>1000$ & $>100$ \\
\hline LY-CoV555 & 13 & $>1000$ & $>100$ & $>1000$ & $>100$ \\
\hline LY-CoV016 & 6.4 & $>1000$ & $>100$ & $>1000$ & $>100$ \\
\hline S309 & 23 & 72 & 3.1 & 87 & 3.8 \\
\hline AZD8895 & 0.6 & 415 & $>100$ & 34 & 56 \\
\hline AZD1061 & 5.5 & 237 & 43 & 207 & 38 \\
\hline Brii-196 & 9.5 & 392 & 41 & 68 & 7.1 \\
\hline Brii-198 & 52 & 30 & 0.6 & 62 & 1.2 \\
\hline
\end{tabular}

IC 50 : green: <10 $\mathrm{ng} / \mathrm{mL}$; orange: $10-100 \mathrm{ng} / \mathrm{mL}$; dark orange: $100-1000 \mathrm{ng} / \mathrm{mL} ;$ red: $>1000 \mathrm{ng} / \mathrm{mL}$

fold change to wt: green: <10-fold; orange: 10-100-fold; red: >100-fold

${ }^{1}$ Set of mutations: A67V, $\triangle 69-70, T 95 I$, G142D, $\triangle 143-145, \Delta 211$, L212I, ins214EPE, G339D, S371L, S373P, S375F, K417N, N440K, G446S, S477N, T478K, E484A, Q493R, G496S, Q498R, N501Y, Y505H, T547K, D614G, H655Y, N679K, P681H, N764K, D796Y, N856K, N969K, L981F.

${ }^{2}$ Set of mutations: A67V, $469-70, T 95 I, G 142 D, \triangle 143-145, \triangle 211$, L212I, ins214EPE, G339D, S371L, S373P, S375F, K417N, N440K, G446S, S477N, T478K E484A, Q493K, G496S, Q498R, N501Y, Y505H, T547K, D614G, H655Y, N679K, P681H, N764K, D796Y, N856K, Q954H, N969K, L981F.

Figure 2: A) Graph reporting $I C_{50}$ values $(\mathrm{ng} / \mathrm{mL})$ for ensovibep measured in neutralization assays performed with lentivirus-, VSV-based pseudoviruses or authentic viruses for the variants indicated. Reference variant is the Wuhan strain for VSV-based pseudovirus, a D614G variant for the lentivirus-based pseudovirus or a patient isolate from the early pandemic for the authentic virus. B) Schematic representation of the residues modified in the SARS-CoV-2 spike protein for the different variants tested compared to the Wuhan strain. C) Graph with global frequencies of point mutations in the spike protein of SARS-CoV-2 according to the GISAID database (as of October 2021) including a heat map table with $I C_{50}$ values for ensovibep, R1, R2, R3, REGN10933, REGN10987 for all point mutations tested (VSV/Lentivirus-based pseudovirus assays). Dashed box: mutations in RBD. D) Titration curves and $I_{50}$ values for VSV-pseudotype neutralization assays with wild-type and two different Omicron variant spike proteins containing either an arginine or a lysine in position Q493. Ensovibep was tested together with a panel of clinically validated monoclonal antibodies. The table provides the numeric $I C_{50}$ values as well as the fold change towards the wild-type values. 
A

Viral Passage \#

(1) 200

Single molecules

DARPin candidates

ensovibep

$\mathrm{R} 2$

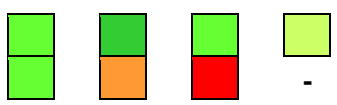

Antibody Candidates

REGN10933

REGN10987

S309

IgG Negative Control

Antibody cocktail

REGN10933 \& REGN10987

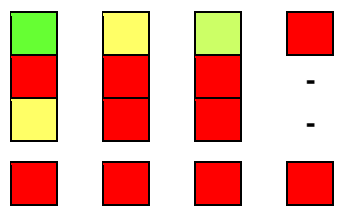

"-“, not continued

Color code representing highest therapeutic concentration with $>20 \%$ CPE [nGffir?]

\begin{tabular}{|c|c|c|c|c|c|}
\hline \multicolumn{2}{|c|}{5} & 10 & & 0 & 0 \\
\hline
\end{tabular}

484

485

486

487

488

489

490

491

492

B

Figure 3: Protection against SARS-CoV-2 escape mutations generated over four viral passages.

A) Tabular representation of the cytopathic effects induced by SARS-CoV-2 cultured in the presence of increasing concentrations of mono-valent DARPin binder R2, multi-specific DARPin antiviral ensovibep and the antibody antivirals REGN10933, REGN10987 and S309 or a cocktail of REGN10933 and REGN10987 through passage 1 to 4. Color code represents the highest concentration showing $\geq 20 \%$ CPE, for which the culture supernatants was passaged to the next round and deep sequenced for the identification of potential escape mutations. B) Identification of escape mutations in viral passages using deep sequencing. 
502 SARS-CoV-2 virus was serially passaged with the mono-valent DARPin binder R2 and 503 ensovibep. To identify putative escape mutations in the spike protein, RNA was extracted and 504 sequenced from supernatant of wells with the greatest selective pressure showing a significant 505 cytopathic effect. All variants in the spike protein relative to the reference genome 506 (NC_045512.2) are shown. Passage 0 of the virus control corresponds to the inoculum used 507 for all experiments. The color of the fields is proportional to the fraction of the reads containing 508 the respective variant ( $r e d=1.0$ white $=0.0$ ). 
A

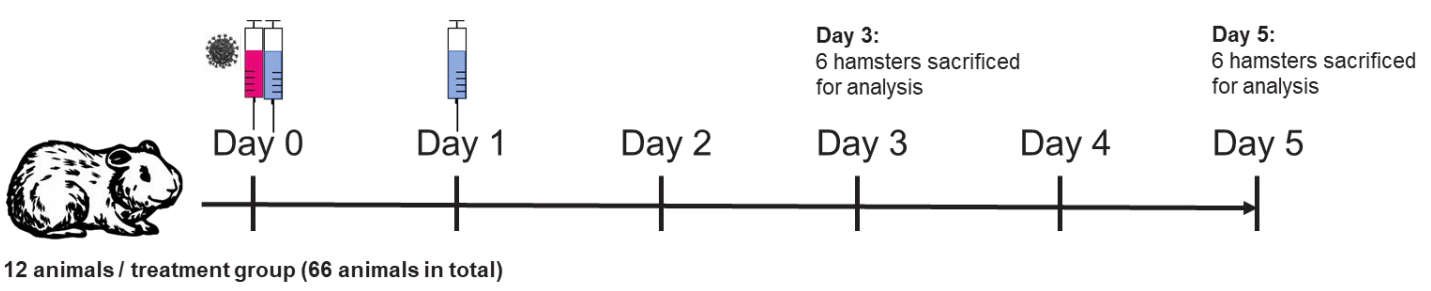

510

511

512

B

\section{Survival of Animals Over Study Duration}

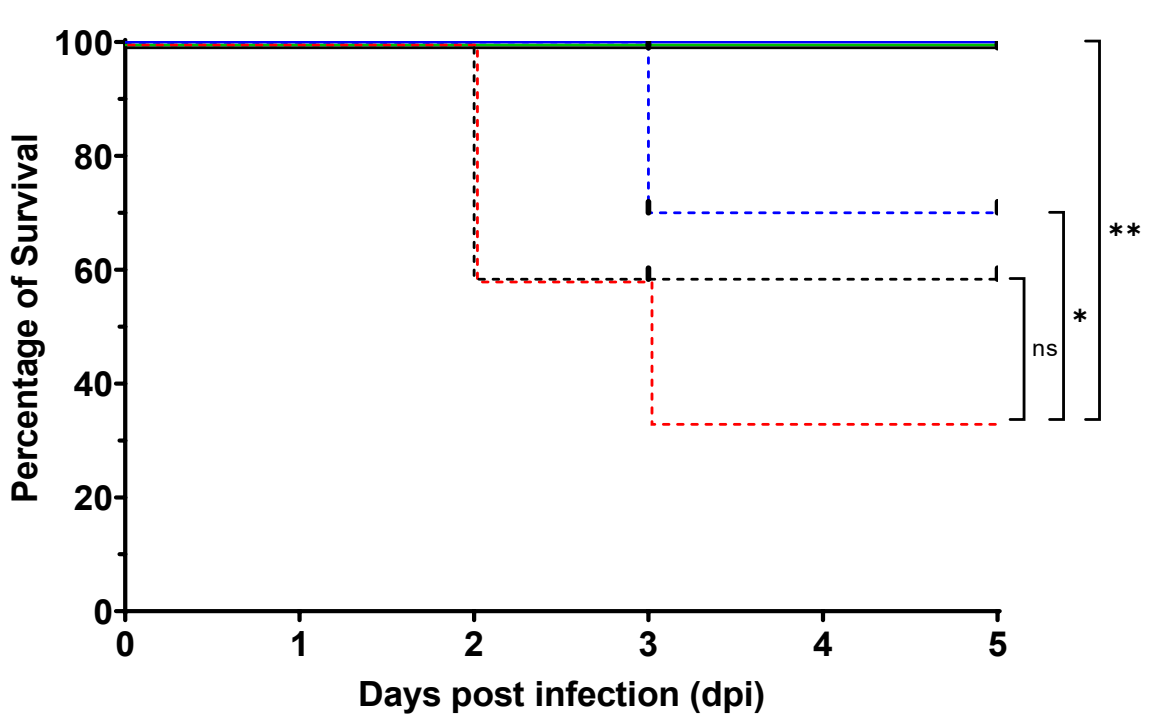

L Ensovibep (Oh p.i.)

I PBS non-infected

$\perp$ mAb cocktail (Oh p.i.)

-I. Ensovibep (24h p.i.)

- . mAb cocktail (24h p.i.)

I. PBS infected

Gehan-Breslow-Wilcoxon Test ns: not significant $(\mathrm{P}=0.51)$

significant $(P<0.05)$

**. $\quad$ significant $(P<0.001)$ 
bioRxiv preprint doi: https://doi org/10.1101/2021.02 03 429164· this version posted December 17, 2021. The copyright holder for this

preprint (which was not certified by peer review) is the author/funder, who has granted bioRxiv a license to display the preprint in perpetuity. It is made available under aCC-BY-NC-ND 4.0 International license.

\section{Average body weights}

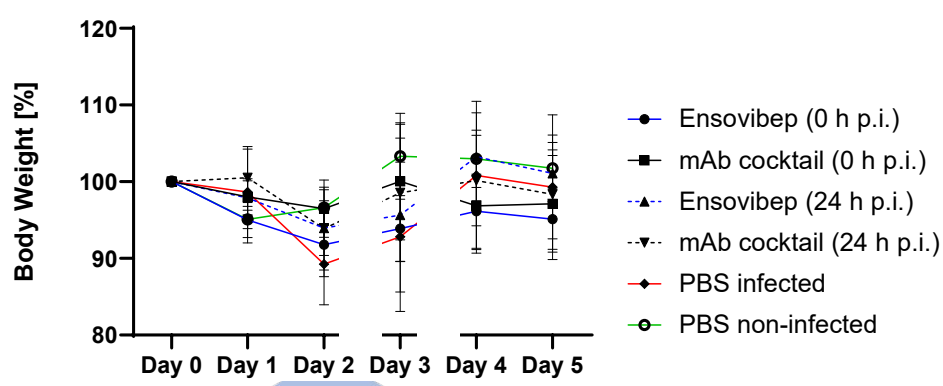

\section{Day 2: Body Weight}

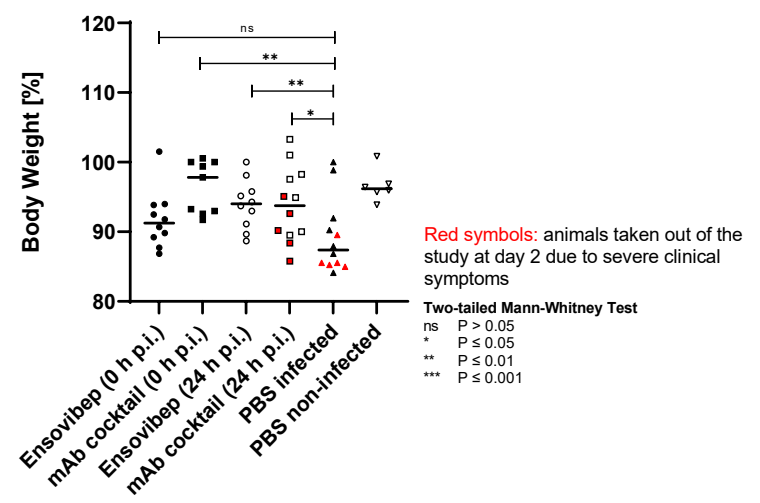

D Average body temperatures

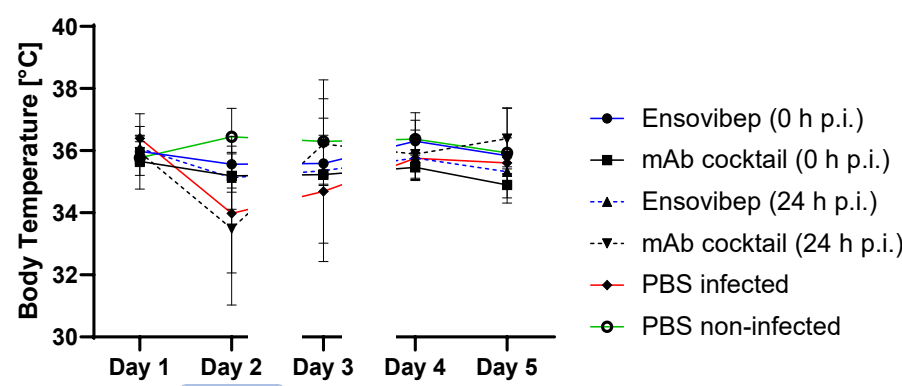

Day 2: Temperature

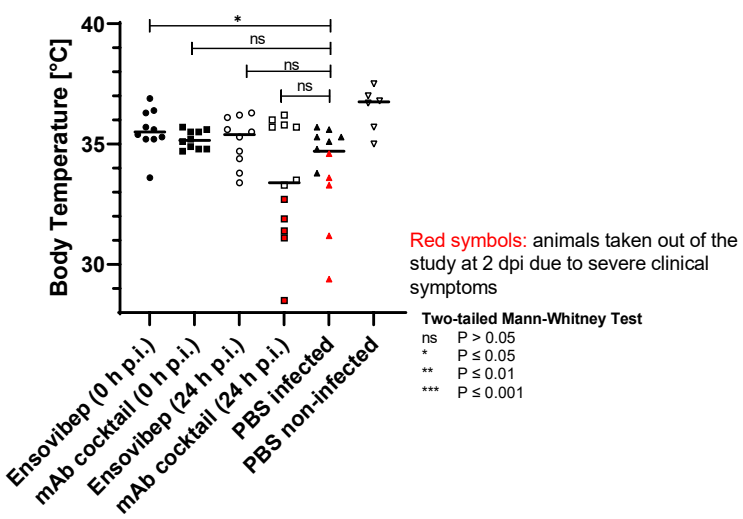


516 Figure 4: A) Design of the Roborovski dwarf hamster study. Animals were infected on day 0 517 with $10^{5} \mathrm{pfu}$ of SARS-CoV-2 alpha (B.1.1.7) variant. Treatment was administered either 518 directly following infection (0 h p.i.) or one day post infection (24 h p.i). For each treatment 519 group, twelve animals were injected i.p. with either $10 \mathrm{mg} / \mathrm{kg}$ of ensovibep, $10 \mathrm{mg} / \mathrm{kg}$ 520 monoclonal antibody cocktail (5 mg/kg REGN10933 \& $5 \mathrm{mg} / \mathrm{kg}$ REGN10987), or PBS 521 (placebo). Additionally, a group of six non-infected and non-treated control animals were 522 included as comparators for the infected and treated groups. Daily measurement of body 523 weight and temperatures as well observation of vital symptoms was undertaken. Animals were 524 sacrificed on day 3 or 5 p.i. or immediately once an individual reached a defined humane 525 endpoint. B) Survival of animals for 5 days p.i.. Animals that had to be euthanized according 526 to defined humane endpoints were considered as non-survived. B) Body weight and C) body 527 temperatures throughout the study duration. Individual data points show mean +/- SD of the 528 following number of animals analyzed per treatment group at (0/1/2/3/4/5) days p.i.: Esovibep 529 Oh: $n=10 / 10 / 10 / 10 / 5 / 5$; mAb cocktail Oh: $n=9 / 9 / 9 / 9 / 5 / 5$; Esovibep 24h: $n=10 / 10 / 10 / 10 / 5 / 5$; 530 mAb cocktail 24h: $n=12 / 12 / 12 / 7 / 6 / 6$; Placebo, infected: $n=12 / 12 / 12 / 7 / 4 / 4$; Placebo, non531 infected: $n=6 / 6 / 6 / 6 / 6 / 6$. The rational for excluding animals is the identification of animals with 532 low drug exposure, likely due to a failure of i.p. injections. These animals were excluded from 533 all analyses. Lines connecting dots are interrupted for any change in animal numbers between 534 consecutive days.

535 Since a considerable number of animals in the mAb cocktail and placebo groups reached 536 defined humane endpoints by day 2 p.i., This day is zoomed in and values are presented for 537 each individual animal with red symbols marking animals that had to be euthanized. 
Throat Swab / Day 2/3

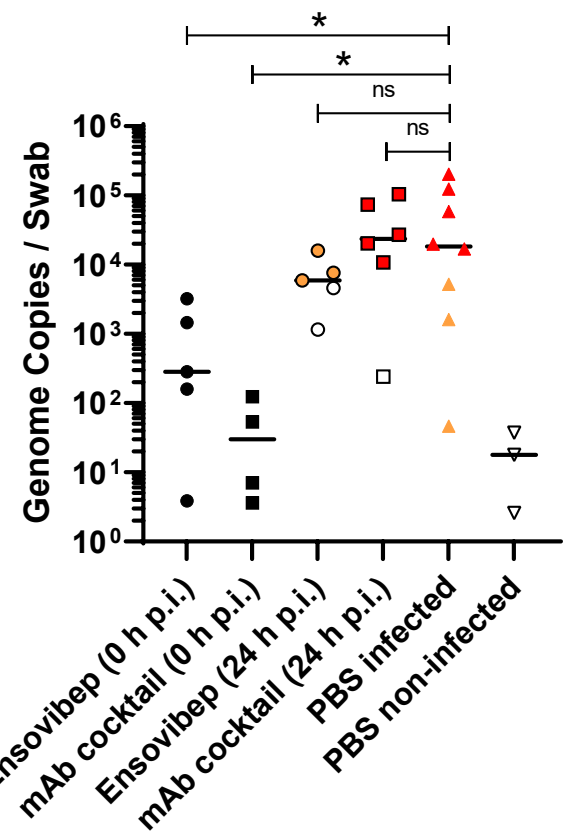

Throat Swab / Day 5
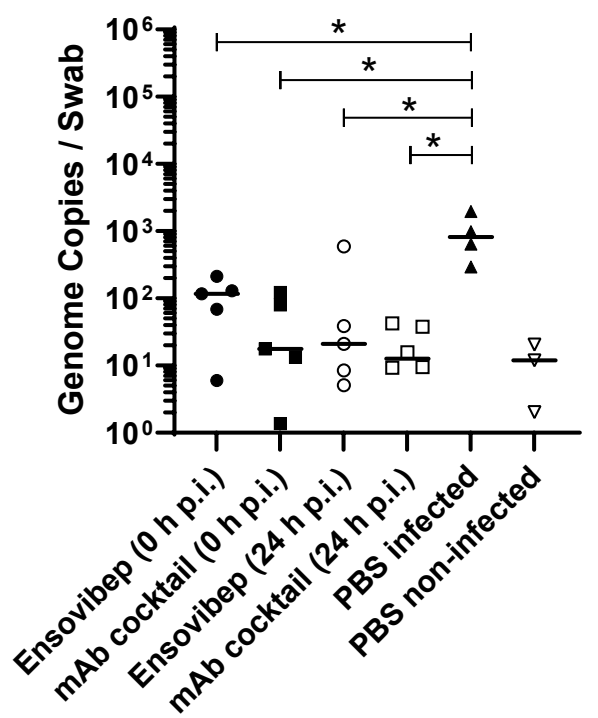

Lung Homogenate / Day 2/3

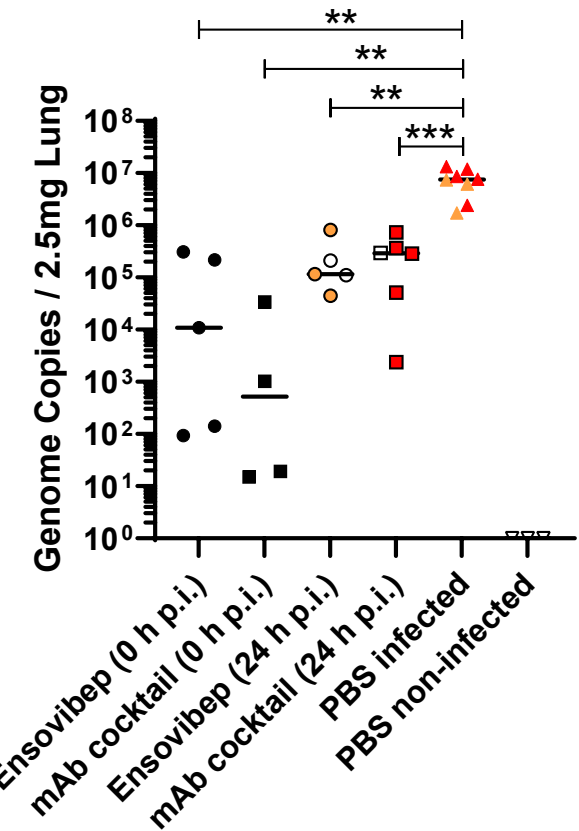

Lung Homogenate / Day 5

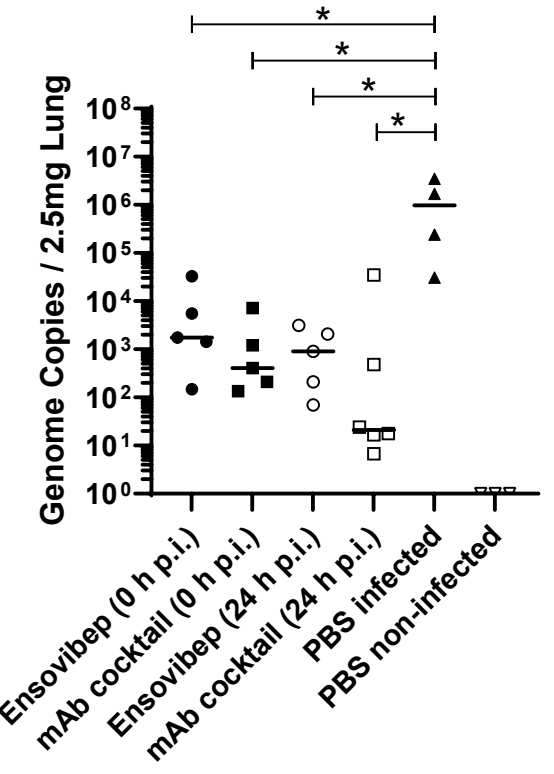


Lung Homogenate Titration / Day 2/3

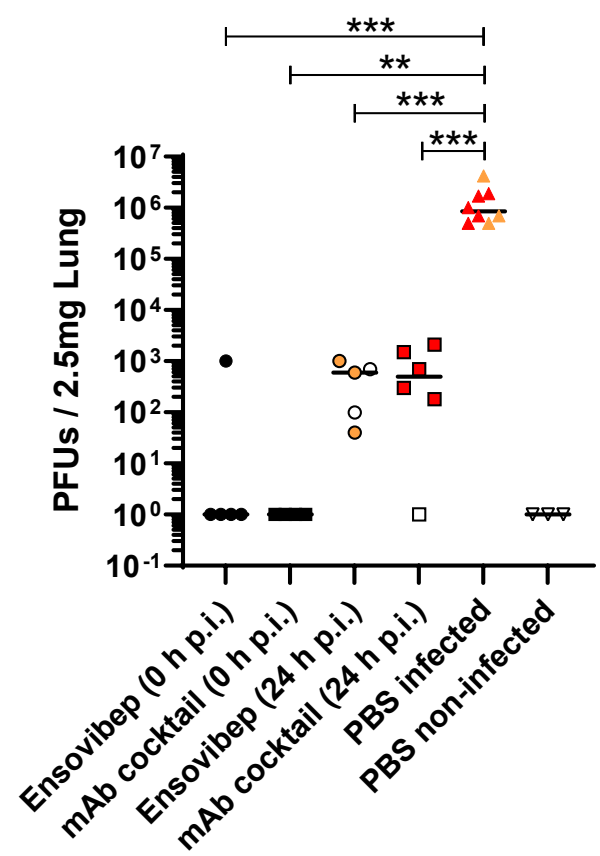

\section{Lung Homogenate Titration / Day 5}

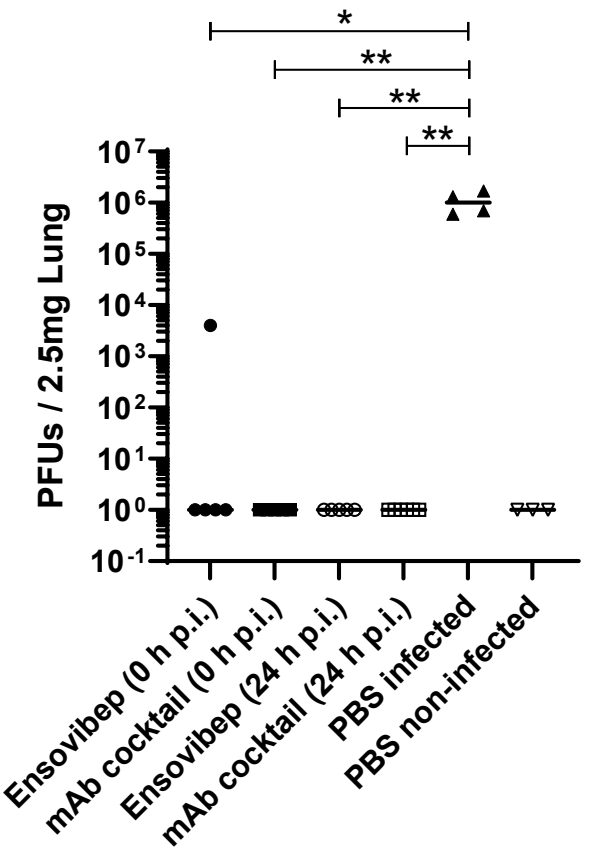

Figure 5: A) qPCR analysis of virus gRNA copy numbers in oropharyngeal swabs and lung homogenates at day $2 / 3$ or day 5 p.i. B) Titration of replication competent virus from lung homogenates as plaque assay on Vero E6 cells at day 2/3 or day 5 post infection. Red symbols: animals taken out of the study at day 2 due to severe clinical symptoms. Orange symbols: animals taken out of the study at day 3 due to severe clinical symptoms. Two-tailed Mann-Whitney Test: ns $P>0.05 ;{ }^{*} P \leq 0.05 ;{ }^{* *} P \leq 0.01 ;{ }^{* * *} P \leq 0.001$. 
bioRxiv preprint doi: https://doi.org/10.1101/2021.02 03 429164; this version posted December 17, 2021. The copyright holder for this preprint (which was not certified by peer review) is the author/funder, who has granted bioRxiv a license to display the preprint in perpetuity. It is made available under aCC-BY-NC-ND 4.0 International license.
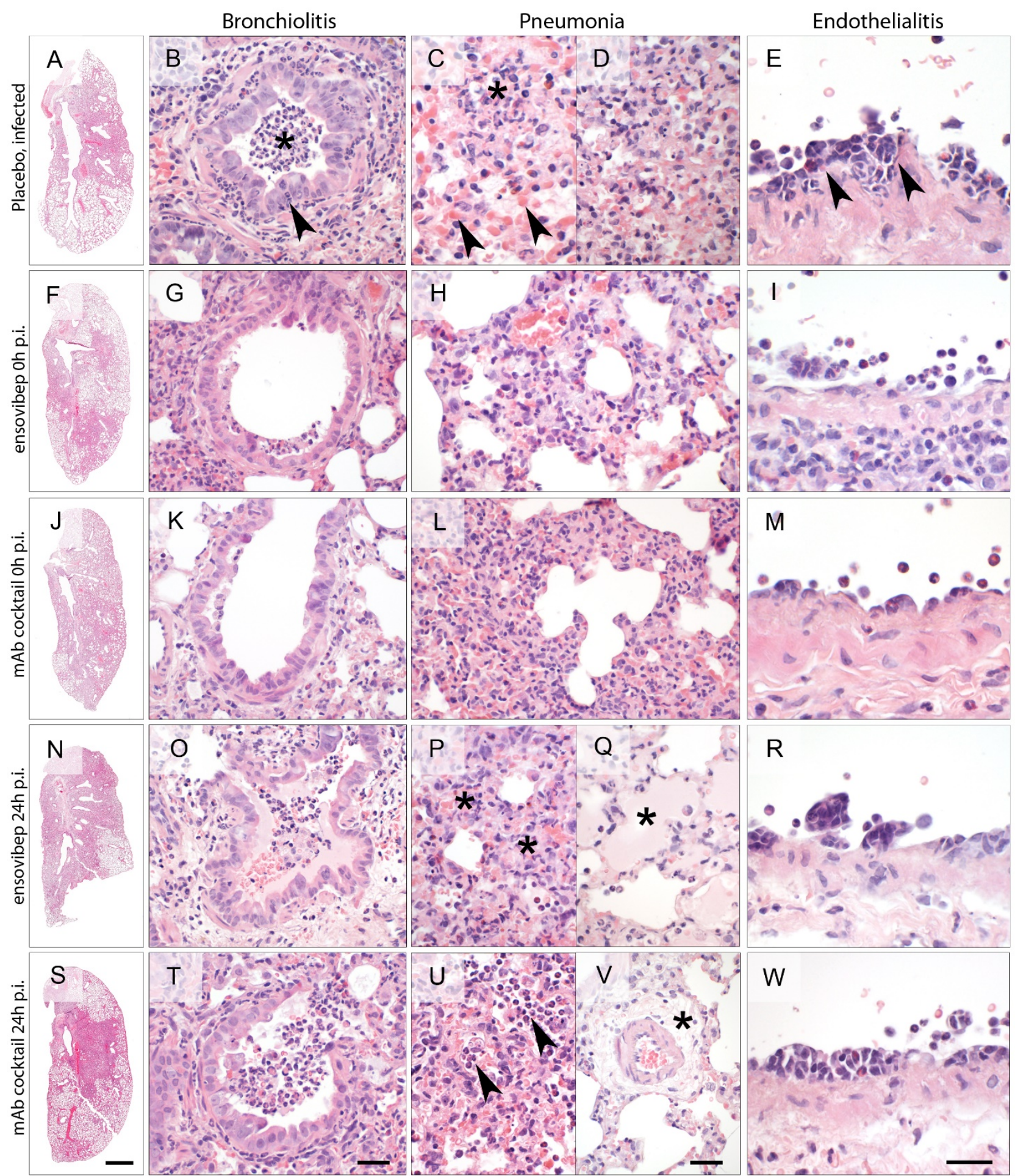
bioRxiv preprint doi: https://doi.org/10.1101/2021.02.03.429164; this version posted December 17, 2021. The copyright holder for this

preprint (which was not certified by peer review) is the author/funder, who has granted bioRxiv a license to display the preprint in perpetuity. It is made available under aCC-BY-NC-ND 4.0 International license.

Inflammation Parameters - Day 2/3

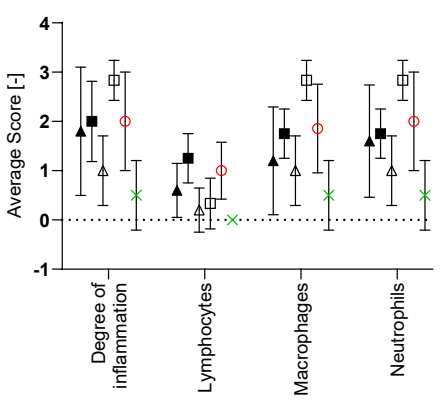

Alveoli - Day 2/3

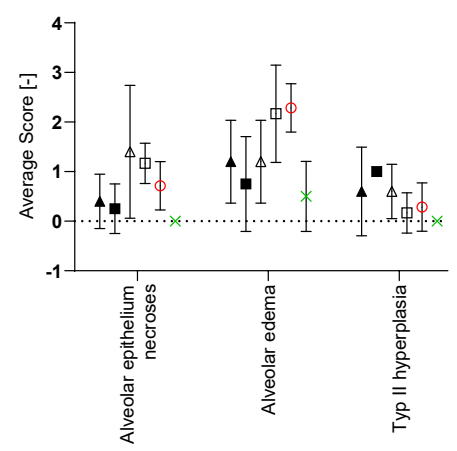

- ensobivep (Oh p.i.)

- mAb cocktail (Oh p.i.)

$\Delta$ ensovibep (24h p.i.)

口 mAb cocktail (24h p.i.)

- Infected placebo

non-infected placebo

ensobivep (Oh p.i.)

mab cocktail (Oh p.i.)

$\Delta \quad$ ensovibep (24h p.i.)

口 mAb cocktail ( $24 \mathrm{~h}$ p.i.)

- Infected placebo

$\times$ non-infected placebo

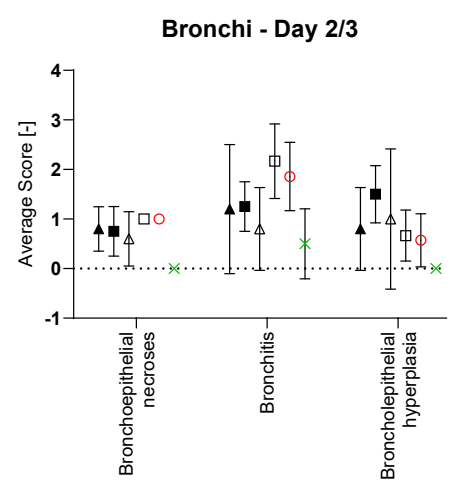

Vasculature - Day 2/3

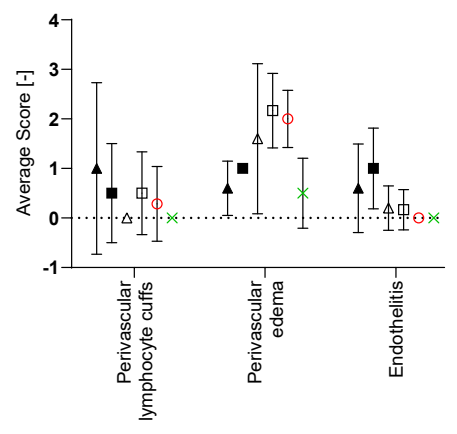

ensobivep (0h p.i.)

- mAb cocktail (Oh p.i.)

$\Delta \quad$ ensovibep (24h p.i.)

口 mAb cocktail (24h p.i.)

- Infected placebo

$\times$ non-infected placebo
Inflammation Parameters - Day 5

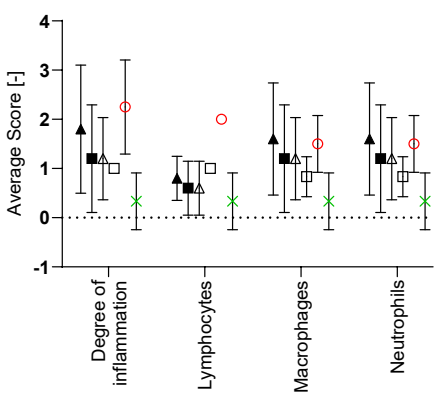

Alveoli - Day 5

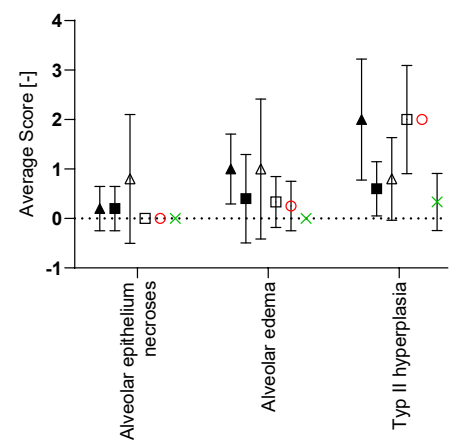

- ensobivep (Oh p.i.)

- mAb cocktail (Oh p.i.)

$\Delta$ ensovibep (24h p.i.)

- mAb cocktail (24h p.i.)

- Infected placebo

non-infected placebo ensobivep (Oh p.i.)

mAb cocktail (Oh p.i.)

$\Delta \quad$ ensovibep (24h p.i.)

mAb cocktail (24h p.i.)

- Infected placebo

$\times$ non-infected placebo

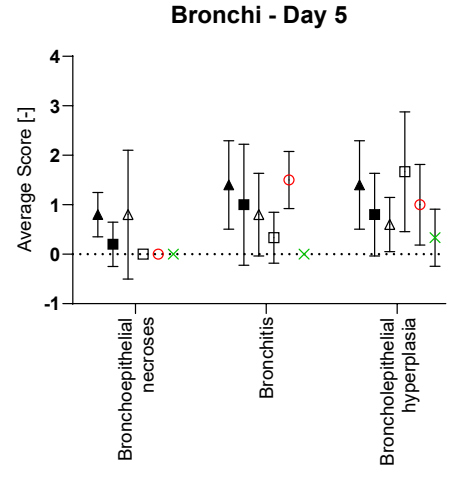

Vasculature - Day 5

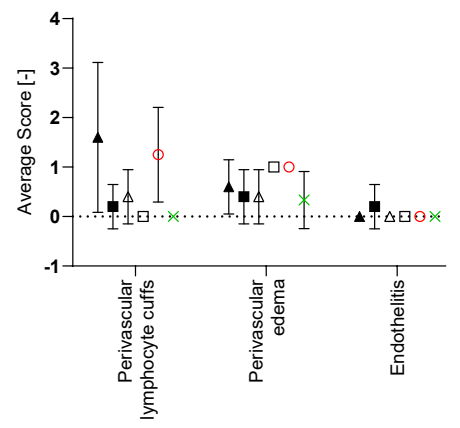

- ensobivep (Oh p.i.)

- mAb cocktail (Oh p.i.)

$\Delta$ ensovibep (24h p.i.)

$\square \quad$ mAb cocktail (24h p.i.)

- Infected placebo

non-infected placebo
A ensobivep (Oh p.i.)

- mAb cocktail (Oh p.i.)

$\Delta \quad$ ensovibep (24h p.i.)

$\square \quad$ mAb cocktail (24h p.i.)

- Infected placebo

$\times$ non-infected placebo 
Figure 6: A-W. Lung histopathology of Roborovski dwarf hamsters at 2 or 3 days p.i. with SARS-CoV-2, hematoxylin and eosin stain. (A-E) Lungs of untreated hamsters at 3 days p.i. developed marked inflammation with lesion patterns as described earlier. (A) Whole slide scan revealing consolidation of approximately $60 \%$ of the left lung. (B) Untreated hamsters had moderate necro-suppurative and hyperplastic bronchiolitis with intraluminal accumulation of neutrophils and cellular debris (asterisk) as well as neutrophils transmigrating through the bronchial epithelium into the lumen (arrowhead). The lung parenchyma presented with a patchy distribution of acute necrosis ( $C$, asterisk) with microvascular thrombosis (arrowheads) or (D) with areas of dense infiltration by macrophages and neutrophils. (E) Pulmonary blood vessels had mild to moderate endothelialitis. (F-I) In contrast, lungs of hamsters treated with ensovibep on the day of infection developed (F) slightly less consolidation of their lungs. (G) Bronchiolitis was milder with less inflammatory cell infiltrate compared to the untreated group. Neutrophils were mostly absent. (H) Alveolar walls were only moderately expanded by neutrophils and macrophages with less alveolar edema and hemorrhage compared to untreated hamsters. (I) Endothelialitis was virtually absent with marginating neutrophils as only immune cells interacting with the vascular lining. (J-M) Hamsters treated with the antibody cocktail at the day of infection developed lesions that were similar to those as described for the ensovibep treated group.

$(\mathrm{N}-\mathrm{W})$ In contrast, lungs of hamsters treated at $1 \mathrm{dpi}$ had lesions similar to the untreated hamsters at that time, regardless of their treatments. (O, T): Both treatment groups developed moderate bronchiolitis similar to the untreated group. $(P, U)$ : Lung parenchyma were characterized by interstitial (asterisks) and alveolar (arrowheads) infiltration with neutrophils and macrophages with variable necrosis of alveolar epithelial cells. Additional lesions in both treatment groups included (Q) moderate to marked alveolar edema (asterisk), here shown for the ensovibep group, and (V) moderate interstitial edema (asterisk), here shown for the antibody group. $(R, W)$ : Both treatment groups developed moderate endothelialitis with monomorphonuclear infiltrates underneath detached endothelial cells, similar to the untreated group. $M, R, W=20 \mu m$

Histopathologic lesions were scored semi-quantitatively and scores plotted as graphs for histologic signs of general inflammation and histologic parameters of bronchiolar, alveolar and vascular lesions at day 2/3 p.i $(X)$ or day 5 p.i. $(Y)$. 


\section{Generation of His-tagged monovalent RBD binders and ensovibep}

604

605

606

607

608

609

610

611

612

613

614

615

616

617

618

619

620

621

622

623

624

625

626

627

628

629

630

631

632

633

DARPin constructs selected and cloned as described in Walser et al. ${ }^{31}$ were transformed in E.coli BL21 cells, plated on LB-agar (containing $1 \%$ glucose and $50 \mu \mathrm{g} / \mathrm{mL}$ ampicillin) and then incubated overnight at $37^{\circ} \mathrm{C}$. A single colony was picked into TB medium (containing $1 \%$ glucose and $50 \mu \mathrm{g} / \mathrm{mL}$ ampicillin) and incubated overnight at $37^{\circ} \mathrm{C}$, shaking at $230 \mathrm{rpm}$. Fresh TB medium (containing $50 \mu \mathrm{g} / \mathrm{mL}$ ampicillin) was inoculated with 1:20 of overnight culture and incubated at $37^{\circ} \mathrm{C}$ at $230 \mathrm{rpm}$. At OD600 $=1.1$ the culture was induced by addition of IPTG (0.5 mM final concentration) and incubated further for $5 \mathrm{~h}$ at $37^{\circ} \mathrm{C}$ and $230 \mathrm{rpm}$. Harvest was done by centrifugation (10 min, $5000 \times \mathrm{g}$ ). After cell disruption by sonication, primary recovery was done by heat treatment for $30 \mathrm{~min}$ at $62.5^{\circ} \mathrm{C}$ and subsequent centrifugation (15 min, $12000 \times$ g). 20 mM Imidazole and 1\% Triton X-100 was added to the supernatant and the $0.22 \mu \mathrm{m}$ filtered supernatant was further purified by immobilized metal affinity chromatography (IMAC) (HisTrap FF crude, Cytiva, Sweden) using the N-terminal His-tag and including a wash step with $1 \%$ Triton X-100 and a step elution with $250 \mathrm{mM}$ Imidazole. In a subsequent step, the elution fraction of the IMAC step was applied on a size exclusion chromatography (Superdex 200, Cytiva, Sweden) and fractions of interest were pooled and concentrated. Finally, the concentrated sample was filtered through a $0.22 \mu \mathrm{m}$ Mustang E filter for Endotoxin removal and sterile filtration and quality controlled.

\section{Cryo-electron microscopy}

$4 \mu \mathrm{l}$ of purified S-ectodomain $(9 \mu \mathrm{M})$ was mixed with $1 \mu$ l of $50 \mu \mathrm{M}$ mono-DARPin R2, and incubated for 15 seconds at room temperature. $3 \mu$ of sample was then dispensed on Quantifoil R1.2/1.3 200-mesh grids (Quantifoil Micro Tools $\mathrm{GmbH}$ ) that had been freshly glow discharged for $30 \mathrm{~s}$ at $20 \mathrm{~mA}$. Grids were blotted using blot force +2 , for $5 \mathrm{~s}$ using Whatman No. 1 filter paper and immediately plungefrozen into liquid ethane cooled by liquid nitrogen using a Vitrobot Mark IV plunger (Thermo Fisher Scientific) equilibrated to $\sim 95 \%$ relative humidity, $4^{\circ} \mathrm{C}$. Movies of frozen-hydrated specimens were collected using Glacios Cryo-TEM (Thermo Fisher Scientific) operating at $200 \mathrm{keV}$ and equipped with a Falcon 4 Direct Electron Detector (Thermo Fisher Scientific). For additional analysis of monovalent DARPin R2, $4 \mu$ of purified S-ectodomain (18 $\mu \mathrm{M})$ was mixed with $1 \mu \mathrm{l}$ of $100 \mu \mathrm{M}$ DARPin, and incubated for $60 \mathrm{~s}$ at room temperature. Grids were prepared as described above, and movies were collected using a Titan Krios Cryo-TEM (Thermo Fisher Scientific) operating at $300 \mathrm{keV}$ and equipped with a Falcon 4 Direct Electron Detector (Thermo Fisher Scientific). All cryo-EM data were acquired using the EPU 2 software (Thermo Fisher Scientific) with a 30-degree stage tilt to account for preferred orientation of 
634

635

636

637

638

639

640

641

642

643

644

645

646

647

648

649

650

651

652

653

654

655

656

657

658

659

660

661

662

663

664

665

666

the samples. Movies were collected in electron counting mode at 92,000x (Glacios) or 75,000x (Titan Krios), corresponding to a pixel size of $1.1 \AA$ Apix or $1.045 \AA$ /pix over a defocus range of -1.25 to $-2.5 \mu \mathrm{m}$.

\section{Image processing}

Movie stacks were manually inspected and then imported in Relion version 3.160. Drift and gain correction were performed with MotionCor ${ }^{61}$, and $\mathrm{GCTF}^{62}$ was used to estimate the contrast transfer function for each movie. Particles were automatically picked using the Laplacian-of-Gaussian (LoG) algorithm and then Fourier binned $(2 \times 2)$ particles were extracted in a 160-pixel box. The extracted particles were subjected to two rounds of 2D classification, ignoring CTFs until the first peak. Using the 'molmap' command in UCSF chimera ${ }^{63}$, a SARS-CoV-2 spike structure (PDB ID: 6VSB) ${ }^{64}$ was used to generate a $50 \AA$ resolution starting model for 3D classification. Particles selected from 2D classification were subject to a single round of 3D classification (with C1 symmetry). Particles belonging to the best classes were re-extracted unbinned in a 320-pixel box, 3D auto-refined (with C1 or C3 symmetry) and post-processed. Iterative rounds of per particle defocus estimation, 3D auto-refinement and postprocessing were used to account for the 30-degree stage tilt used during data collection. When CTF refinement did not yield any further improvement in resolution, Relion's Bayesian polishing procedure was performed on the particle stacks, with all movie frames included, followed by 3D auto-refinement and post-processing. Subsequently, additional rounds of per particle defocus estimation, 3D autorefinement and post-processing were performed on the polished particles until no further improvement in resolution or map quality was observed. The nominal resolution for each map was determined according to the 'gold standard' Fourier shell correlation (FSC) criterion (FSC $=0.143$ ) and local resolution estimations were performed using Relion. Map sharpening was performed using DeepEMhancer ${ }^{65}$ as implemented in COSMIC $2^{66}$. To improve the quality of the mono-DARPin R2 density in the fully open spike reconstruction, a focused 3D classification approach was employed. Briefly, each particle contributing to the final C3-symmetry-imposed reconstruction was assigned three orientations corresponding to its symmetry related views using the "relion_particle_symmetry_expand" tool. A soft mask was placed over the map to isolate the mono-DARPin R2-bound RBD, and the symmetryexpanded particles were subjected to masked 3D classification without alignment using a regularization parameter (' $T$ ' number) of 20. Particles corresponding to the 3D class with the best resolved DARPin density were re-extracted in a 200-pixel box and centered on the mask used for focused classification. In conjunction with this, the signal for the protein outside the masked was subtracted. The re-extracted particles were then 3D auto-refined (with C1 symmetry) using local angular searches (1.8 degrees) and sharpened using DeepEMhancer ${ }^{65}$. Three copies of the locally refined map were aligned to the globally refined map using the UCSF Chimera 'fit in map' tool and resampled using the 'vop resample' command. 
Finally, a composite map was generated using the "vop add" command. An overview of the image processing workflows is shown in supplementary Figure $2 \mathrm{~A}$.

Homology models of monovalent DARPin molecules R1, R2 and R3 were generated with Rosetta ${ }^{67-69}$.

671 The consensus designed ankyrin repeat domain PDB ID:2XEE was used as template. Mutations were

672 introduced with RosettaRemodel with fixed backbone, and the structure was refined with RosettaRelax.

673 Forty refined structures were clustered using RosettaCluster with $0.3 \AA$ radius, and the lowest-energy

674 model from the largest cluster served as the final model. The UCSF Chimera 'fit in map' tool was used

675 to fit the monovalent DARPin R2 model into the cryo-EM map produced from focused refinement. This

676 fitted model of DARPin R2, together with the RBD domain (PDB ID:6MOJ) was further refined with

677 Rosetta. The structure was pre-relaxed for docking and served as input for local, high-resolution docking 678 with RosettaDock with fixed backbone. Five hundred models were generated and clustered with $1 \AA$ 679 radius (RosettaCluster). Two largest clusters were inspected and the lowest-energy model from more 680 conserved group (i.e., with lower rigid-body perturbation from the input structure) was taken further 681 for additional all-atom refinement with RosettaRelax, with protocol optimized for interfaces 682 (InterfaceRelax2019). Fifty models were generated, and the lowest scoring model was selected. This 683 model was used to describe the interactions between DARPin R2 and the RBD. The PDB file with the 684 coordinates of the trimer of DARPin R2:RBD was used as an input structure for the conceptual modeling 685 of ensovibep bound to the spike ectodomain as shown in Figure 1G. The linkers were generated using 686 Rosetta modeling tools. Figures were generated using LigPlot ${ }^{70}$, UCSF Chimera ${ }^{63}$, UCSF ChimeraX ${ }^{71}$, 687 PyMOL (The PYMOL Molecular Graphics System, Version 2.0, Schrödinger, LLC) and BioRender 688 (BioRender.com).

\section{Generation of monoclonal antibodies}

690 Publicly available sequences of variable domains from monoclonal antibodies were used to synthetize 691 the corresponding cDNA fragments and cloned into a proprietary expression vector at Evitria AG 692 (Schlieren, Switzerland). Generated vectors containing the constant immunoglobulin chains were used 693 for transfection in Chinese hamster ovary cells by Evitria. Sterile filtered cell supernatants were purified 694 via affinity purification with HiTrap MabSelect column followed by a size exclusion chromatography 695 using HiLoad 26/600 Superdex 200 column in PBS pH7.4. Selected fractions were pooled and quality 696 controlled (by SDS-PAGE, size exclusion chromatography and endotoxin measurement) before use in 697 assays. 
Plasmid pCAGGS containing the spike protein of SARS-CoV- $2^{31}$ was used as template for generation of single and multiple spike protein mutants. Forward and reverse complementary primers encoding the mutation were synthesized by Microsynth (Balgach, Switzerland). High-fidelity Phusion polymerase (New England Biolabs, USA) was used for all DNA amplification.

Single mutations of the spike protein were generated via two PCR fragments of the spike ORF using high-fidelity Phusion polymerase (New England Biolabs, USA). The first fragment was generated via a generic forward primer (pCAGGS-5) annealing upstream of the spike ORF and the specific reverse primer encoding the mutation. The second fragment was generated using the specific forward primer encoding the mutation and a reverse primer (rbglobpA-R). The two fragments were gel-purified and used as input for an assembly PCR without addition of flanking primers.

For multi-mutation spike proteins, a complementary pair of primers (forward and reverse) encoding each mutation was designed. Fragment 1 was generated with forward primer PCAGGS-5 and reverse primer encoding mutation 1. Fragment 2 was generated using forward primer encoding mutation 1 and reverse primer encoding mutation 2 . All subsequent fragments were generated analogously. DNA fragments were gel-purified and mixed in equimolar amounts. This mix was used for re-assembly of the full spike ORF using outer primers pCAGGS-5 and rbglobpA-R.

For both single as well as multi-mutation spike protein, the full-length spike ORF was isolated from an agarose gel, digested by restriction enzymes Nhel/EcoRI and inserted into the pCAGGS vector backbone. The correct sequence was verified via sequencing the whole ORF of the spike protein by Microsynth (Balgach, Switzerland).

\section{VSV-SARS-CoV-2 pseudotype neutralization assay for mutational analysis}

The pseudotype viral system was based on the recombinant VSV*AG-Luc vector in which the glycoprotein gene $(G)$ had been deleted and replaced with genes encoding green fluorescent protein and luciferase ${ }^{72}$. Pseudoviruses were generated as reported previously ${ }^{73,74}$. For the neutralization assay, an initial dilution of the compounds was followed by three-fold dilutions in quadruplicates in DMEM-2 $\%$ [vol/vol] FCS supplemented with $20 \mu \mathrm{M}$ human serum albumin (CSL Behring). The mixture was mixed with an equal volume of DMEM-2 \% FCS containing 250 infectious units (IU) per well of SARS-CoV-2 pseudoviruses and incubated for $90 \mathrm{~min}$ at $37^{\circ} \mathrm{C}$. The mix was inoculated onto Vero E6 cells $\mathrm{s}^{75,76}$ in a clear bottom white walled 96 -well plate during $90 \mathrm{~min}$ at $37^{\circ} \mathrm{C}$. The inoculum was removed and fresh medium added, and cells further incubated at $37^{\circ} \mathrm{C}$ for $16 \mathrm{~h}$. Cell were lysed according to the ONE-Glo $\mathrm{T}^{\mathrm{TM}}$ luciferase assay system (Promega, Madison, US) and light emission was recorded using a Berthold ${ }^{\circledR}$ 
TriStar LB941 luminometer. The raw data (relative light unit values) were exported to GraphPad Prism v8.4.3, and the \% neutralization values were normalized to the untreated PsV signal. I $C_{50}$ with 95\% confidence interval were estimated by model of nonlinear regression fit with settings for log (inhibitor) vs normalized response curves. Data points are plotted by the mean \pm SEM (standard error of mean).

\section{SARS-CoV-2 lentivirus-based pseudovirus neutralization assay}

The neutralizing activity of therapeutic antibodies against SARS-COV-2 variants was measured using lentiviral particles pseudotyped with spike proteins of SARS-COV-2 variants, as previously described ${ }^{77}$. Briefly, pseudoviruses bearing the spike proteins and carrying a firefly luciferase ${ }^{78}$ reporter gene were produced in 293T cells by co-transfection of pCMVAR8.2, pHR'CMVLuc and pCDNA3.1-spike variants. Plasmids encoding human codon-optimized spike genes with the desired mutations were purchased (GenScript, Piscataway, NJ). Supernatants containing pseudoviruses were collected $48 \mathrm{~h}$ posttransfection, filtered through a $0.45 \mu \mathrm{m}$ low protein binding filter, and stored at $-80^{\circ} \mathrm{C}$. Pseudovirus titers were measured by infecting 293T-ACE2.TMPRSS2s cells for $48 \mathrm{~h}$ prior to measuring luciferase activity (luciferase assay reagent, Promega, Madison, WI). For neutralization assays, pseudoviruses with titers of approximately $10^{6}$ relative luminescence units $(\mathrm{RLU}) / \mathrm{ml}$ were incubated with serially diluted antibodies for two $\mathrm{h}$ at $37^{\circ} \mathrm{C}$ before adding the pseudovirus and antibody mixtures (100 $\mu \mathrm{L}$ ) onto 96 well plates pre-seeded one day earlier with $3.0 \times 10^{4}$ 293T-ACE2.TMPRSS2s cells/well. Pseudovirus infection was scored $48 \mathrm{~h}$ later by measuring luciferase activity. The therapeutic concentration causing a $50 \%$ reduction of RLU compared to control $\left(I_{50}\right)$ was reported as the neutralizing antibody titer. Titers were calculated using a nonlinear regression curve fit (GraphPad Prism software Inc., La Jolla, CA). The ratio of the neutralizing antibody titer of the variant compared to the neutralizing antibody titer of wild type was calculated. The mean titer from at least two independent experiments with intra-assay duplicates was reported as the final titer. This work was performed independently by investigators at the US Food and Drug Administration, Center for Biologics Evaluation and Research as part of Therapeutics Research Team for the US government COVID-19 response efforts.

\section{Cells and pathogenic virus}

Vero E6 cells (kindly provided by Prof. Volker Thiel, University of Bern, Switzerland) were passaged in Minimum Essential Medium (MEM) (Cat N M3303) containing $10 \%$ fetal bovine serum (FBS) and supplements (2 mM L-Glutamine, 1\% Non-essential amino acids, 100 units $/ \mathrm{ml}$ Penicillin, $100 \mu \mathrm{g} / \mathrm{ml}$ Streptomycin, $0.06 \%$ Sodium bicarbonate, all from Bioswisstec, Schaffhausen, Switzerland) at $37^{\circ} \mathrm{C}$, $>85 \%$ humidity and $5 \% \mathrm{CO}_{2}$. Vero E6/TMPRSS2 cells $^{75,76}$ obtained from the Centre For AIDS Reagents (National Institute for Biological Standards and Control) were passaged in Dulbecco's Modified Eagle Medium (DMEM) (Cat N M1452) containing 10\% fetal bovine serum (FBS) and supplements (2 mM L- 
Glutamine, 1\% Non-essential amino acids, $100 \mathrm{U} / \mathrm{mL}$ Penicillin, $100 \mu \mathrm{g} / \mathrm{mL}$ Streptomycin, $0.06 \%$ Sodium bicarbonate and $2 \%$ Geneticin G418, all from Bioswisstec, Schaffhausen, Switzerland) at $37^{\circ} \mathrm{C},>85 \%$ humidity and $5 \% \mathrm{CO}_{2}$.

SARS-CoV-2 (2019-nCoV/IDF0372/2020), kindly provided by Dr. Sylvie van der Werf from the National Reference Centre for Respiratory Viruses hosted by Institut Pasteur (Paris, France) was propagated in Vero E6 cells in MEM containing $2 \% \mathrm{FBS}$ and supplements (2\%-FBS-MEM) at $37^{\circ} \mathrm{C}$, $>85 \%$ humidity and $5 \% \mathrm{CO}_{2}$. SARS-CoV-2 variants (B.1.1.7, B.1.351 and P.1) were provided from University Hospital of Geneva, Laboratory of Virology ${ }^{25}$ and propagated in Vero E6/TMPRSS2 cells in DMEM containing $2 \%$ FBS and supplements (2\%-FBS-DMEM) at $37^{\circ} \mathrm{C},>85 \%$ humidity and $5 \% \mathrm{CO}_{2}$. Viral titer was determined by standard plaque assay, by incubating 10 -fold serial dilutions of the virus for $1 \mathrm{~h}$ at $37^{\circ} \mathrm{C}$ on a confluent 24-well plate with Vero E6 cells. Then inoculum was removed and $1 \mathrm{~mL}$ overlay medium $(20 \mathrm{ml}$ Dulbecco's Modified Eagle's Medium, 5 ml FBS, 100 U/mL Penicillin, 100 mg/mL Streptomycin, and 25 $\mathrm{ml}$ Avicel rc581) was added. After 3 days incubation at $37^{\circ} \mathrm{C}$ the overlay was removed and the plates stained with crystal violet solution (spatula tip ( $4 \mathrm{mg}$ ) crystal violet powder (Sigma Aldrich) solved in $30 \mathrm{ml}$ 37\% formalin and $120 \mathrm{~mL}$ PBS (Sigma Aldrich).

\section{Viral passaging experiment with authentic SARS-CoV-2}

Virus escape studies were adapted from a previously published protocol by Baum et al. ${ }^{27}$. Briefly, 1:5 serial dilutions of DARPin molecules and monoclonal antibodies from $100 \mu \mathrm{g} / \mathrm{mL}$ to $0.032 \mu \mathrm{g} / \mathrm{mL}$ were prepared in Minimum Essential Medium (MEM) containing 2\% FBS, supplements and $10 \mu \mathrm{M}$ human serum albumin (HSA; CSL Behring, Switzerland; 2\%-FBS-MEM + HSA). $500 \mu \mathrm{L}$ of virus suspension containing $1.5 \times 10^{6}$ plaque forming units (pfu) SARS-CoV-2 in 2\%-FBS-MEM + HSA were mixed with 500 $\mu \mathrm{L}$ of serially diluted DARPin molecules or monoclonal antibodies and subsequently incubated for 1 hour at $37^{\circ} \mathrm{C}$. The mixtures were then transferred to confluent Vero E6 cells in 12 well plates and incubated for 4 days at $37^{\circ} \mathrm{C},>85 \%$ humidity and $5 \% \mathrm{CO}_{2}$. Each culture well was assessed for cytopathic effect (CPE) by microscopy. Supernatant was removed from wells with the highest DARPin or antibody concentrations showing significant CPE ( $\geq 20 \%)$ and used for total RNA extraction and further passaging. For subsequent rounds of passaging, remaining $900 \mu \mathrm{L}$ supernatant of selected wells was diluted in 4 $\mathrm{mL}$ in 2\%-FCS-MEM + HSA and from the $4.9 \mathrm{~mL}, 500 \mu \mathrm{L}$ mixed with serial dilutions of DARPin molecules or antibodies, incubated and the mixture transferred to 12-well plates with fresh Vero E6 cells as described above. Cell culture wells were assessed for CPE again after 4 days and the supernatant of wells with highest DARPin or antibody concentrations with evident viral replication (CPE) harvested and used for additional passages. A total of 4 passages were performed this way. 
796

797

798

799

800

801

802

803

804

805

806

807

808

809

810

811

812

813

814

815

816

817

818

819

820

821

822

823

824

825

826

827

828

\section{Deep sequencing of viral passages}

RNA of the cell culture supernatant was extracted using the RNeasy Universal Plus kit (Qiagen, Basel, Switzerland) according to the manufacturer's protocol. $10.5 \mu \mathrm{L}$ of the extract was reverse transcribed using Superscript VILO (ThermoFisher Scientific, Reinach, Switzerland) following the manufacturer's instructions. Barcoded libraries were prepared on the Ion Chef Instrument (ThermoFisher Scientific) using the Ion AmpliSeq SARS-CoV-2 Research Panel (ThermoFisher Scientific). 8-16 barcoded samples were pooled and loaded on one Ion 530 chip using the Ion Chef Instrument (ThermoFisher Scientific) and sequenced on the lon S5 System with 550 flows.

The resulting BAM files were converted to fastq format using Samtools $1.10^{79}$ and subjected to adapter and quality trimming using Trimmomatic $0.39^{80}$ (options: ILLUMINACLIP:adapters.fasta:2:30.10, LEADING: 3, TRAILING: 3, SIDINGWINDOW:4:15, MINLEN:36). Reads were aligned to the SARS-CoV-2 reference genome (NC_045512.2) using bwa 0.7.17 ${ }^{81}$ and variants were determined using LoFreq V2.1.5 $5^{82}$. Variants were filtered for a minimal depth (DP) of 400X and a minimal allele frequency (AF) of $3 \%$ using bcftools $1.10^{79}$. Functional annotation of the variants was performed using SNPEff $5.0^{83}$. Variants were visualized in R 3.6.1 using ComplexHeatmap 2.2 ${ }^{84}$.

\section{Virus neutralization of authentic wild type and variants of SARS-COV-2 determined by Cell Titer-Glo}

Virus neutralization capacity of mono-valent DARPin candidate and multispecific DARPin molecules was determined for 100 TCID 50 SARS-CoV-2 variants from lineage B.1.1.7 (H69_V70del, Y145del, N501Y, A570D, D614G, P681H, T716I, S982A, D1118H), B.1.351 (L18F, D80A, D215G, L242_L244del, T302T, K417N, E484K, N501Y, D571D,D614G, A701V) and P.1 (L18F, T20N, P26S, D138Y, R190S, K417T, E484K, N501Y, D614G, H655Y, T1027I, V1176F) in reference to a wild-type French isolate (with the following differences to the Wuhan wild-type: V367F; E990A) by measuring ATP levels of protected cells in a cell viability assay. DARPin molecules were serially diluted 1:4 from $40 \mathrm{nM}$ to $2.4 \mathrm{pM}$ (in triplicates) in 100 $\mu \mathrm{L}$ cell culture medium (2\%-FBS-DMEM) supplemented with $10 \mu \mathrm{M} \mathrm{HSA}$ in 96 well plates. The diluted DARPin antivirals were mixed with $100 \mathrm{TCID}_{50}$ SARS-CoV-2 in $100 \mu \mathrm{L} 2 \%$-FBS-MEM + HSA and incubated for $1 \mathrm{~h}$ at $37^{\circ} \mathrm{C}$. DARPin/virus mixtures $(200 \mu \mathrm{L})$ were transferred onto confluent Vero E6/TMPRSS2 cells. The controls consisted of cells exposed to virus suspension only, to determine maximal cytopathic effect and of cells incubated with medium only, to determine baseline cell viability. The plates were incubated for 3 days at $37^{\circ} \mathrm{C},>85 \%$ humidity and $5 \% \mathrm{CO}_{2}$. Cell viability was determined by removing $100 \mu \mathrm{L}$ supernatant from all wells and adding $100 \mu \mathrm{L}$ CellTiter-Glo reagent to the cells as described in the manufacturers protocol (CellTiter-Glo ${ }^{\circledR}$ Luminescent Cell Viability Assay, Promega, Madison, USA). After 2 minutes shaking on an orbital shaker, lysis of the cells during 10 min and transfer to an opaquewalled plate at room temperature, luminescence was read using a GloMax instrument (Promega). 
bioRxiv preprint doi: https://doi org/10.1101/2021.02.03,429164: this version posted December 17,2021 . The copyright holder for this preprint (which was not certified by peer review) is the author/funder, who has granted bioRxiv a license to display the preprint in perpetuity. It is made available under aCC-BY-NC-ND 4.0 International license.

\section{Surface plasmon resonance (SRP) affinity determination of ensovibep and individual RBD-binding domains}

SPR assays were used to determine the binding affinity of monovalent DARPin as well as multivalent DARPin molecules to the spike protein of SARS-CoV-2. All SPR data were generated using a Bio-Rad ProteOn XPR36 instrument with PBS-T (0.005\% Tween20) as running buffer. A new neutravidin sensor chip (NLC) was air-initialized and conditioned according to Bio-Rad manual.

Monovalent DARPin molecules R1, R2, R3: Chemically biotinylated (via lysines) SARS-CoV-2 spike protein 20 (Sino Biologics) was captured to $\sim 3400 \mathrm{RUs}(30 \mu \mathrm{g} / \mathrm{mL}, 30 \mu \mathrm{L} / \mathrm{min}, 300 \mathrm{~s})$. Two buffer injections (100 $\mu \mathrm{L} / \mathrm{min}, 60 \mathrm{~s})$ followed by two $12.5 \mathrm{mM} \mathrm{NaOH}$ regeneration steps (100 $\mu \mathrm{L} / \mathrm{min}, 18 \mathrm{~s})$ were applied before the first injections. Mono-domain DARPin proteins were injected (at 50/16.7/5.6/1.9/0.6 nM) for $180 \mathrm{~s}$ at $100 \mu \mathrm{L} / \mathrm{min}$ for association and dissociation was recorded for $3600 \mathrm{~s}$ (at $100 \mu \mathrm{L} / \mathrm{min})$. The ligand was regenerated with a $12.5 \mathrm{mM} \mathrm{NaOH}$ pulse $(100 \mu \mathrm{L} / \mathrm{min}, 18 \mathrm{~s})$. The data was double referenced against the empty surface and a buffer injection and fitted according to the 1:1 Langmuir model.

Multivalent DARPin molecules: Avi-tagged biotinylated SARS-CoV-2 S protein (Acro Biosystems) was captured to $\sim 1200 \mathrm{RUs}(1.33 \mathrm{ug} / \mathrm{mL}, 30 \mu \mathrm{l} / \mathrm{min}, 300 \mathrm{~s})$ on a precoated neutravidin chip (NLC). Two buffer injections $(100 \mu \mathrm{L} / \mathrm{min}, 60 \mathrm{~s})$ followed by three $12.5 \mathrm{mM} \mathrm{NaOH}$ regeneration steps $(100 \mu \mathrm{L} / \mathrm{min}$, 18s) were applied before the first injections. One single concentration of $20 \mathrm{nM}$ of ensovibep was injected for $180 \mathrm{~s}$ at $100 \mathrm{\mu L} / \mathrm{min}$ for association and dissociation was recorded for $36^{\prime} 000 \mathrm{~s}$ (at $100 \mu \mathrm{L} / \mathrm{min}$ ). The data was double referenced against the empty surface and a buffer injection. Due to avidity gain, no significant dissociation could be recorded during the measured time.

\section{Surface plasmon resonance (SRP) affinity determination of wt-RBD and RBD F486V to ACE2}

SPR assays were used to determine the binding affinity of wt-RBD as well as RBD-F486V human ACE2 protein. SPR data were generated using a Bruker Sierra SPR-32 Pro instrument with PBS-T $10.005 \%$ Tween20) as running buffer. A Bruker biotin tag capture sensor chip (BTC) was initialized and conditioned according to Bruker manual.

Avi-tagged biotinylated monomeric human ACE2 (Acro Biosystems) was captured to 170 RUs (3.3 $\mu \mathrm{g} / \mathrm{mL}, 10 \mu \mathrm{L} / \mathrm{min}, 60 \mathrm{~s})$. SARS-CoV-2 S protein RBD (wt, Acro biosystems, 500nM-0.229nM, threefold dilution series) and SARS-CoV-2 S protein RBD-F486V (in-house produced, 1500nM-0.229nM, threefold dilution series) were injected for $240 \mathrm{~s}$ at $25 \mu \mathrm{L} / \mathrm{min}$ for association and dissociation was recorded for $300 \mathrm{~s}$ (at $25 \mathrm{\mu L} / \mathrm{min}$ ). After each injection, a $15 \mathrm{~min}$ pause was performed to ensure full 
dissociation of analyte from the ligand. The data was double referenced against the empty surface and a buffer injection and fitted according to the 1:1 Langmuir model.

\section{CoV-2 and the B.1.1.7 (alpha) variant}

For in vivo experiments, SARS-CoV-2 isolates BetaCoV/Germany/BavPat1/2020 85 and

A total of 120 female and male Roborovski dwarf hamsters (Phodopus roborovskii) was used for infection experiments. Animals were housed in groups of 3 to 6 animals of the same sex in individually ventilated GR900 cages (Tecniplast, Buguggiate, Italy) and provided with food and water ad libitum and bountiful enrichment (Carfil, Oud-Turnhout, Belgium). Infection was performed by intranasal administration of $1 \times 10^{5}$ pfu SARS-CoV-2 in $20 \mu \mathrm{L}$ cell culture medium under general anesthesia ${ }^{38}$. All animal procedures were performed in accordance with relevant institutional and legal regulations and approved by the responsible state authority, Landesamt für Gesundheit und Soziales Berlin, Germany, permit number $\mathrm{G} 0086 / 20$.

DARPin molecules and monoclonal antibodies were administered intraperitoneally in sterile PBS. The final drug concentration was adjusted based on the desired dose and respective animal weight to a 100 $\mu \mathrm{L}$ injection volume. For intraperitoneal administration the animal was fixed by grasping the neck skin and the back skin between thumb and fingers. Subsequently, the hand was turned over so that the animal rests with its back in the palm of the hand. The head of the animal was kept downwards to prevent injection/damage in/of the organs and the needle was inserted left of the median line in the 
From a total of 120 Roborovski dwarf hamsters, 54 were used to determine dose and time dependency of treatment success. In these cohorts, 6 animals per group were infected with $1 \times 10^{5}$ pfu SARS-CoV-2 WT (BetaCoV/Germany/BavPat1/2020) and treated with either 3, 10 or $20 \mathrm{mg} / \mathrm{kg}$ ensovibep at the time of infection, with 1 or $20 \mathrm{mg} / \mathrm{kg} 6 \mathrm{~h}$ post infection, or with $10 \mathrm{mg} / \mathrm{kg} 24 \mathrm{~h}$ post infection, a placebo (PBS) treatment group with 6 animals was also included in each of three studies performed for this purpose.

897 (Suppl. Figure 7)

898 To compare efficacy of ensovibep and Regeneron antibody cocktail treatment, 60 animals were 899 infected with $1 \times 10^{5}$ pfu SARS-CoV-2 variant B.1.1.7 (BetaCoV/Germany/ChVir21652/2020). Subjects 900 were divided into groups of 12 animals and treated with $10 \mathrm{mg} / \mathrm{kg}$ ensovibep, $10 \mathrm{mg} / \mathrm{kg}$ Regeneron $\mathrm{mAb}$ cocktail or a placebo (PBS) at the time of infection or with $10 \mathrm{mg} / \mathrm{kg}$ ensovibep or $10 \mathrm{mg} / \mathrm{kg}$ Regeneron mAb cocktail $24 \mathrm{~h}$ post infection. An additional 6 animals served as non-infected control group.

904

In all animal experiments performed in this study, half of each respective group was scheduled for take out at $3 \mathrm{dpi}$, the other half was to be terminated at $5 \mathrm{dpi}$. In some of the experiments, several animals had to be terminated at time points other than these for humane reasons. Defined humane endpoints included a body temperature $<33^{\circ} \mathrm{C}$, body weight loss $>15 \%$ together with signs of respiratory distress, body weight loss $>20 \%$ or a combination of these factors. Animals were monitored at least twice a day to prevent any prolonged suffering.

RNA was extracted from throat swabs and lung tissue using the innuPREP Virus DNA/RNA Kit (Analytic Jena, Jena, Germany). Viral RNA was quantified using a one-step RT qPCR reaction with the NEB Luna Universal Probe One-Step RT-qPCR (New England Biolabs, Ipswich, MA, USA) and the 2019-nCoV RTqPCR primers and probe (E_Sarbeco) ${ }^{86}$ on a StepOnePlus RealTime PCR System (Thermo Fisher Scientific, Waltham, MA, USA) according to the manufacturer's instructions. Standard curves for

916 absolute quantification were generated from serial dilutions of SARS-CoV-2 DNA obtained from a full-

917 length virus genome cloned as a bacterial artificial chromosome and propagated in E. coli. Duplicate 918 10-fold serial dilutions were used to determine replication competent virus titers on confluent layers 919 of Vero E6 cells. To this end, serial dilutions of lung tissue homogenates were made and incubated on 920 Vero E6 monolayers for 2 hours at $37^{\circ} \mathrm{C}$. Cells were washed and overlaid with semi-solid cell culture 921 medium containing $1.5 \%$ microcrystalline cellulose (Avicel) and incubated for $48 \mathrm{~h}$ at $37^{\circ} \mathrm{C}$ after which plates were fixed with $4 \%$ formalin and stained with $0.75 \%$ crystal violet for plaque counting. 
924 For histopathology, the left lung lobe was carefully removed, immersion-fixed in formalin, $\mathrm{pH}$ 7.0, for $48 \mathrm{~h}$, embedded in paraffin, and cut in $2 \mu \mathrm{m}$ sections. Slides were stained with hematoxylin and eosin (HE) after dewaxing in xylene and rehydration in decreasing ethanol concentrations. Lung sections were microscopically evaluated in a blinded fashion by a board-certified veterinary pathologist to assess the character, distribution and severity of pathologic lesions using lung-specific inflammation scoring parameters as described for other lung infection models before. Three different scores were used that included the following parameters: (1) lung inflammation score including severity of (i) interstitial pneumonia (ii) bronchiolitis, (iii) necrosis of bronchial and alveolar epithelial cells, and (iv) hyperplasia of alveolar epithelial type II cells as well as (v) hyperplasia of bronchial epithelial cells; (2) immune cell

933 infiltration score taking into account the presence of (i) neutrophils, (ii) macrophages, and (iii) 934 lymphocytes in the lungs as well as (iv) perivascular lymphocytic cuffing; and (3) edema score including 935 (i) alveolar edema and (ii) perivascular edema. HE-stained slides were analyzed and images were taken using an Olympus BX41 microscope with a DP80 Microscope Digital Camera and the cellSens ${ }^{\mathrm{TM}}$ Imaging Software, version 1.18 (Olympus Corporation, Münster, Germany). For the display of overviews of whole lung lobe sections, slides were automatically digitized using the Aperio CS2 slide scanner (Leica Biosystems Imaging Inc., Vista, CA, USA), and image files were generated using the Image Scope Software (Leica Biosystems Imaging Inc.). The percentages of lung tissues affected by inflammation were determined histologically by an experienced board certified experimental veterinary pathologist (O.K.) as described previously ${ }^{87}$. Lung inflammation scores were determined as absent, (1) mild, (2) moderate or (3) severe and quantified as described previously ${ }^{87}$. Immune cell influx scores and edema scores were rated from absent to, (1) mild, (2) moderate, or (3) severe.

\section{Whole genome sequencing of SARS-CoV-2 isolated from treated hamsters}

Following RNA extraction from swabs and lung samples, libraries were prepared and sequenced using Illumina technology (Illumina, San Diego, California, USA). For library preparation, a multiplexed amplicon-based whole-viral-genome approach using the NEBNext ${ }^{\circledR}$ ARTIC SARS-CoV-2 Library Prep Kit (Illumina ${ }^{\circledR}$ ) was employed (New England Biolabs, Ipswich, Massachussets, USA). Briefly, this approach relies on cDNA synthesis from total RNA and amplification of target SARS-CoV-2 cDNA using the V3 ARTIC primers; these amplicons then undergo the usual library preparation steps for Illumina sequencing (end repair, adaptor ligation and PCR enrichment). Quantification of enriched sequencing libraries was performed using the NEBNext ${ }^{\circledR}$ Library Quant Kit for Illumina ${ }^{\circledR}$ (New England Biolabs, Ipswich, Massachussets, USA). Libraries were then pooled and sequenced on an Illumina Miseq System (Illumina, San Diego, California, USA). 
The generated Illumina sequencing data were processed with Trimmomatic v.0.3980 and mapped against genome reference MT270101.1, using the Burrows-Wheeler aligner v.0.7.1781. Mapping statistics were generated using Samtools v1.1088 and alignments were visualized using IGV v2.9.4 for Linux $^{89}$. For detection of single-nucleotide polymorphisms (SNPs), Freebayes, a Bayesian genetic variant detector was used. All SNPs with a minimum mapping quality of 5, minimum count of 3 and minimum fraction of 0.01 were considered. Consensus sequences for each sample were obtained using BCFtools.

962 All SNP-containing open reading frame (ORFs) sequences were extracted from these consensus 963 genomes and translated using the Expasy ${ }^{908}$. Translate tool. The resulting protein sequences were then

964 aligned to the corresponding reference protein sequences using the Expasy ${ }^{8}$ SIM Protein Alignment

965 tool. For SNPs that resulted in amino acid substitutions, their possible effect on protein function was

966 gauged using two predictors: PROVEAN Protein ${ }^{91}{ }^{92}$ and SIFT ${ }^{93}$. Results from both predictors were taken

967 into account, except on instances where the SIFT predictor could not resolve the proposed substitution

968 or made "low confidence" predictions, then PROVEAN's prediction was prioritized as its protein

969 database is larger and newer.

\section{Hamster pharmacokinetic study}

971 Single intraperitoneal injections of $10 \mathrm{mg} / \mathrm{kg}$ were administered to female hamsters. Fifteen animals

972 were enrolled in each study ( $n=3$ per time point). Blood was sampled from individual animals at $2 \mathrm{~h}$,

$97324 \mathrm{~h}, 48 \mathrm{~h}, 72 \mathrm{~h}$ and $168 \mathrm{~h}$ post administration and processed to serum. MP0420 serum

974 concentrations were determined by sandwich ELISA using an anti-DARPin antibody as capture reagent

975 and biotinylated RBD and HRP conjugated Streptavidin as detection reagent and quantified against a

976 standard curve. Serum concentrations for detection of both antibodies REGN10933 and REGN10987

977 were determined by sandwich ELISA using an anti-IgG antibody as capture reagent and biotinylated

978 RBD and HRP conjugated Streptavidin as detection reagent and using a standard curve.

979 Pharmacokinetic parameters were determined with non-compartmental analyses using the software

980 Phoenix WinNonLin (Certara, Princeton, USA) or GraphPadPrism (GraphPad Software, La Jolla,USA).

981 For the in vivo efficacy study, terminal bleed samples were collected at 2, 3 or 5 days p.i. according to study description. 
A

$\mathrm{R} 1$

B

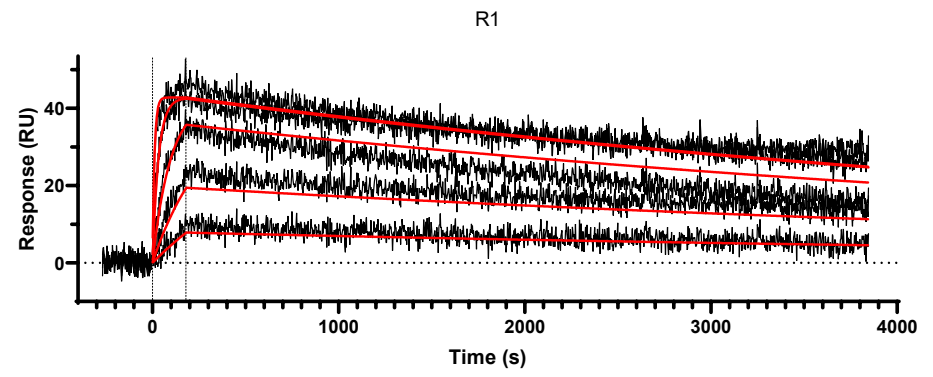

$\mathrm{R} 2$

985

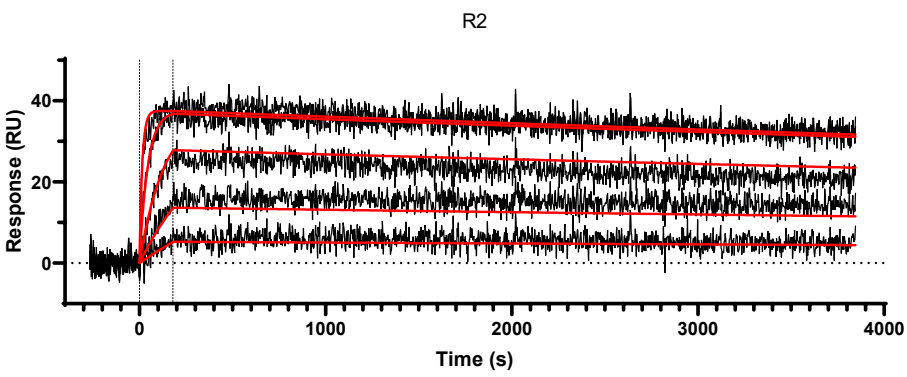

\section{C}

Time (s)

986

R3

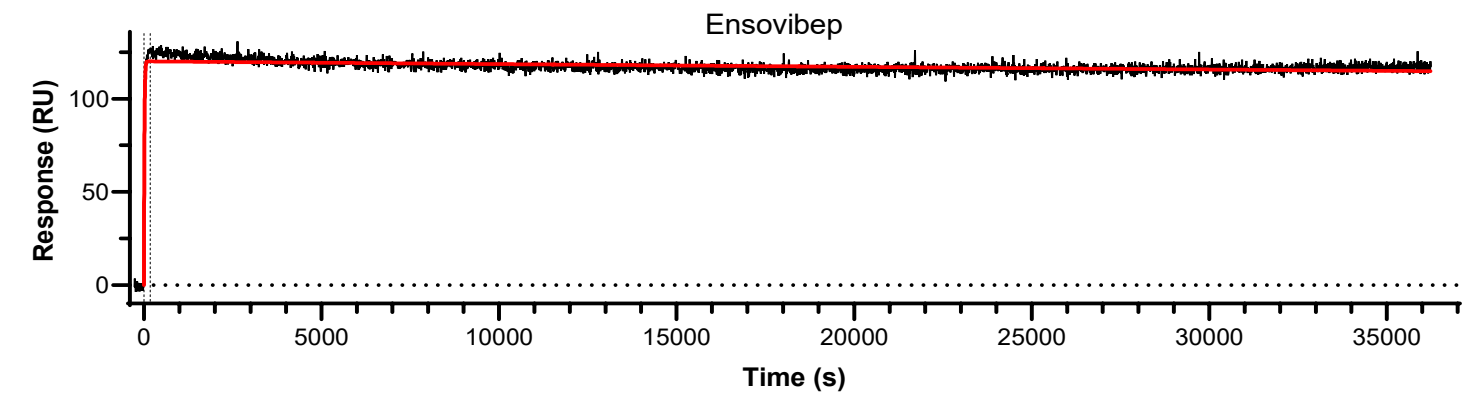

987

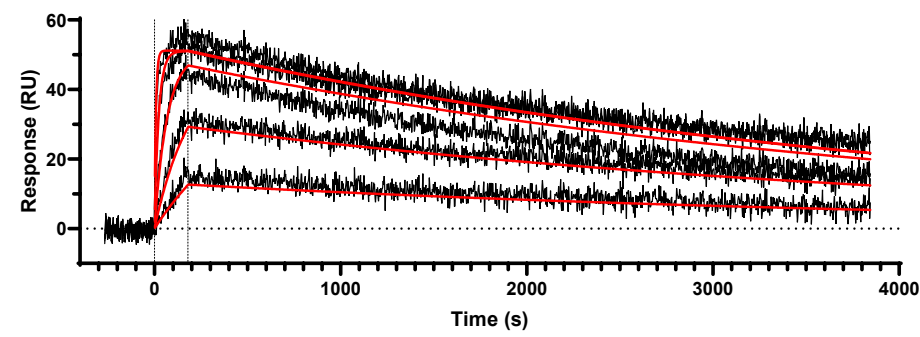

988 Supplementary Figure 1: A-C) Surface plasmon resonance (SPR) sensorgrams of the 989 monovalent DARPin modules (R1, R2, R3), incorporated in ensovibep binding to immobilized 990 trimeric spike protein. DARPin concentrations for A-C: 50/16.67/5.56/1.85/0.62 nM. 991 Determined $K_{D}$ values: A) 80 pM, B) 30 pM, C) 90 pM. D) SPR sensorgram of ensovibep 992 binding to immobilized spike protein. Off-rate was measured over $10 \mathrm{~h}$ and no physical off993 rate could be determined by SPR due to very strong avidity of the three interlinked RBD 994 binding modules. 
A

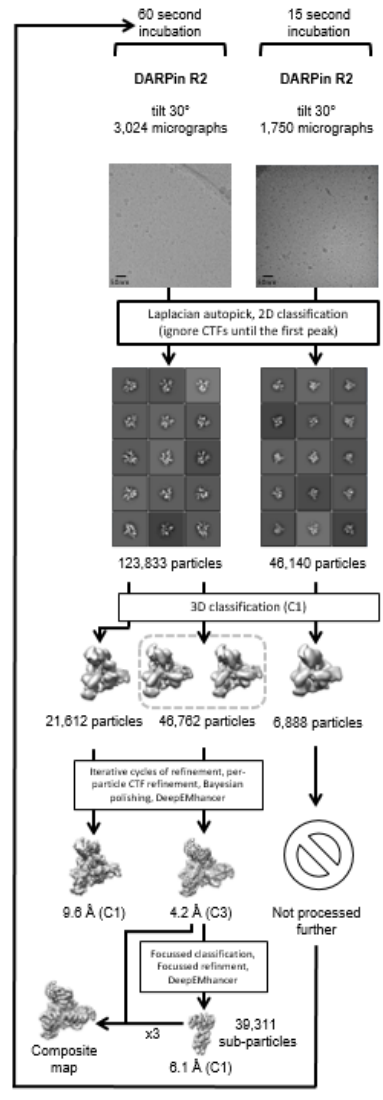

B

C

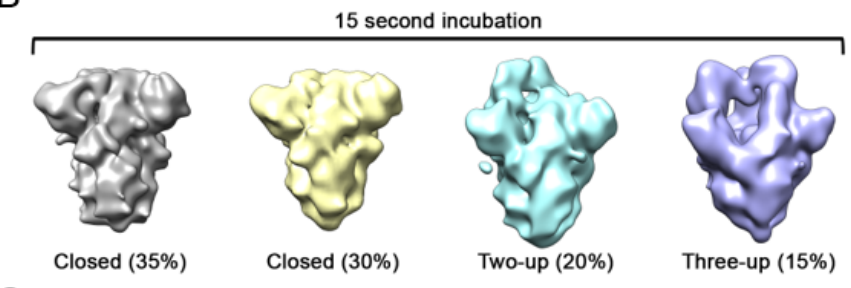

60 second incubation

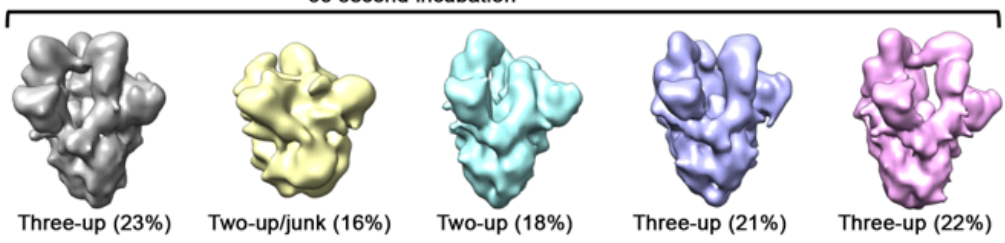

D

E

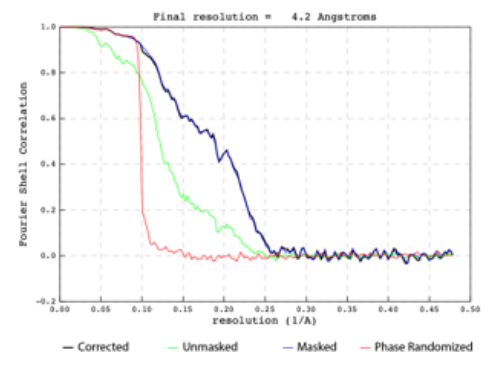

$\mathrm{F}$

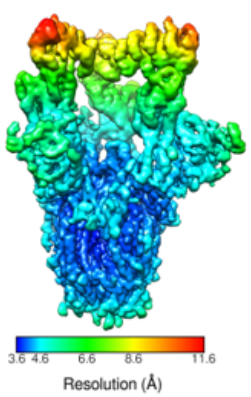

997 Supplementary Figure 2: Single-particle cryo-EM data processing. A) Single-particle cryo-EM image processing workflow for the monovalent DARPin R2 data collections. B) 3D classes obtained from spike ectodomains incubated with monovalent DARPin R2 for 15

1000 seconds, and C) for 60 seconds. D) Gold-standard Fourier shell correlation (FSC) curve generated from the independent half maps contributing to the $4.2 \AA$ resolution density map. E) Angular distribution plot of the final C3 refined EM density map. F) The EM density map of the spike ectodomain bound to three copies of monovalent DARPin R2, colored according to local resolution. 

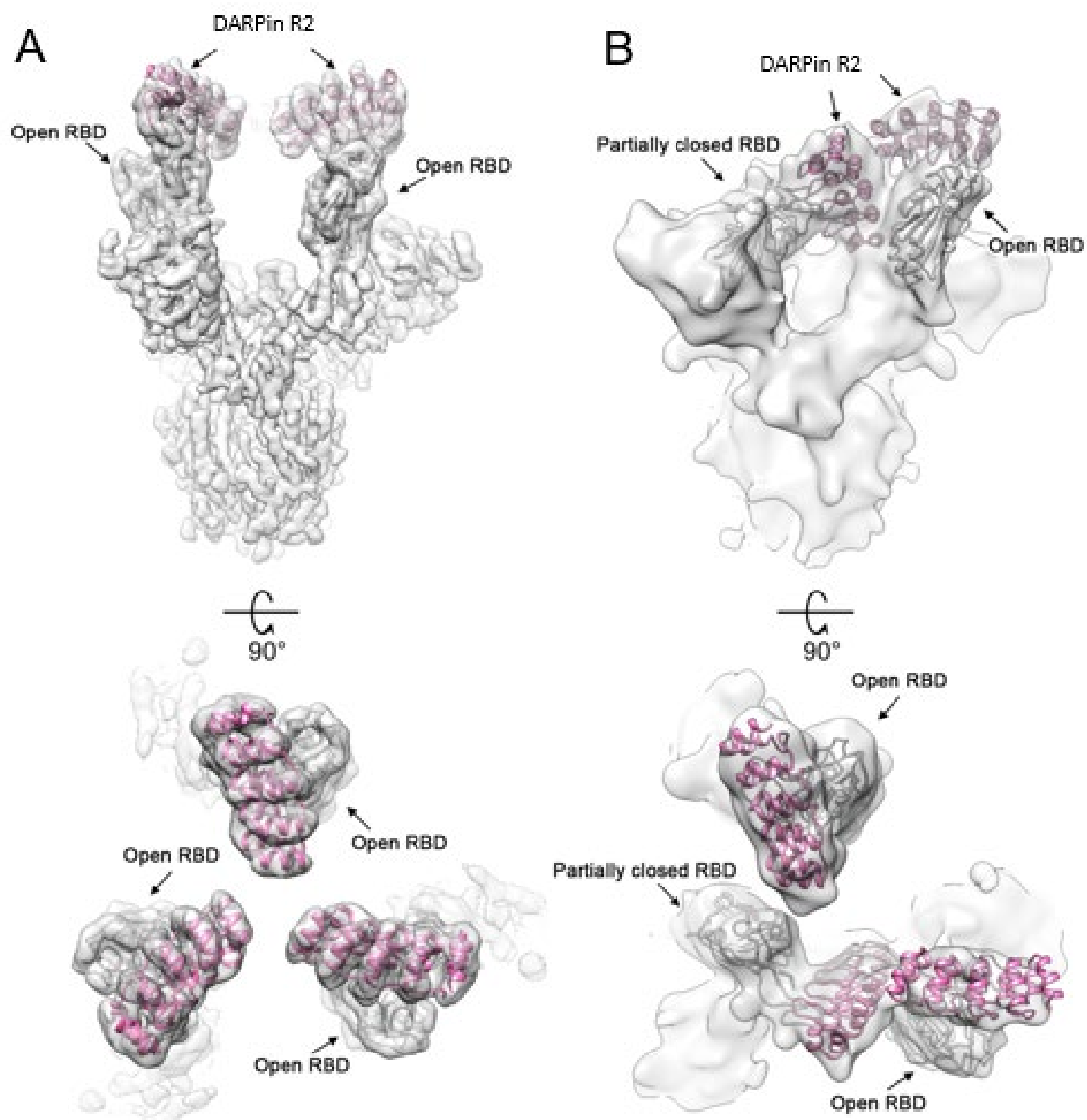

(State 1)

(State 2)

Supplementary Figure 3: Monovalent DARPin R2 prevents full closure of the RBD. A) Cryo-EM density for state 1 and B) state 2 of the SARS-CoV-2 spike ectodomain in complex with the RBD targeting monovalent DARPin R2, shown as two orthogonal views. The pseudoatomic model of monovalent DARPin R2 in complex with RBD, derived from molecular docking experiments, is fitted in each of the spike protomers and colored grey and pink, respectively. 
bioRxiv preprint doi: https://doi org/10.1101/2021.02 03 429164; this version posted December 17, 2021. The copyright holder for this preprint (which was not certified by peer review) is the author/funder, who has granted bioRxiv a license to display the preprint in perpetuity. It is made available under aCC-BY-NC-ND 4.0 International license.

VSV-PsV Wuhan

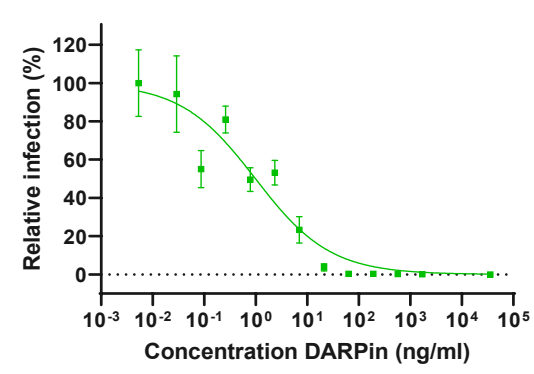

SARS-CoV-2 French isolate

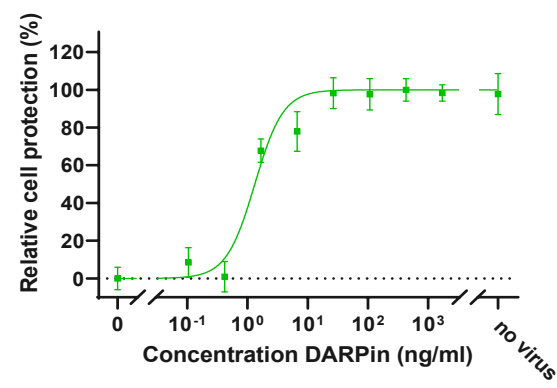

Lentivirus-PsV Alpha/B.1.1.7

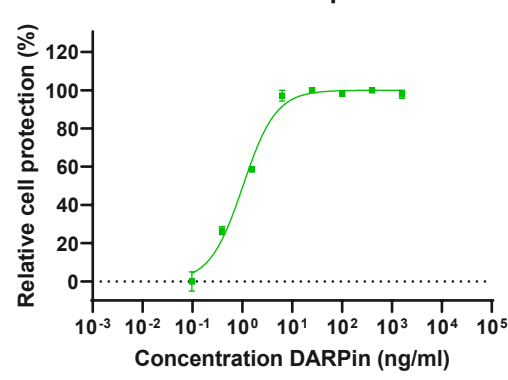

Lentivirus-PsV Alpha+S494P

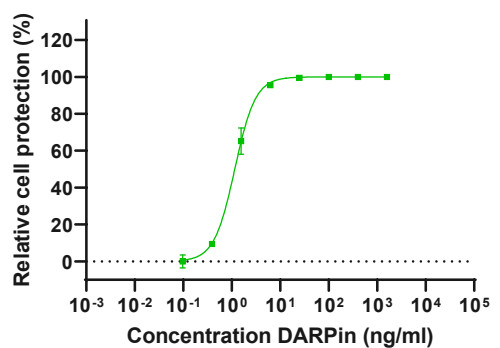

Lentivirus-PsV D614G

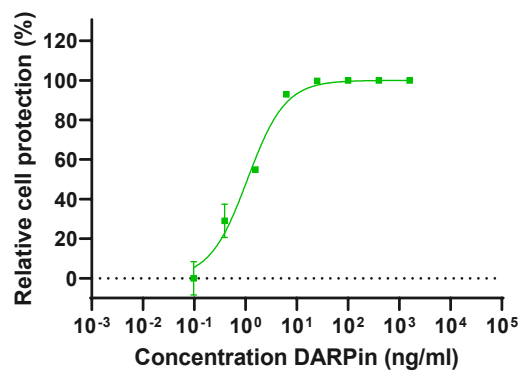

VSV-PsV Alpha/B.1.1.7

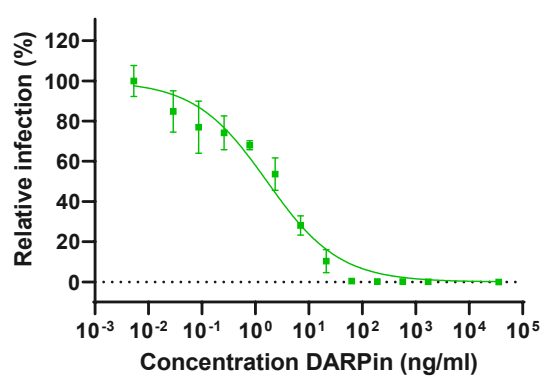

VSV-PsV Alpha+E484K

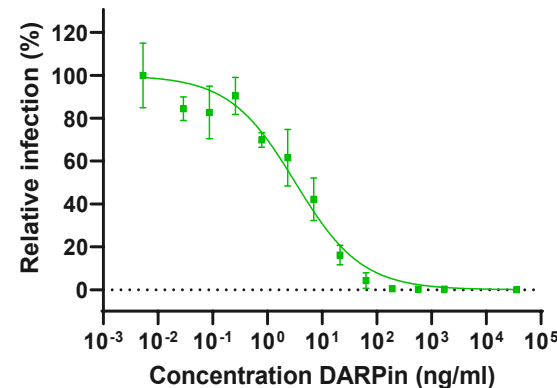

SARS-CoV-2 Alpha/B.1.1.7

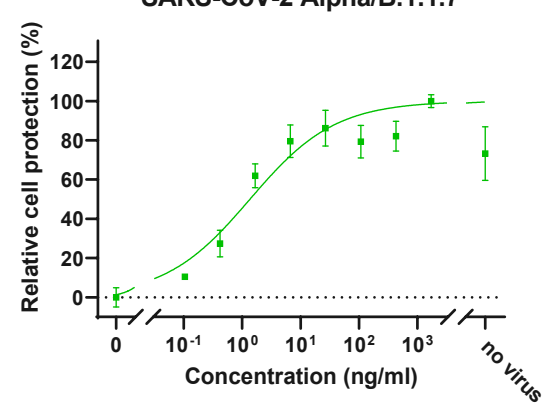


VSV-PsV B.1.351 $\Delta 10$

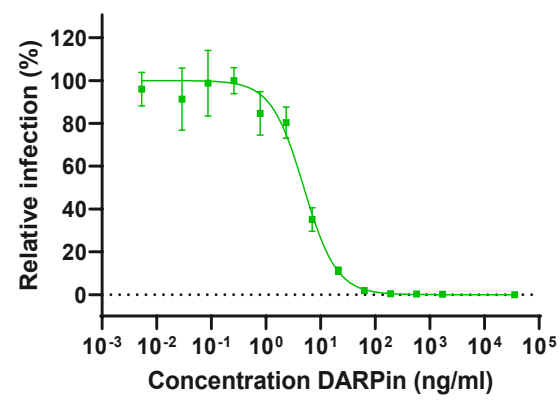

1015

SARS CoV-2 B.1.351

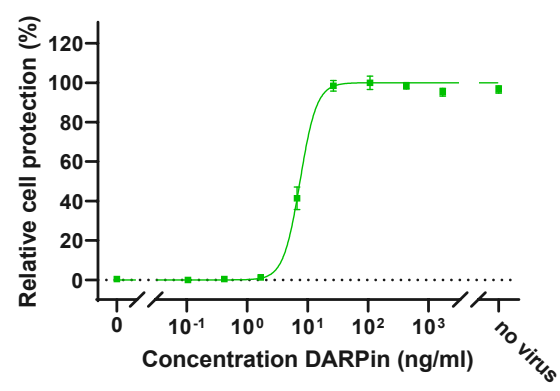

Lentivirus-PsV P.1 $\Delta 12$

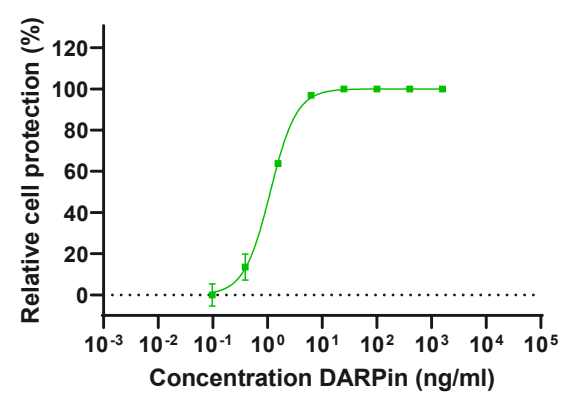

1017

Lentivirus-PsV B.1.617.2

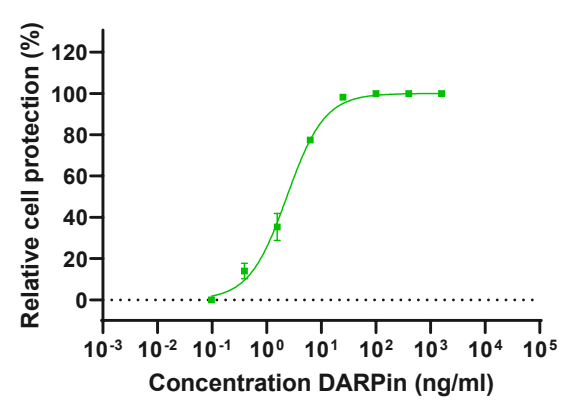

Lentivirus-PsV B.1.351 $\Delta 9$

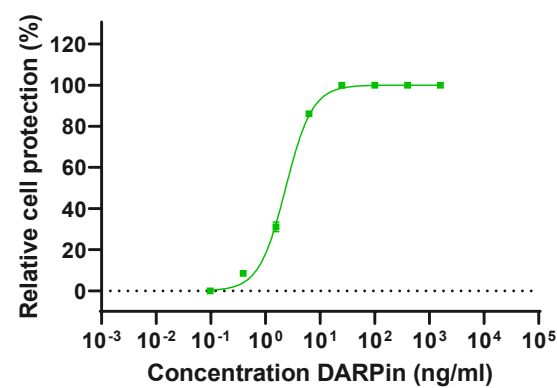

VSV-PsV P.1 $\Delta 12$

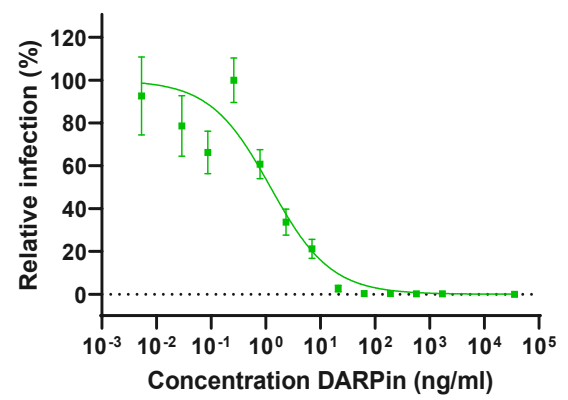

SARS CoV-2 P.1

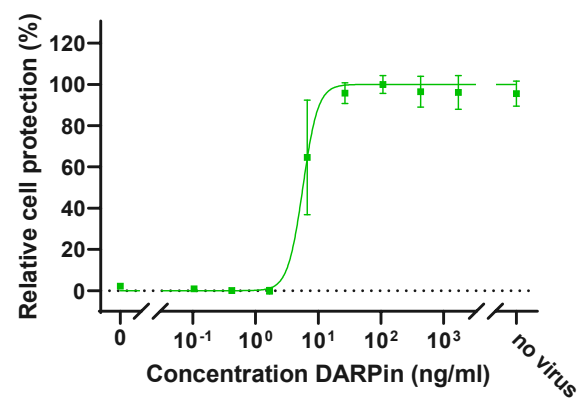

Lentivirus-PsV B.1.617.2+K417N

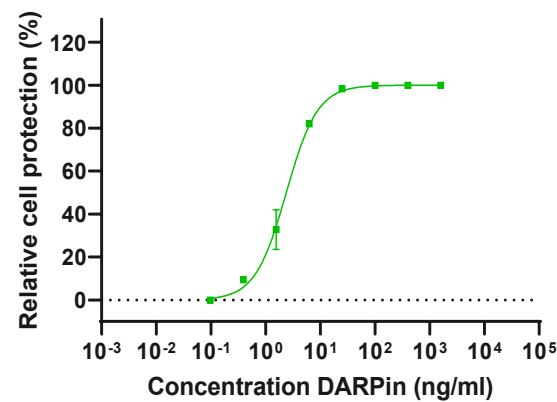


Lentivirus-PsV B.1.429 $\Delta 5$

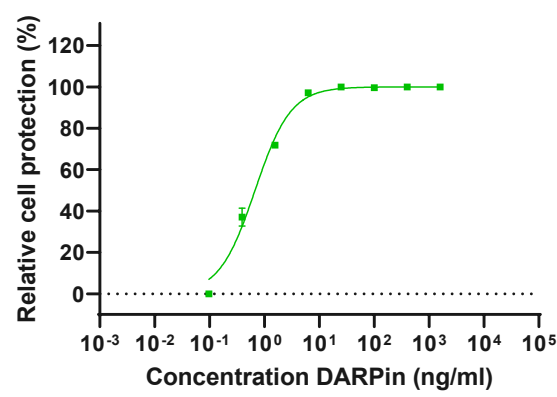

1019

Lentivirus-PsV B.1.526

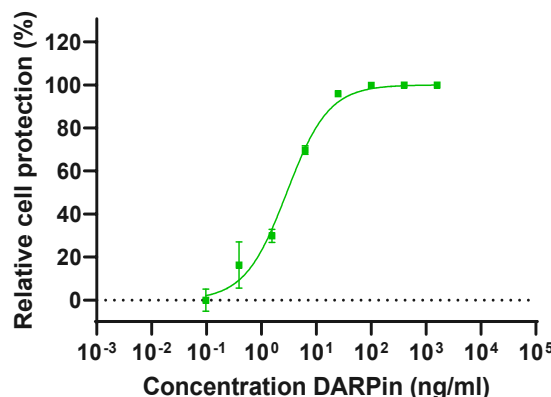

1020

Lentivirus-PsV B.1.617.1 $\Delta 9$

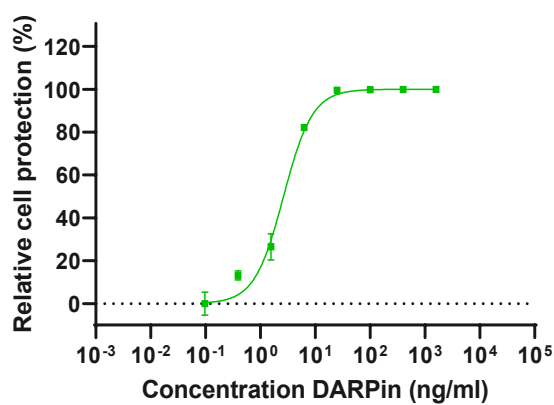

1021

VSV-PsV B.1.618

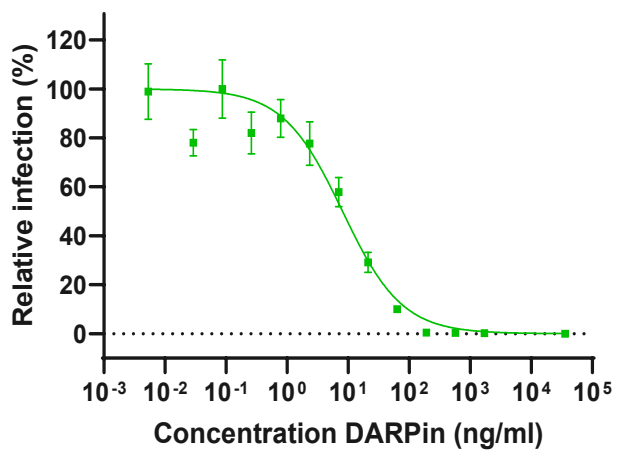

VSV-PsV B.1.525 / Eta

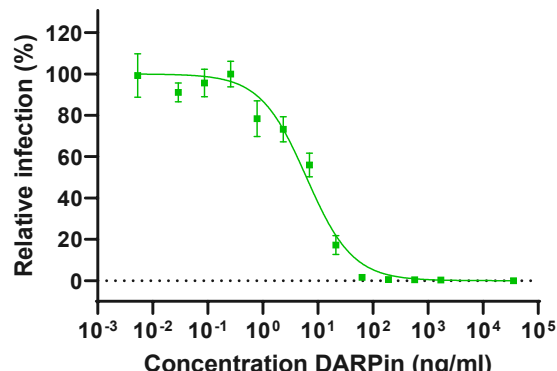

MP0420

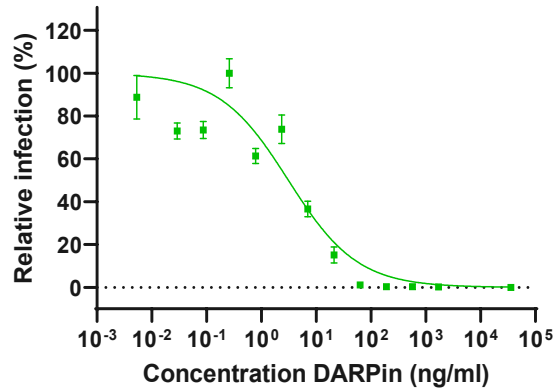

Lentivirus-PsV C.37

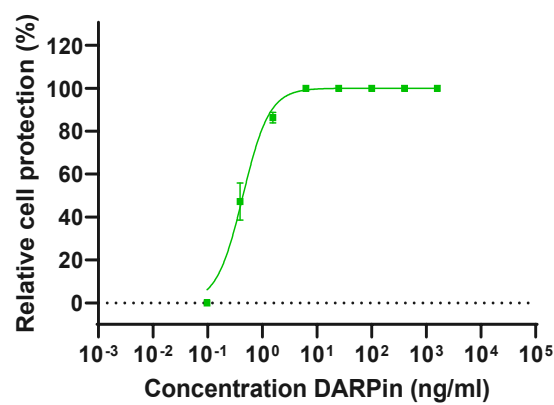

Lentivirus-PsV B.1.621

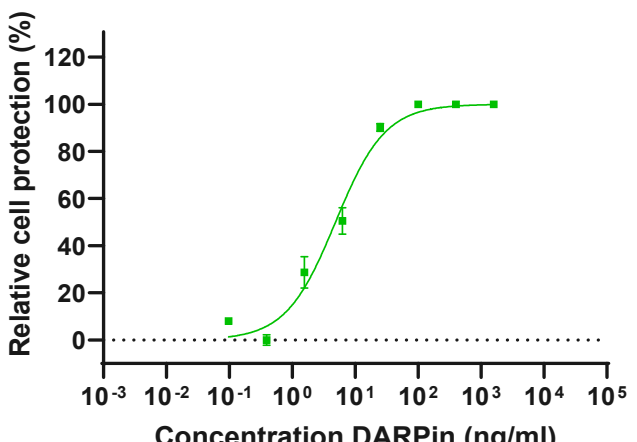

Concentration DARPin (ng/ml) 
bioRxiv preprint doi: https://doi org/10.1101/2021.02 03 429164· this version posted December 17, 2021. The copyright holder for this preprint (which was not certified by peer review) is the author/funder, who has granted bioRxiv a license to display the preprint in perpetuity. It is made available under aCC-BY-NC-ND 4.0 International license.

VSV-PsV B.1.618

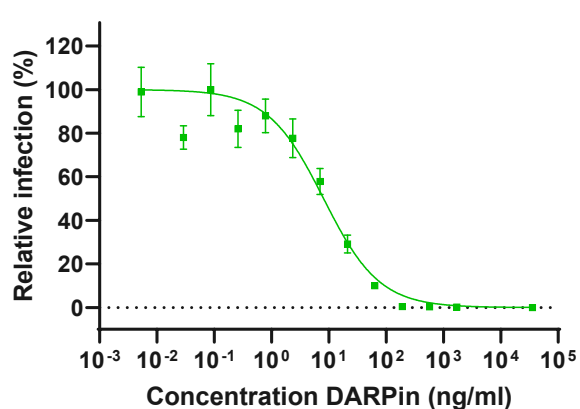

Lentivirus-PsV R.1

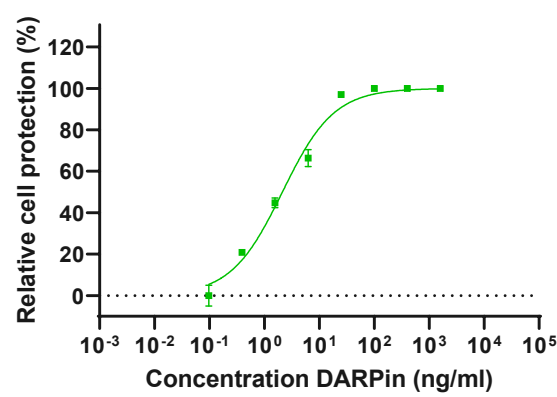

1024

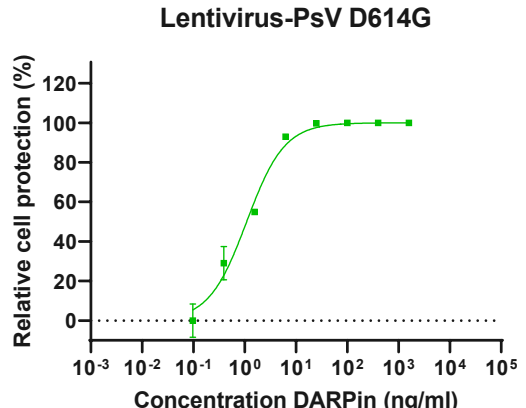

1025

VSV-PsV Alpha/B.1.1.7

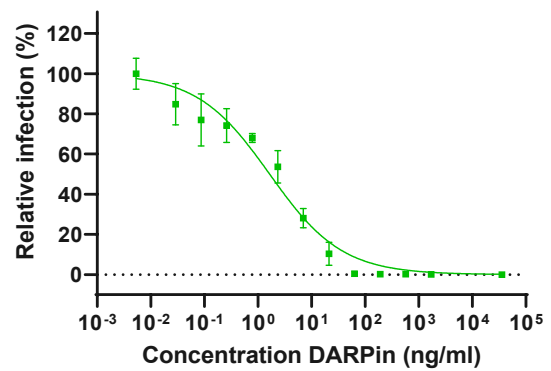

Lentivirus-PsV A.23.1

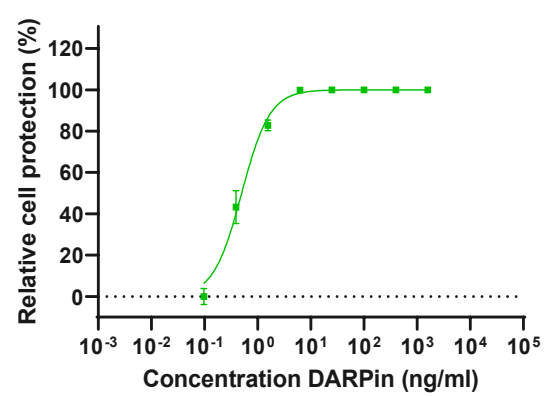

VSV-PsV Wuhan

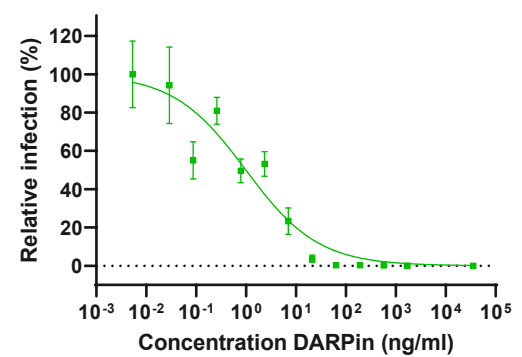

SARS-CoV-2 French isolate

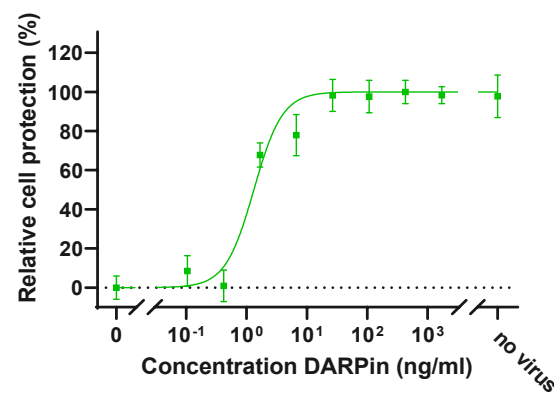

Lentivirus-PsV Alpha/B.1.1.7

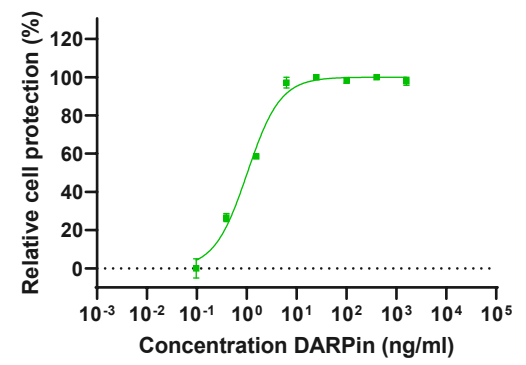


VSV-PsV Alpha+E484K

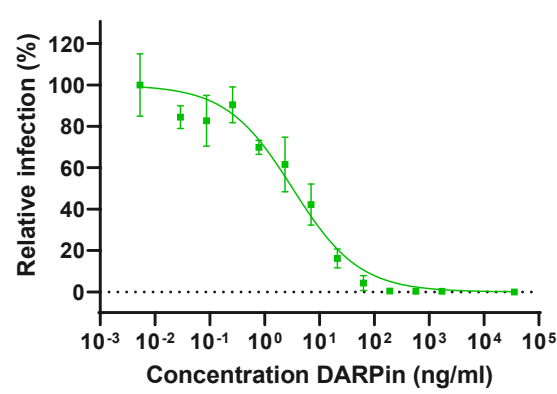

SARS-CoV-2 Alpha/B.1.1.7

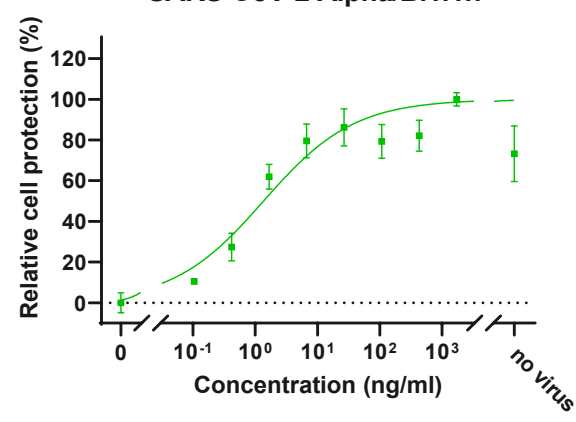

1028

1029

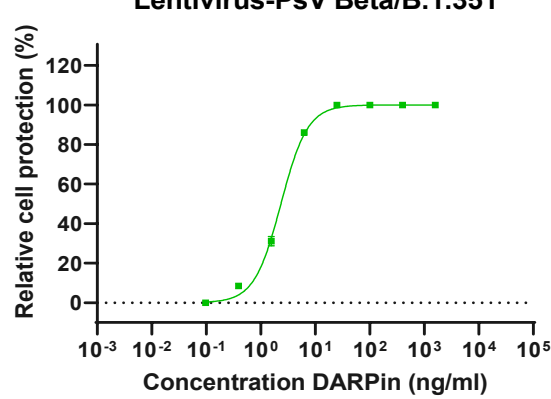

VSV-PsV Gamma/P.1

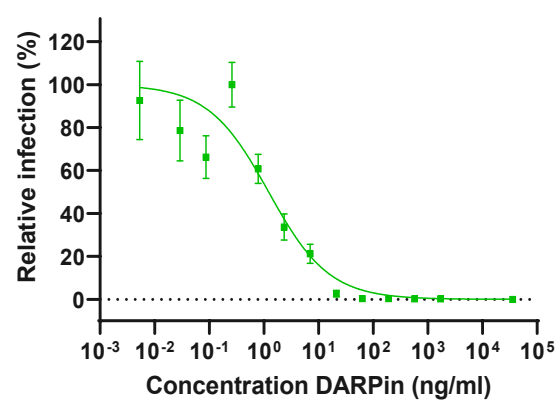

Lentivirus-PsV Alpha+S494P

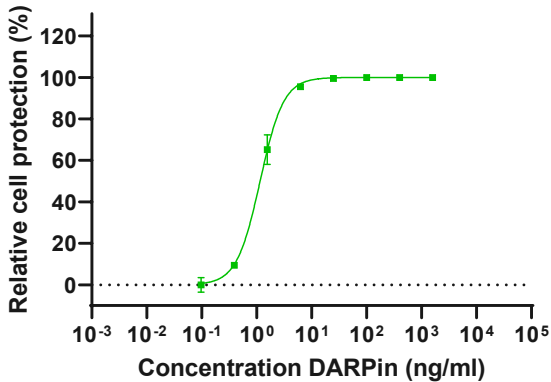

VSV-PsV Beta/B.1.351

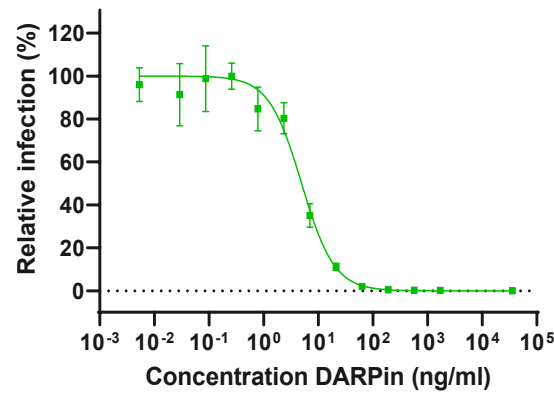

SARS-CoV-2 Beta/B.1.351

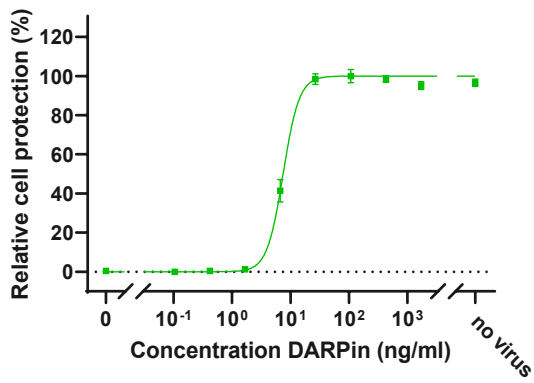

Lentivirus-PsV Gamma/P.1

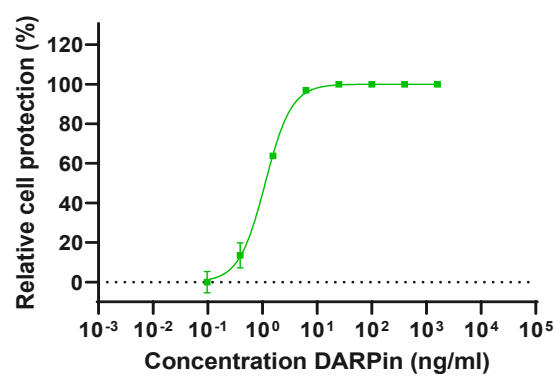


bioRxiv preprint doi: https://doi org/10.1101/2021.02 03.429164; this version posted December 17, 2021. The copyright holder for this preprint (which was not certified by peer review) is the author/funder, who has granted bioRxiv a license to display the preprint in perpetuity. It is made available under aCC-BY-NC-ND 4.0 International license.

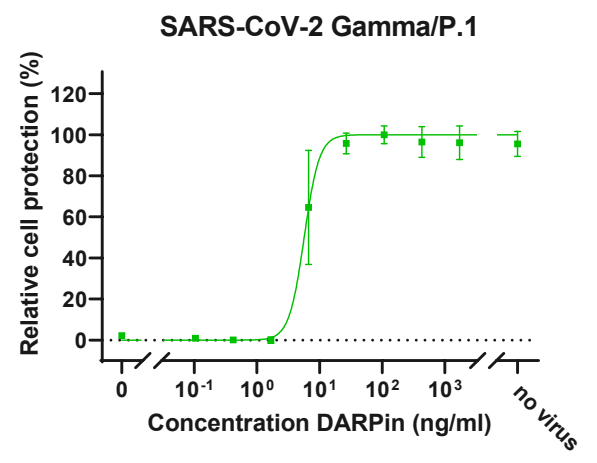

1031

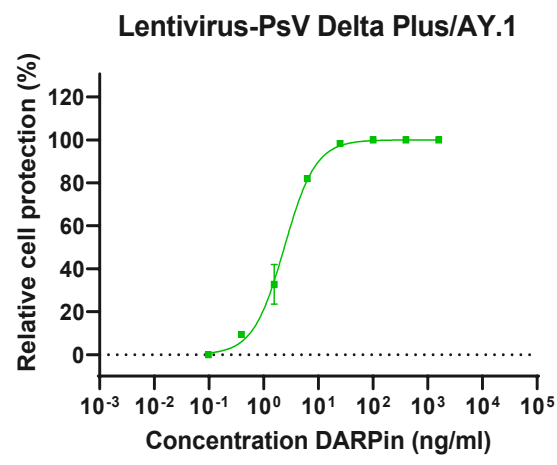

1032

VSV-PsV Eta/B.1.525

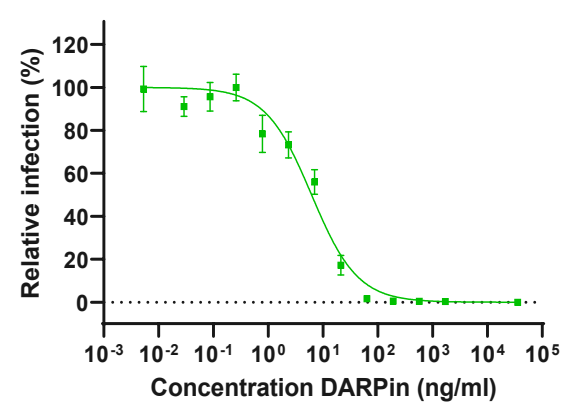

Lentivirus-PsV Delta/B.1.617.2

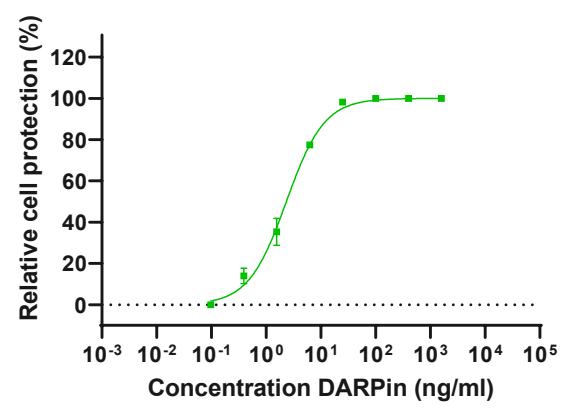

Lentivirus-PsV Epsilon/B.1.429

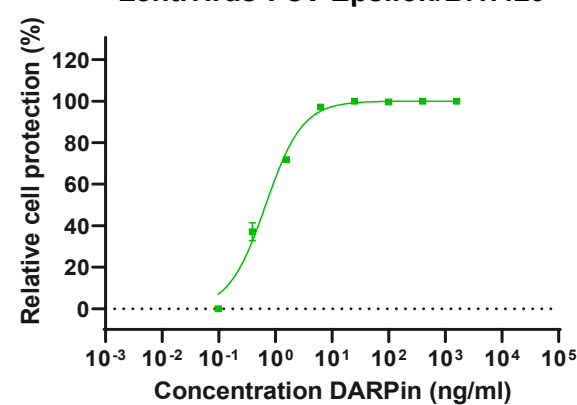

Lentivirus-PsV lota/B.1.526

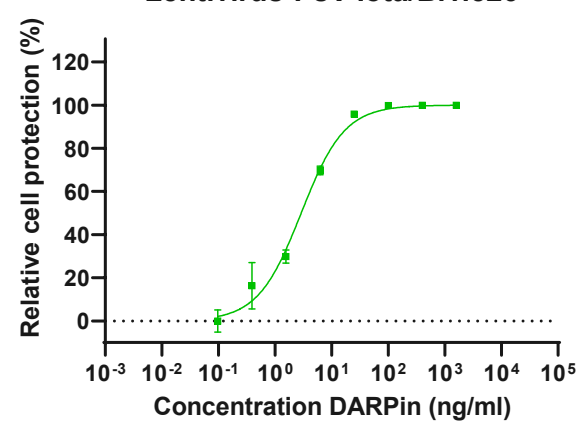


VSV-PsV Kappa/B.1.617.1

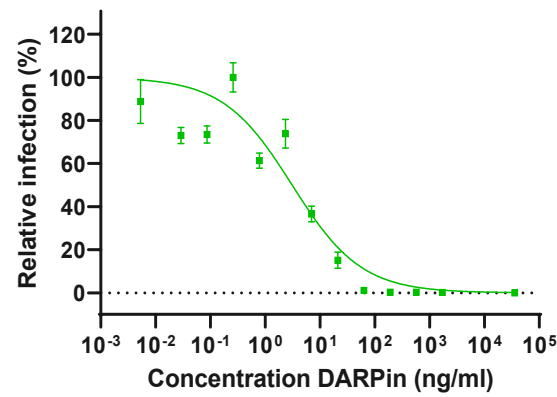

Lentivirus-PsV Lambda/C.37

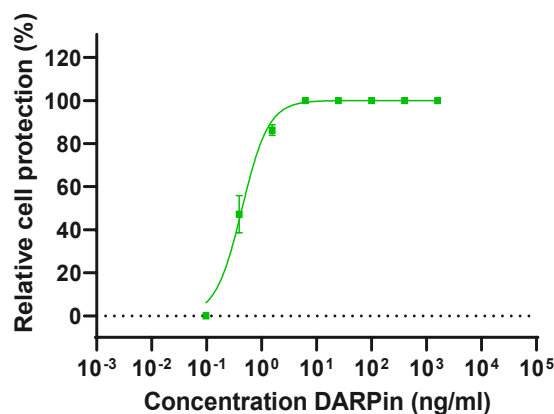

1035

VSV-PsV B.1.618

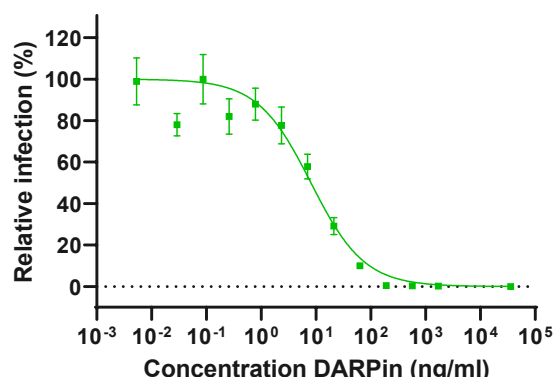

Concentration DARPin (ng/ml)

1036

Lentivirus-PsV R.1

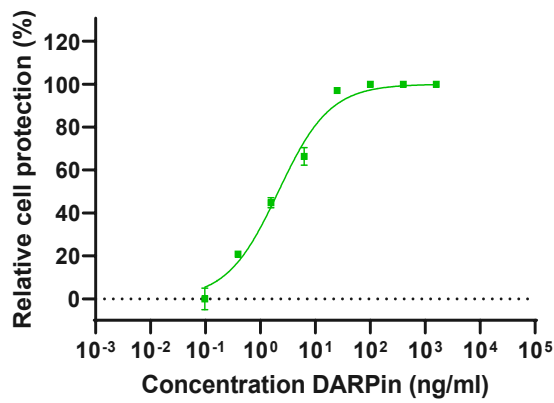

1037
Lentivirus-PsV Kappa/B.1.617.1

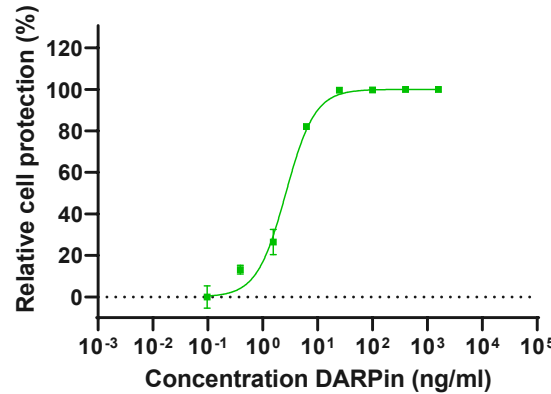

Lentivirus-PsV Mu/B.1.621

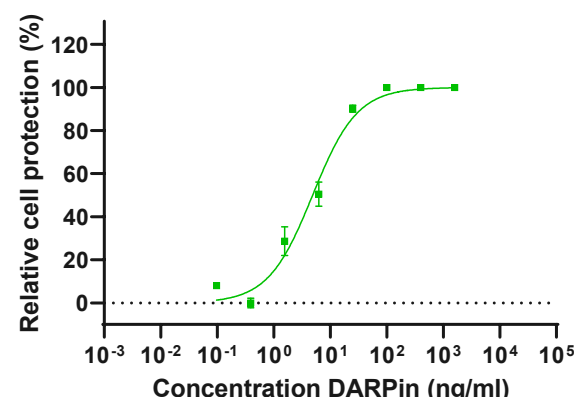

Lentivirus-PsV A.23.1

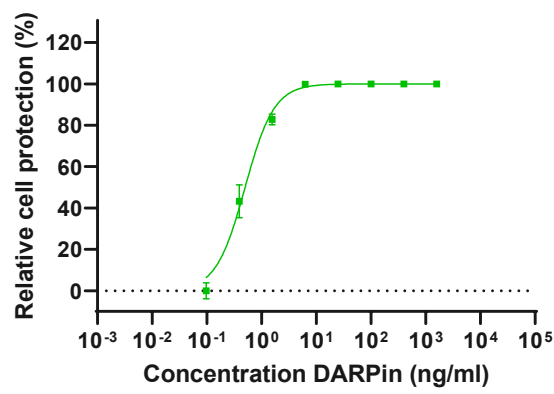

Lentivirus-PsV Omicron/B.1.1.529

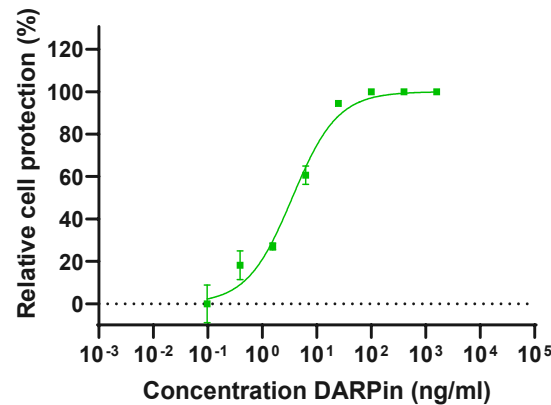


bioRxiv preprint doi: https://doi org/10.1101/2021.02.03 429164; this version posted December 17, 2021. The copyright holder for this

preprint (which was not certified by peer review) is the author/funder, who has granted bioRxiv a license to display the preprint in perpetuity. It is made available under aCC-BY-NC-ND 4.0 International license.

Lentivirus-PsV L5F_D614G

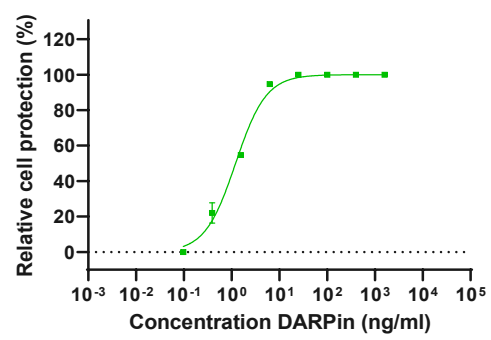

1039

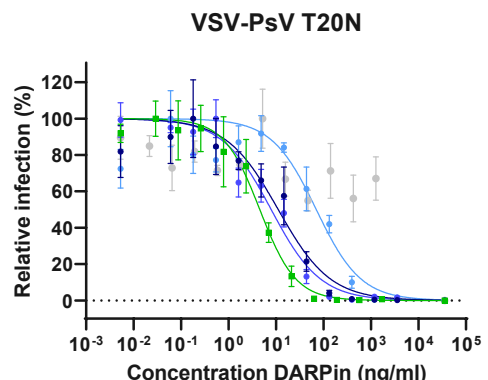

$\rightarrow$ MP0420

$\rightarrow \mathrm{R} 1$

$\rightarrow \mathrm{R} 2$

$\rightarrow \mathrm{R} 3$

Multi-DARPin

isotype control

VSV-PsV del69_70

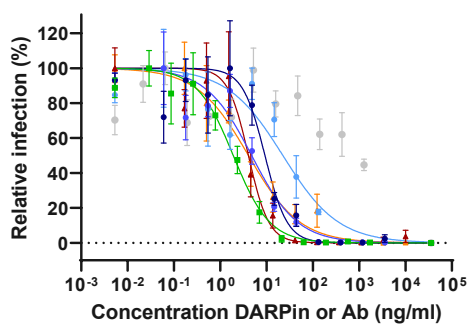

$\rightarrow-$ MP0420

$\rightarrow \mathrm{R} 1$

$\rightarrow \mathrm{R} 2$

$\rightarrow \mathrm{R} 3$

$\rightarrow$ REGN10933

- REGN10987

Multi-DARPin

isotype control

1041

Lentivirus-PsV T95I_D614G

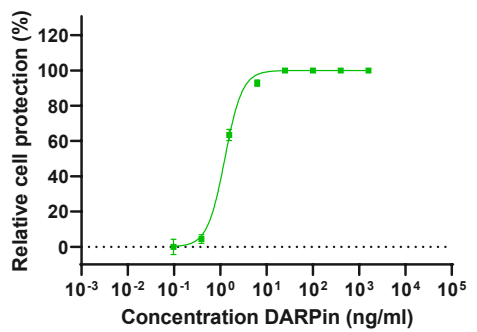

MP0420

1042

\section{VSV-PsV del145}

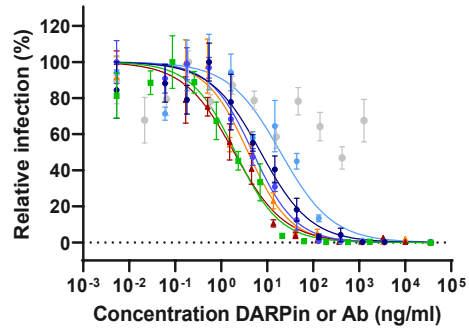

- MP0420

- R1

- $\mathrm{R} 2$

- R3

- REGN10933

REGN10987

Multi-DARPin

isotype control

VSV-PsV L18F

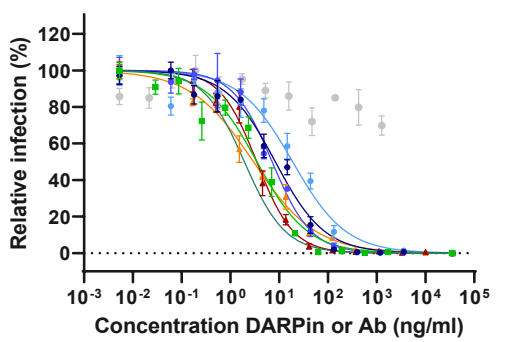

- MP0420

- $\mathrm{R} 1$

- $\mathrm{R} 2$

- R3

- REGN10933

- REGN10987

Multi-DARPin

isotype control

VSV-PsV P26S

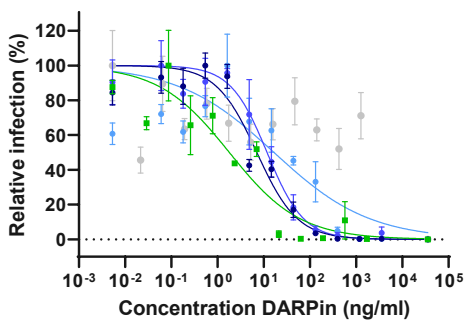

- MP0420

- R1

- $\mathrm{R} 2$

$\rightarrow \mathrm{R} 3$

Multi-DARPin isotype control
VSV-PsV D80A

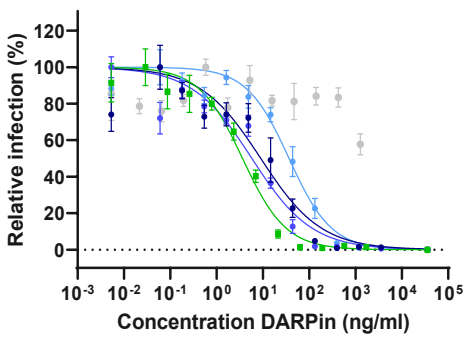

- MP0420

- $\mathrm{R} 1$

- $\mathrm{R} 2$

- R3

Multi-DARPin isotype control 
bioRxiv preprint doi: https://doi org/10.1101/2021.02.03 429164; this version posted December 17, 2021. The copyright holder for this

preprint (which was not certified by peer review) is the author/funder, who has granted bioRxiv a license to display the preprint in perpetuity. It is made available under aCC-BY-NC-ND 4.0 International license.

VSV-PsV R190S

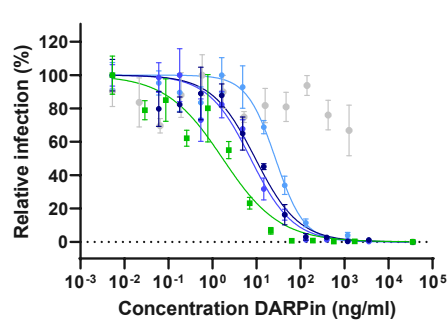

VSV-PsV A222V

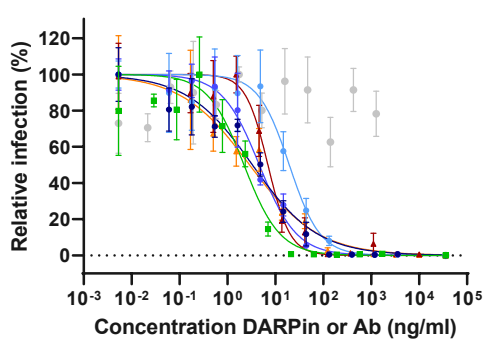

VSV-PsV del242-244

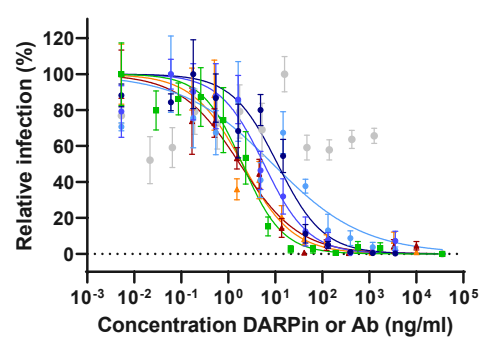

1046

Lentivirus-PsV D253G_D614G

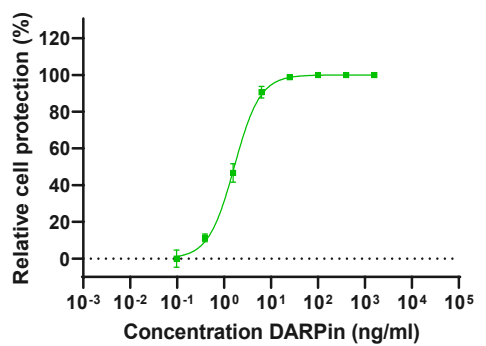

VSV-PsV D215G
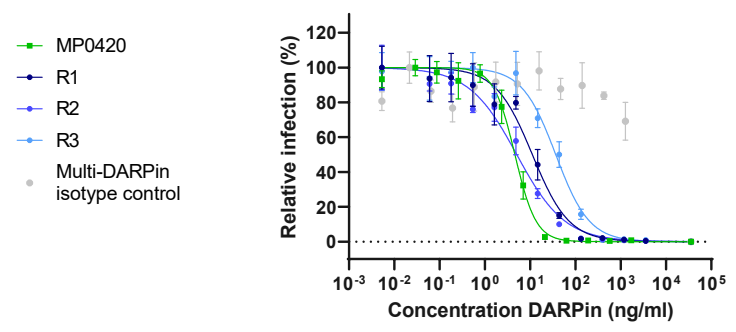

$\rightarrow$ MP0420

$\rightarrow \mathrm{R} 1$

$\rightarrow \mathrm{R} 2$

$\rightarrow \mathrm{R} 3$

Multi-DARPin

isotype control
- MP0420

- $\mathrm{R} 1$

- $\mathrm{R} 2$

- R3

- REGN10933

- REGN10987

Multi-DARPin isotype control
VSV-PsV N234Q

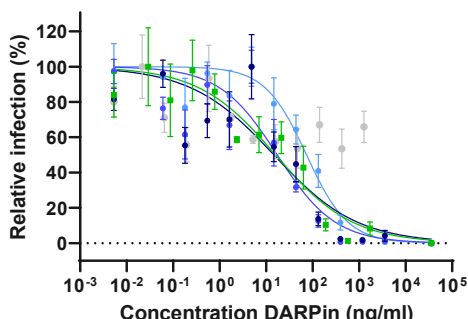

MP0420

$\rightarrow \mathrm{R} 1$

$\rightarrow \mathrm{R} 2$

$-\mathrm{R} 3$

Multi-DARPin isotype control
- MP0420

$\rightarrow \mathrm{R} 1$

$\rightarrow \mathrm{R} 2$

- R3

- REGN10933

- REGN10987 Multi-DARPin

- MP0420
VSV-PsV R246I

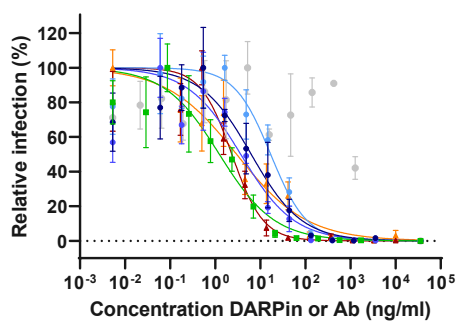

$\rightarrow$ MP0420

- $\mathrm{R} 1$

$\rightarrow \mathrm{R} 2$

$\rightarrow \mathrm{R} 3$

- REGN10933

- REGN10987

Multi-DARPin isotype control

Lentivirus-PsV G339D

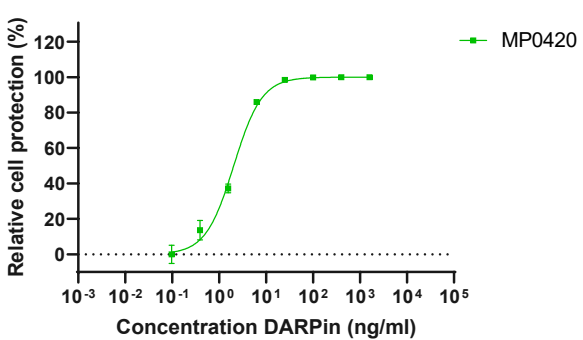


bioRxiv preprint doi: https://doi org/10.1101/2021.02.03 429164; this version posted December 17, 2021. The copyright holder for this

preprint (which was not certified by peer review) is the author/funder, who has granted bioRxiv a license to display the preprint in perpetuity. It is made available under aCC-BY-NC-ND 4.0 International license.

VSV-PsV E406W

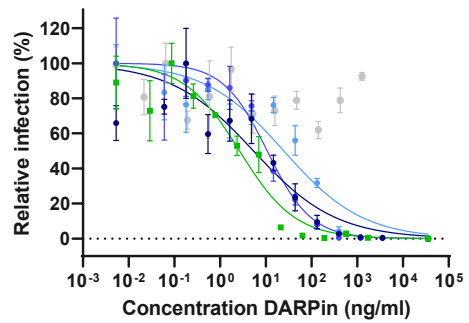

1048

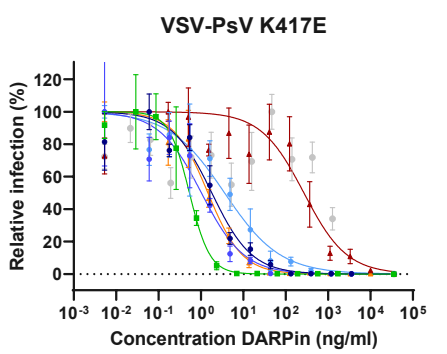

$\rightarrow$ MP0420

$\rightarrow \mathrm{R} 1$

$\rightarrow \mathrm{R} 2$

$\rightarrow \mathrm{R} 3$

- REGN10933

- REGN10987

Multi-DARPin

isotype control
VSV-PsV K417N

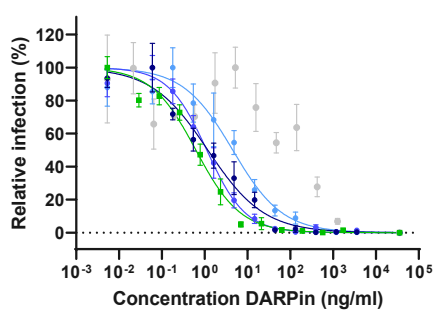

VSV-PsV K417R

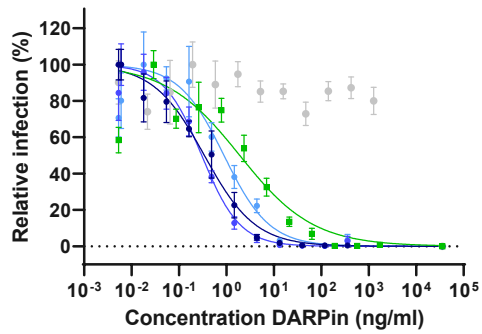

1051

VSV-PsV N439K

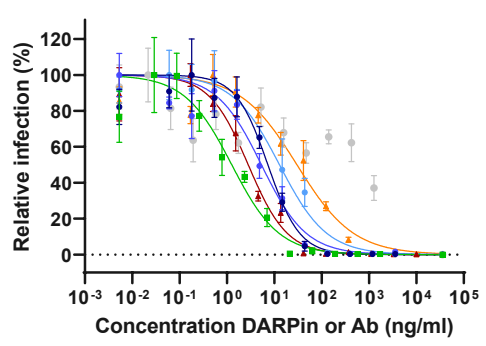

$\rightarrow$ MP0420

$\rightarrow \mathrm{R} 1$

$\rightarrow \mathrm{R} 2$

- R3

Multi-DARPin

isotype control
- $\mathrm{R} 1$

R2

Multi-DARPin sotype control
- MP0420

- $\mathrm{R} 1$

$\rightarrow \mathrm{R} 2$

- R3

- REGN10933

4 REGN10987

Multi-DARPin isotype control
MP0420

ulti-DARPin

type control

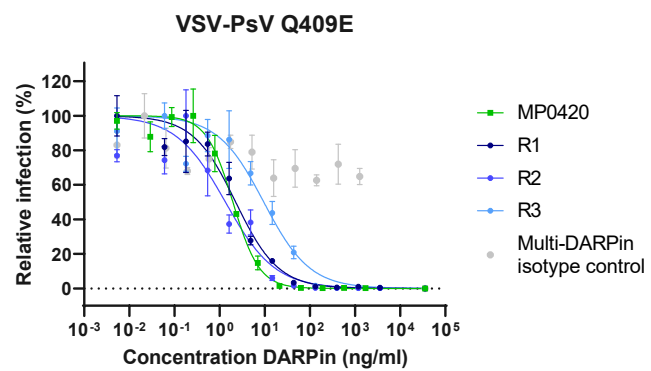

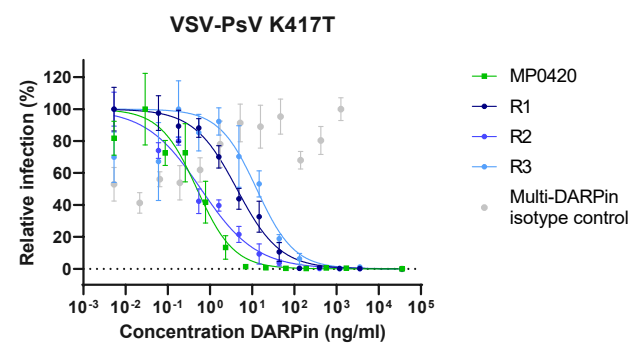

VSV-PsV D420N

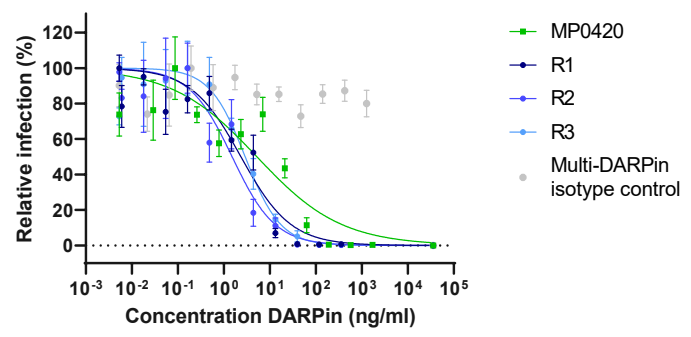

VSV-PsV K444Q

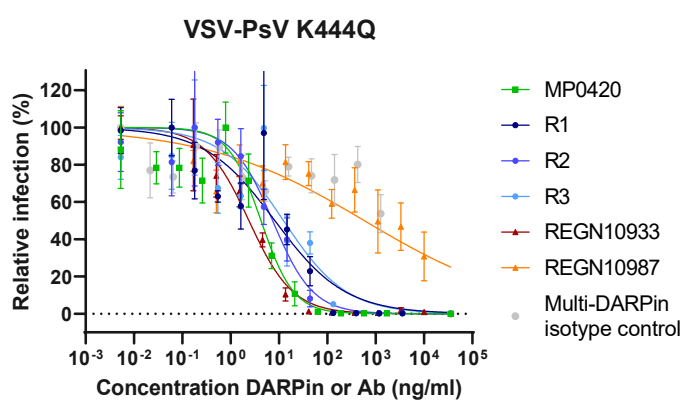


bioRxiv preprint doi: https://doi org/10.1101/2021.02.03.429164; this version posted December 17, 2021. The copyright holder for this

preprint (which was not certified by peer review) is the author/funder, who has granted bioRxiv a license to display the preprint in perpetuity. It is made available under aCC-BY-NC-ND 4.0 International license.

VSV-PsV K444N

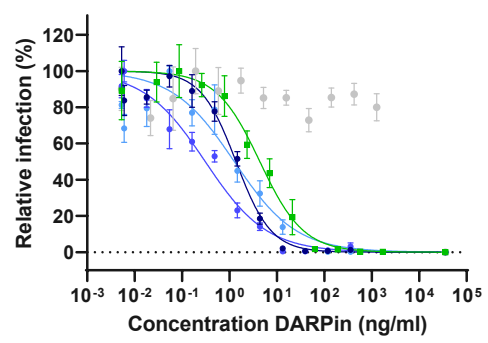

VSV-PsV V445A

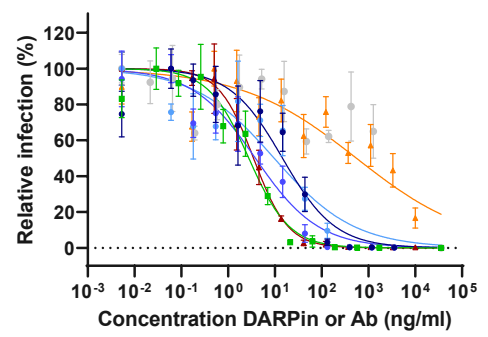

VSV-PsV G446V

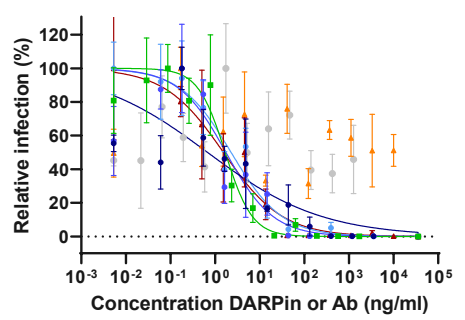

$\rightarrow \mathrm{R} 1$

$-\mathrm{R} 2$

$\rightarrow \mathrm{R} 3$

- REGN10933

1055

Lentivirus-PsV L452R_D614G

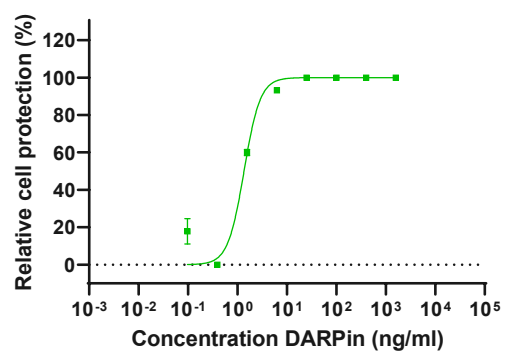

1056

Lentivirus-PsV L455F_D614G
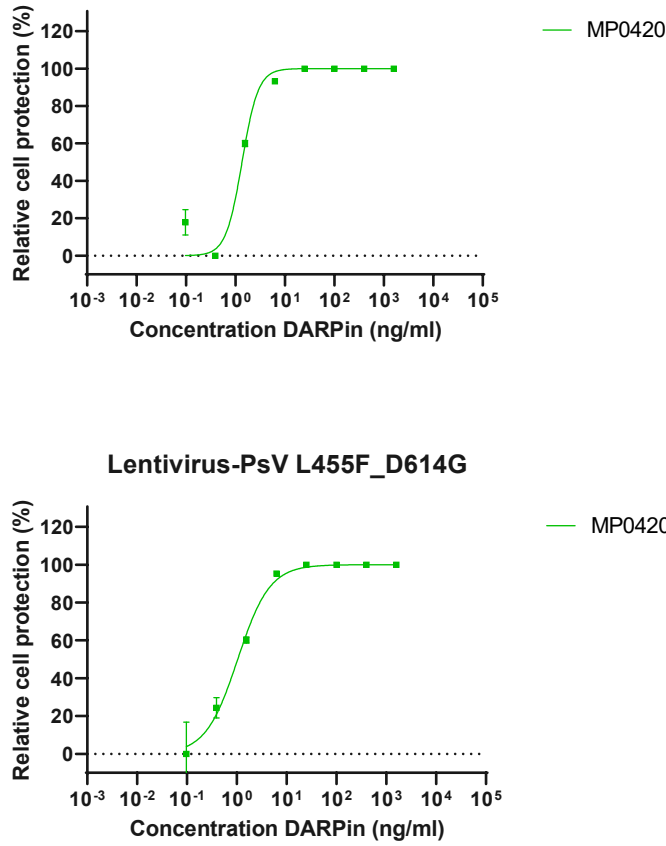

- MP0420

REGN10987

Multi-DARPin

isotype contro

$\rightarrow-\mathrm{MP} 0420$

- R1

$\mathrm{R} 3$

Multi-DARPin

isotype control

MP0420

$\mathrm{R} 2$

Multi-DARPin

sotype control

.
VSV-PsV K444T

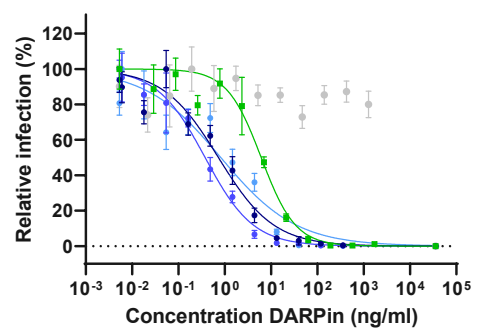

- MP0420

$\rightarrow \mathrm{R} 1$

$\rightarrow \mathrm{R} 2$

$\therefore$ R3

Multi-DARPin

isotype control

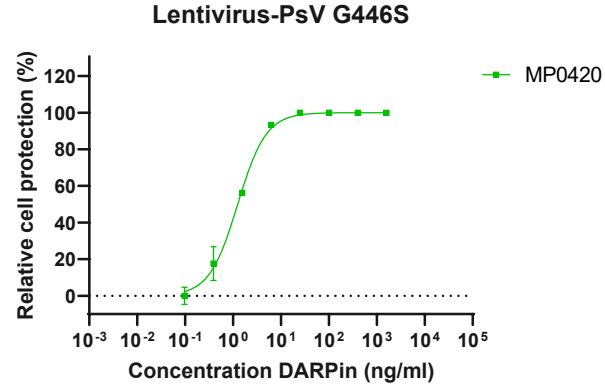

VSV-PsV Y453F

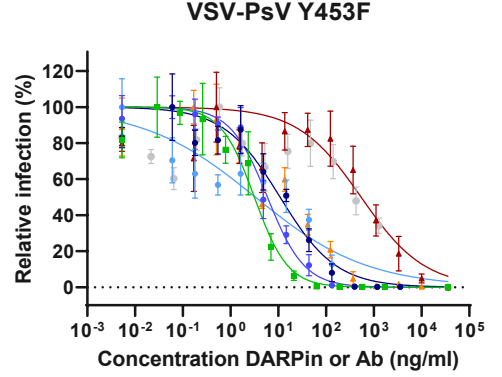

- MP0420

$\rightarrow \mathrm{R} 1$

- $\mathrm{R} 2$

$\rightarrow \mathrm{R} 3$

- REGN10933

+ REGN10987

Multi-DARPin

isotype control

- MP0420

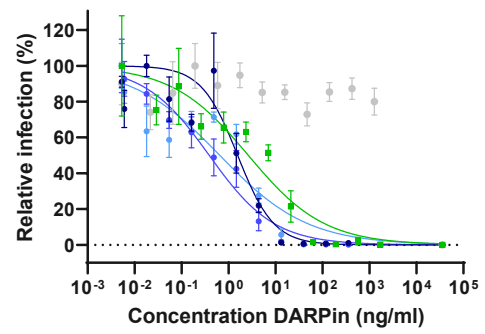

- MP0420

- R1

$\rightarrow \mathrm{R} 2$

$\rightarrow \mathrm{R} 3$

Multi-DARPin

isotype control 
bioRxiv preprint doi: https://doi org/10.1101/2021.02.03 429164; this version posted December 17, 2021. The copyright holder for this

preprint (which was not certified by peer review) is the author/funder, who has granted bioRxiv a license to display the preprint in perpetuity. It is made available under aCC-BY-NC-ND 4.0 International license.

VSV-PsV N460T

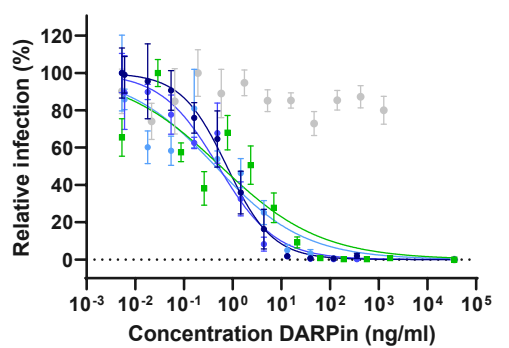

1058
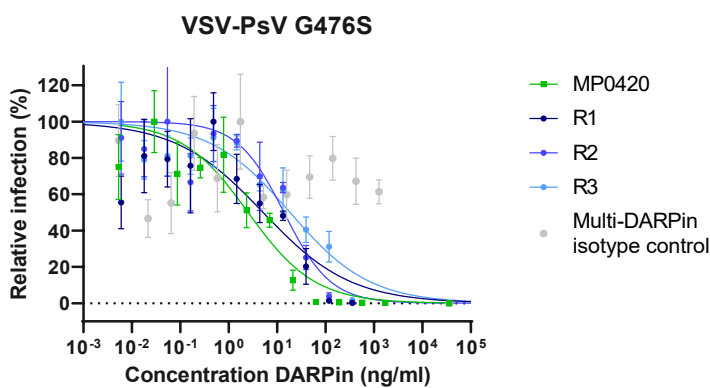

1059

VSV-PsV T478K

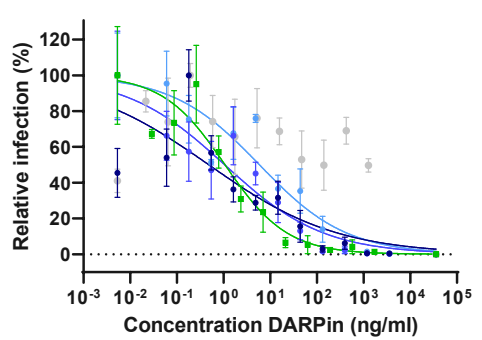

- MP0420

$\rightarrow \mathrm{R} 1$

$\rightarrow \mathrm{R} 2$

$\rightarrow \mathrm{R} 3$

Multi-DARPin

isotype control
$=$ MP0420

R2

- R3

Multi-DARPin isotype control
Lentivirus-PsV A475V_D614G

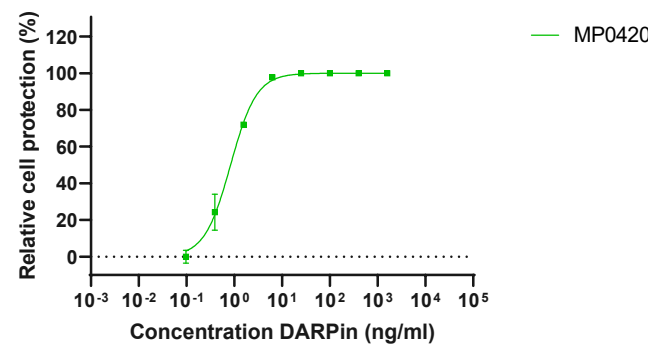

VSV-PsV S477N

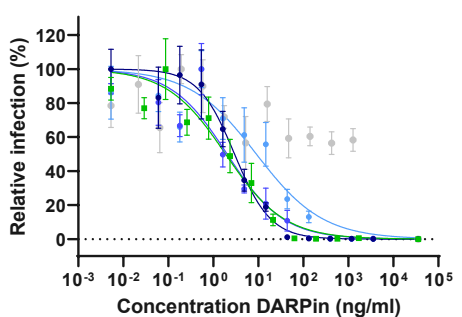

- MP0420

$\rightarrow \mathrm{R} 1$

$\rightarrow \mathrm{R} 2$

$\rightarrow \mathrm{R} 3$

Multi-DARPin isotype control
VSV-PsV P479S

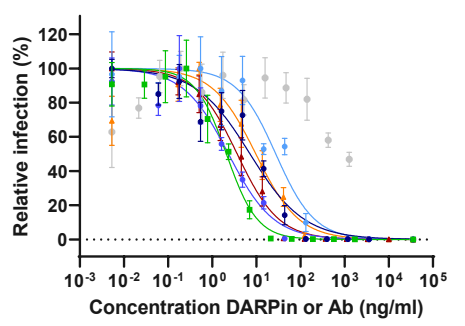

- MP0420

$\rightarrow \mathrm{R} 1$

$\rightarrow \mathrm{R} 2$

- R3

- REGN10933

- REGN10987

Multi-DARPin

isotype contro

1061

Lentivirus-PsV E484A

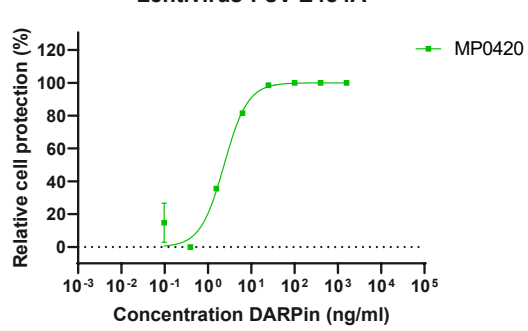


bioRxiv preprint doi: https://doi org/10.1101/2021.02.03 429164; this version posted December 17, 2021. The copyright holder for this

preprint (which was not certified by peer review) is the author/funder, who has granted bioRxiv a license to display the preprint in perpetuity. It is made available under aCC-BY-NC-ND 4.0 International license.

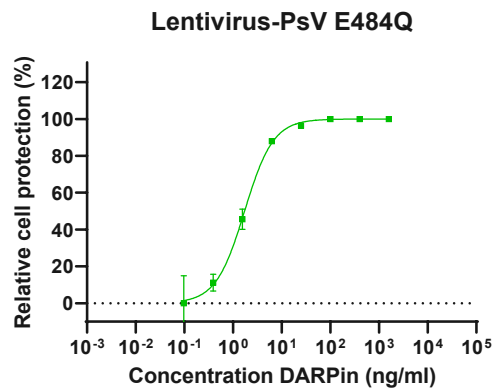

1063

VSV-PsV F490S

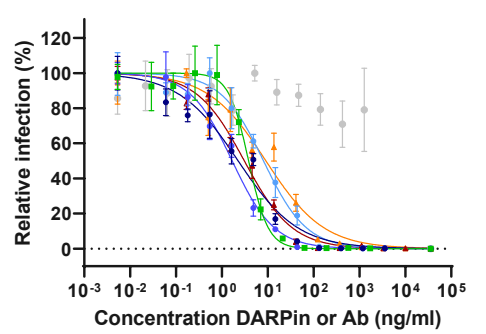

- MP0420

$\rightarrow$ R1

$\rightarrow \mathrm{R} 2$

$-\mathrm{R} 3$

+ REGN10933

- REGN10987

Multi-DARPin isotype control

VSV-PsV Q493R

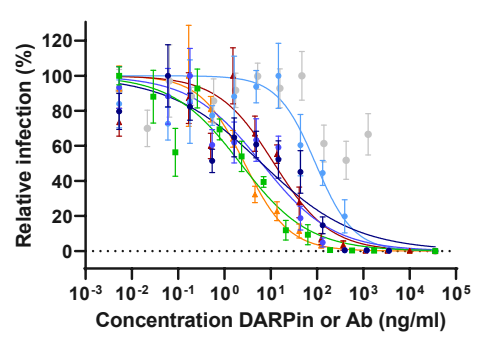

- MP0420

- R1

- R2

- R3

4 REGN10933

- REGN10987 Multi-DARPin
isotype contro - istype control

1065

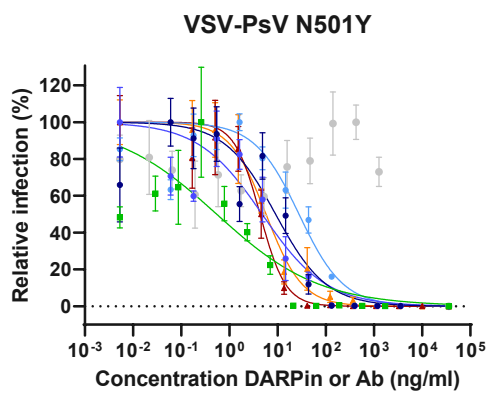

$\rightarrow$ MP0420

- $\mathrm{R} 1$

$\rightarrow \mathrm{R} 2$

$\rightarrow \mathrm{R} 3$

- REGN10933

- REGN10987

Multi-DARPin isotype control
VSV-PsV F486V

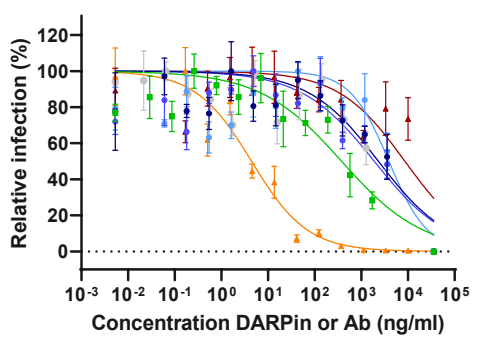

- MP0420

- $\mathrm{R} 1$

- $\mathrm{R} 2$

$\rightarrow \mathrm{R} 3$

- REGN10933

- REGN10987

Multi-DARPin

isotype control

VSV-PsV Q493K

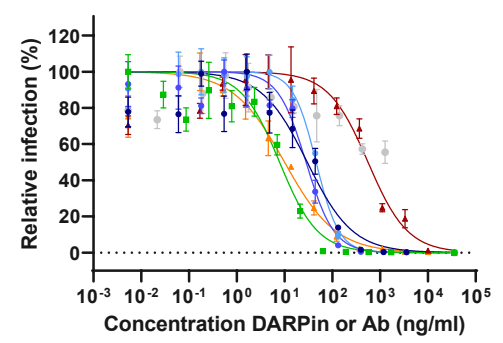

- MP0420

$\rightarrow \mathrm{R} 1$

$\rightarrow \mathrm{R} 2$

$\rightarrow \mathrm{R} 3$

- REGN10933

- REGN10987

Multi-DARPin isotype contro

VSV-PsV A570D

- MP0420

$\rightarrow \mathrm{R} 1$

$\rightarrow \mathrm{R} 2$

$\rightarrow \mathrm{R} 3$

- REGN10933

- REGN10987

Multi-DARPin isotype control
Lentivirus-PsV S494P D614G

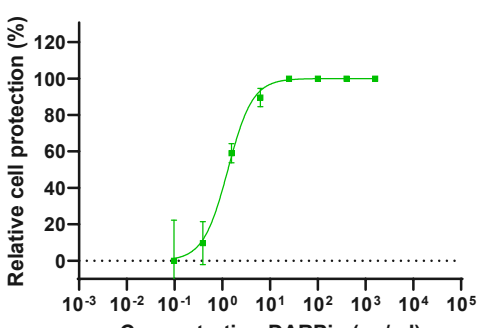

Concentration DARPin $(\mathrm{ng} / \mathrm{ml})$
VSV-PsV D614G

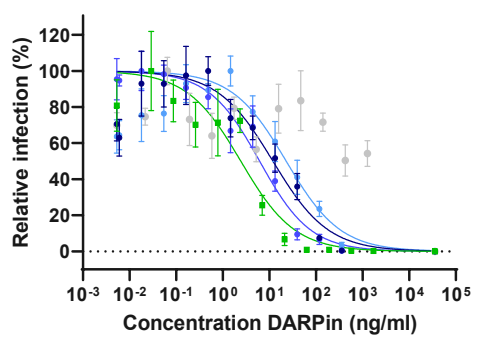

- MP0420

- $\mathrm{R} 1$

$\rightarrow \mathrm{R} 2$

- R3

Multi-DARPin isotype control 
bioRxiv preprint doi: https://doi org/10.1101/2021.02.03 429164; this version posted December 17, 2021. The copyright holder for this

preprint (which was not certified by peer review) is the author/funder, who has granted bioRxiv a license to display the preprint in perpetuity. It is made available under aCC-BY-NC-ND 4.0 International license.

VSV-PsV H655Y

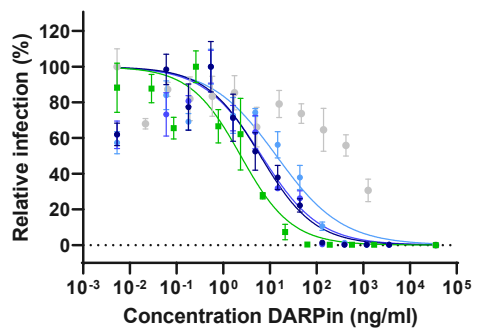

$\rightarrow$ MP0420

$\rightarrow \mathrm{R} 1$

$\rightarrow \mathrm{R} 2$

$\rightarrow$ R3

Mult-DARPin isotype control

1068

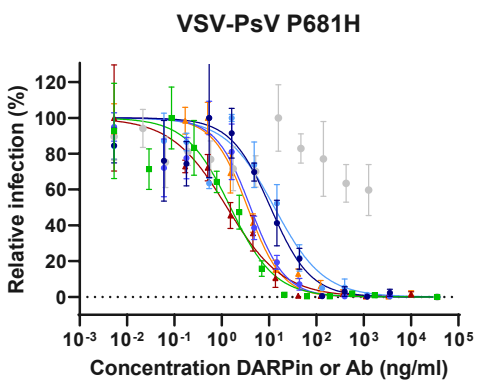

- MP0420

- R1

$-\mathrm{R} 2$

- R3

- REGN10933

- REGN10987

Multi-DARPin isotype contro

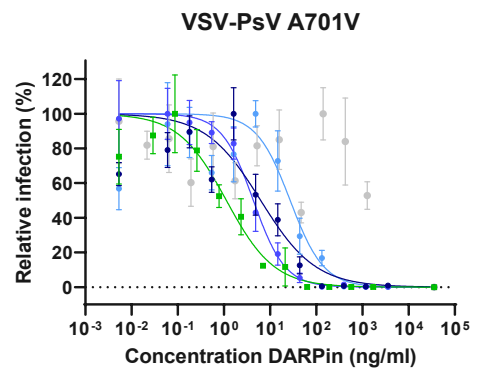

- MP0420

$\rightarrow \mathrm{R} 1$

$\rightarrow \mathrm{R} 2$

$\rightarrow \mathrm{R} 3$

Multi-DARPin isotype control

1069

VSV-PsV T716I

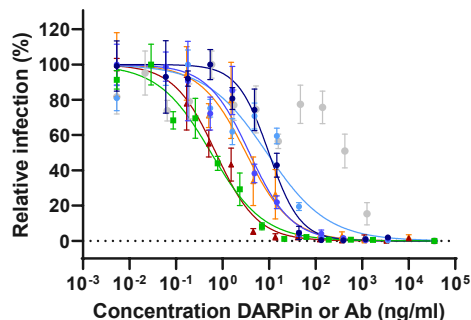

- MP0420

$\rightarrow \mathrm{R} 1$

- R2

$\rightarrow \mathrm{R} 3$

- REGN10933

- REGN10987

Multi-DARPin isotype control

\section{VSV-PsV S982A}

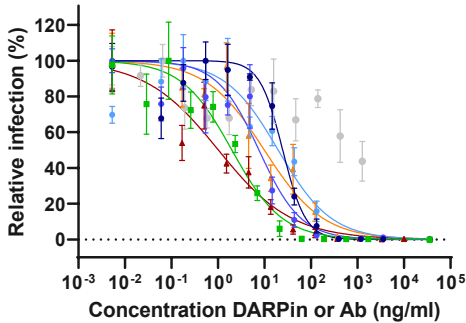

- MP0420

- $\mathrm{R} 1$

- R2

$\rightarrow \mathrm{R} 3$

- REGN10933

- REGN10987

Multi-DARPin isotype control

VSV-PsV T1027I

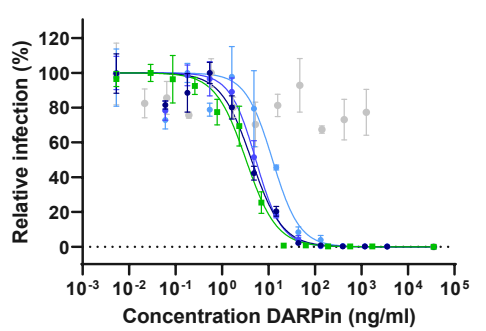

- MP0420

$\rightarrow \mathrm{R} 1$

$\rightarrow \mathrm{R} 2$

$\rightarrow \mathrm{R} 3$

Multi-DARPin isotype control

1071

VSV-PsV D1118H

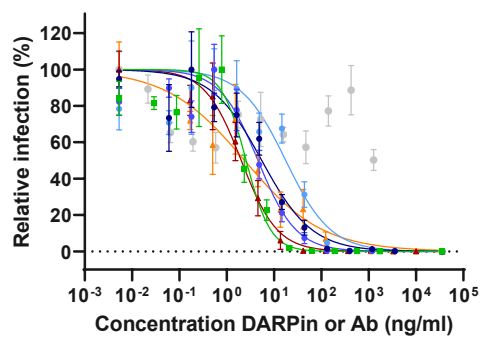

- MP0420

$\rightarrow \mathrm{R} 1$

$\rightarrow \mathrm{R} 2$

$\rightarrow$ R3

- REGN10933

- REGN10987

Multi-DARPin isotype contro 
bioRxiv preprint doi: https://doi org/10.1101/2021.02.03.429164: this version posted December 17, 2021. The copyright holder for this preprint (which was not certified by peer review) is the author/funder, who has granted bioRxiv a license to display the preprint in perpetuity. It is made available under aCC-BY-NC-ND 4.0 International license.

1073 Supplementary Figure 4: Titration curves for ensovibep (MP0420) and its RBD-binding 1074 domains (i.e. R1, R2 and R3), REGN10933 and REGN10987 to determine IC 50 neutralization 1075 potencies on multiple spike mutants or only for ensovibep (MP0420) on the variants, which 1076 are summarized in Figure 2. Reported is the mean +/- SEM (standard error of the mean). 


\section{SARS-CoV-2 Passage: \# X}

Therapeutic concentration $[\mu \mathrm{g} / \mathrm{mL}]$

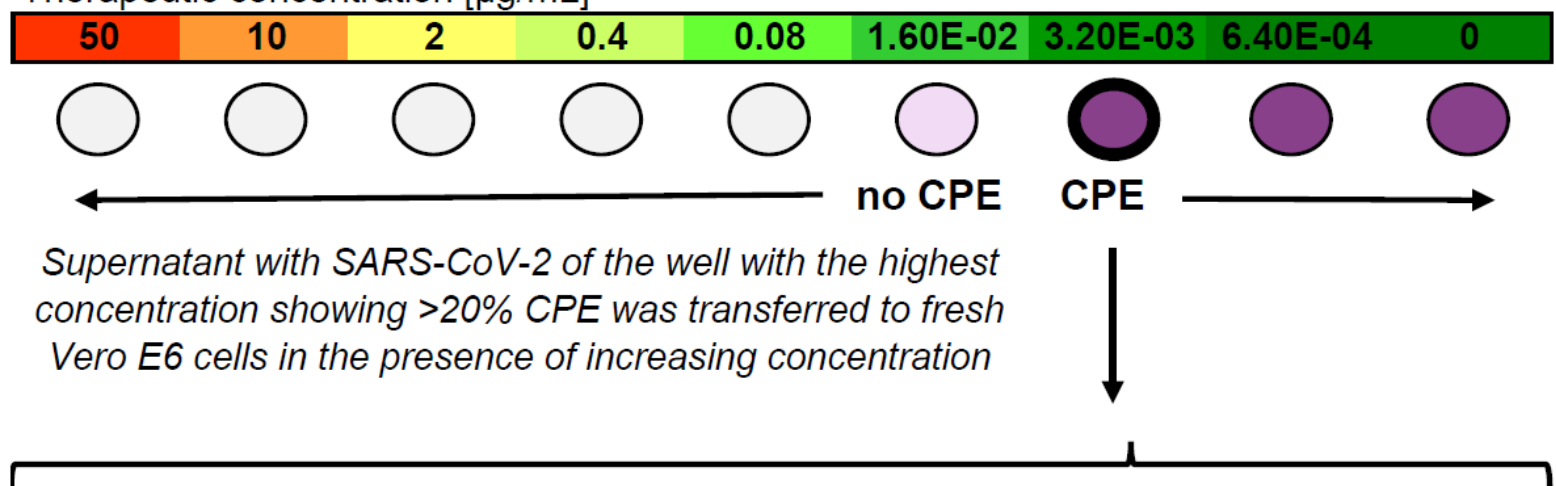

SARS-CoV-2 Passage: \# X + 1

Therapeutic concentration $[\mu \mathrm{g} / \mathrm{mL}]$

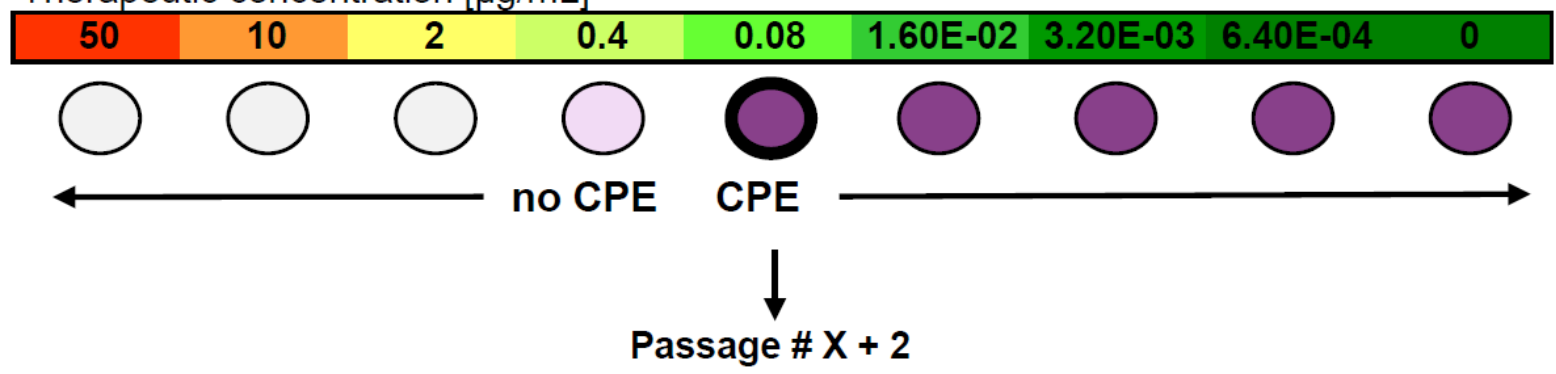

CPE: Cytopathic effect; no CPE: no or minor (<20\%) cytopathic effect (by crystal violet staining)

Supplementary Figure 5: Overview of the experimental protocol for viral passaging: A patient SARS-CoV-2 isolate from early $2020\left(1.5 \times 10^{6} \mathrm{pfu}\right)$ was incubated in presence of increasing concentrations of DARPin candidate or antibody for 4 days on Vero E6 cells and virus-induced cytopathic effects (CPE) were determined by microscopy. For each DARPin and antibody condition, cultures showing significant cytopathic effect $(\geq 20 \%)$ under the greatest selective pressure were selected and virus-containing supernatant collected to start a new culture passage on Vero E6 cells (bold circle), again under increasing concentrations of the corresponding DARPin candidate or antibody condition. Passaging of virus containing supernatant was continued in the same manner for a total of 4 passages. 


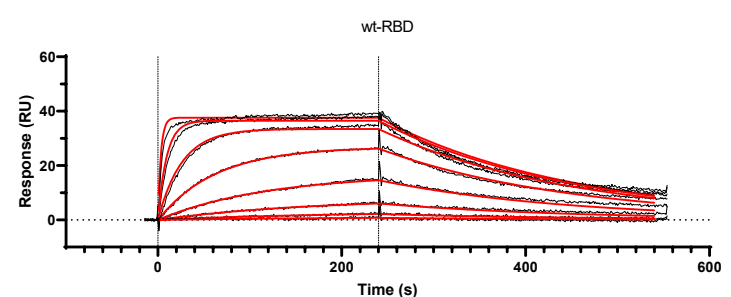

C

F486L

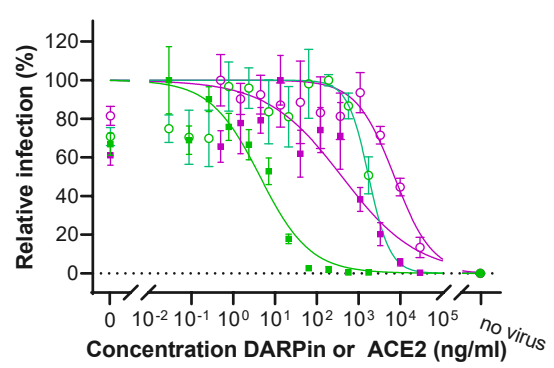

- MP0420_wt

- MP0420 F486L

- ACE2_wt

- ACE2_F486L

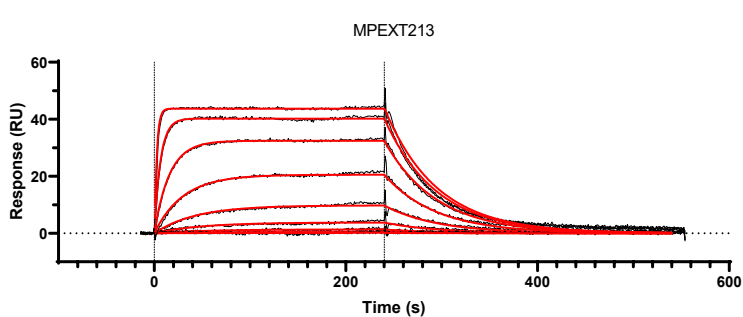

D
1091

1092

1093

1094

1095

1096

1097

1098

1099

1100

1101

1102

1103

1104

1105

1106

1107

1108

1109

\section{Supplementary Figure 6: Impact of mutation F486L in the RBD on ACE2 binding and} neutralization potency of ACE2 or ensovibep (MP0420) in a pseudotype assay

A, B) Binding kinetics for different concentrations of ACE2 was determined by SPR (surface plasmon resonance) with $A$ ) immobilized wild type $R B D$ and $B$ ) immobilized $R B D$ with the substitution F486L (MPEXT213). Consequently, a drop in affinity was observed upon tested substitution from a KD of $7.8 \mathrm{nM}$ (wild type) to a KD of $68.1 \mathrm{nM}$ (F486L).

$C, D)$ Titration of ACE2 and ensovibep (MP0420) for neutralization of a VSV pseudotype with SARS-CoV-2 wild type spike protein compared to F486L substituted in the spike protein. D) $I C_{50}$ values with $95 \%$ confidential interval for the titrations shown in C) demonstrating the loss of potency for ACE2 and ensovibep due to the F486L substitution. In accordance with the SPR measurement, a >10-fold drop in neutralization potency was observed in a VSV pseudotype assay, when ACE2 was used as a competitor. In relation, a $>100$-fold drop in potency was observed for ensovibep based on the F486L substitution.

Shown experiments further underlines the reduction in binding of ACE2 to the F486L substitution and the importance of F486 for the SARS-CoV-2 virus to maintain the interaction with the human ACE2 receptor. So far, based on the global SARS-CoV-2 database sequences published in GISAID, mutations in position F486 (the core RBD-interaction residue for ensovibep) occur at very low frequencies. 


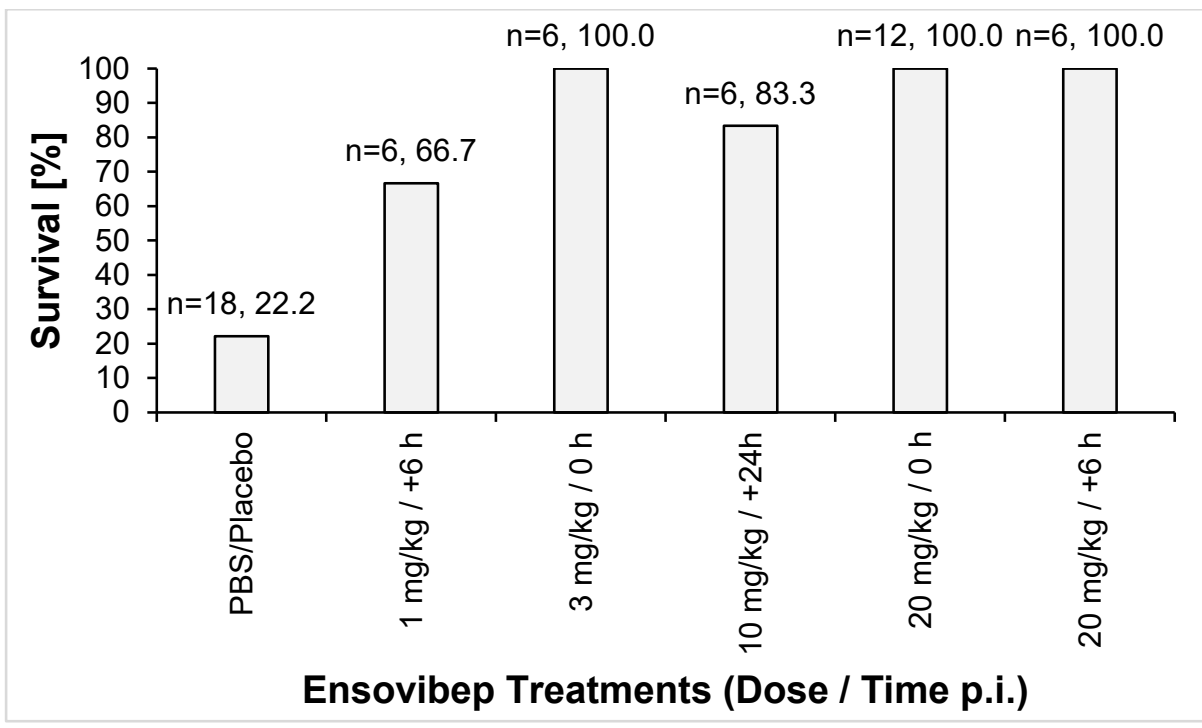

Day 3 - Viral RNA genome copies

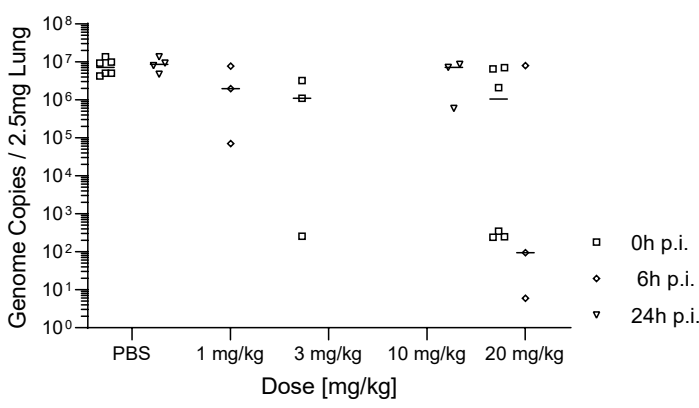

Day 3 - Titration of infectious virus

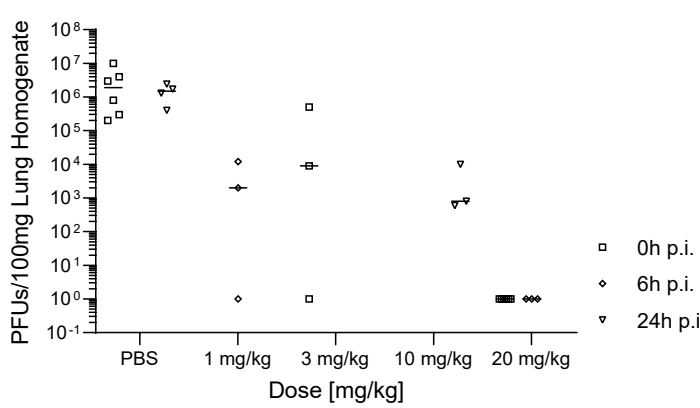

Day 5 - Viral RNA genome copies

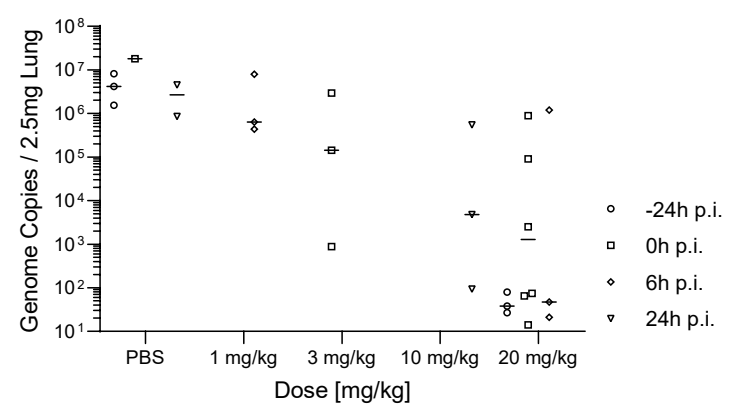

Day 5 - Titration of infectious virus

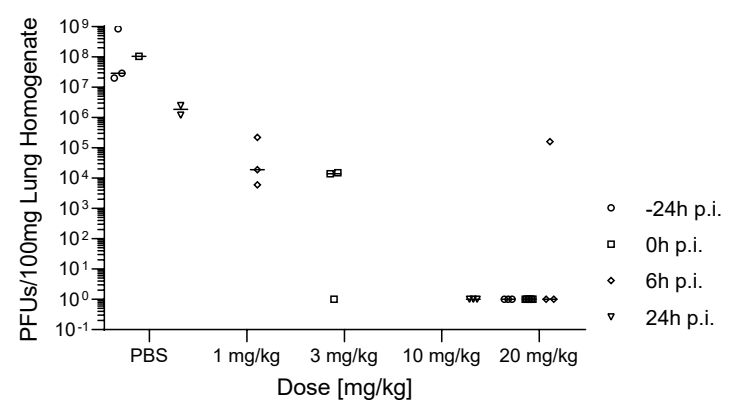

Supplementary Figure 7: Summarized previous in vivo studies with Roborovski dwarf

1117 hamster infected with WT SARS-CoV-2 and treated with ensovibep at various doses and

1118 administration time points. A) Animal survival, end-point analysis, animals that had to be euthanized according to score sheet criteria were considered non-survived, animals that reached their respective defined take-out at day 3 or 5 post infection were considered 
bioRxiv preprint doi: https://doi org/10.1101/2021.02.03.429164; this version posted December 17, 2021. The copyright holder for this preprint (which was not certified by peer review) is the author/funder, who has granted bioRxiv a license to display the preprint in perpetuity. It is made available under aCC-BY-NC-ND 4.0 International license.

1121 survived. B) qPCR analysis of virus gRNA copy numbers in oropharyngeal swabs and lung

1122 homogenates at day 3 or day 5 post infection C) Titration of replication competent virus from

1123 lung homogenates as plaque assay on Vero E6 cells at day 3 or day 5 post infection. 

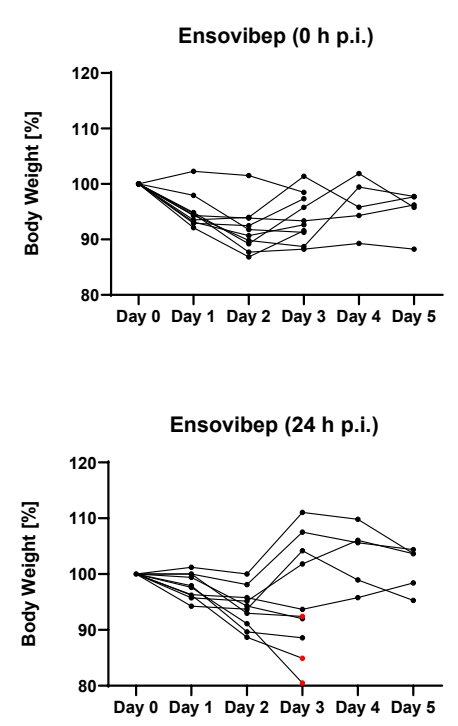

1125

1126

$\mathbf{B}$
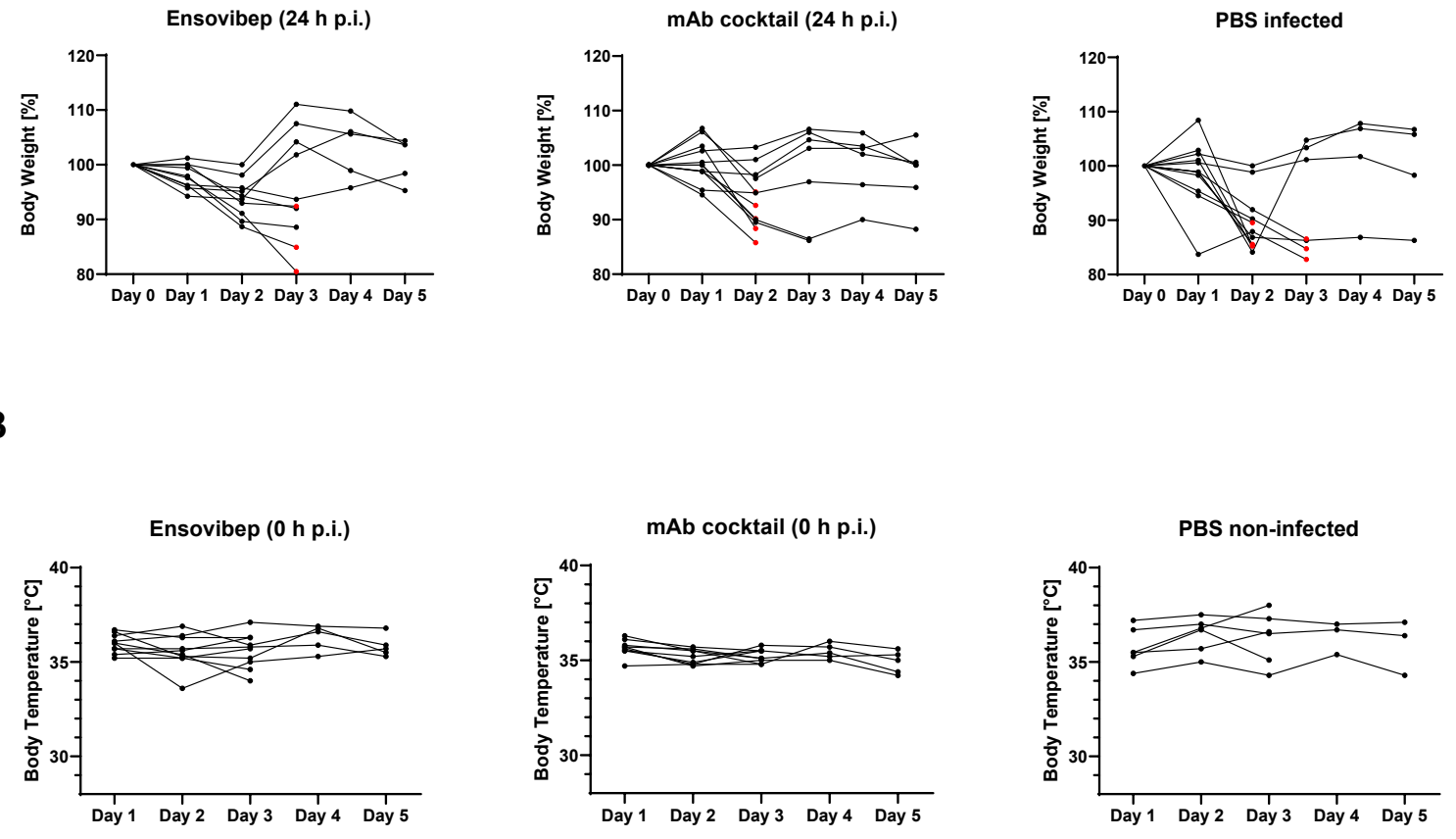
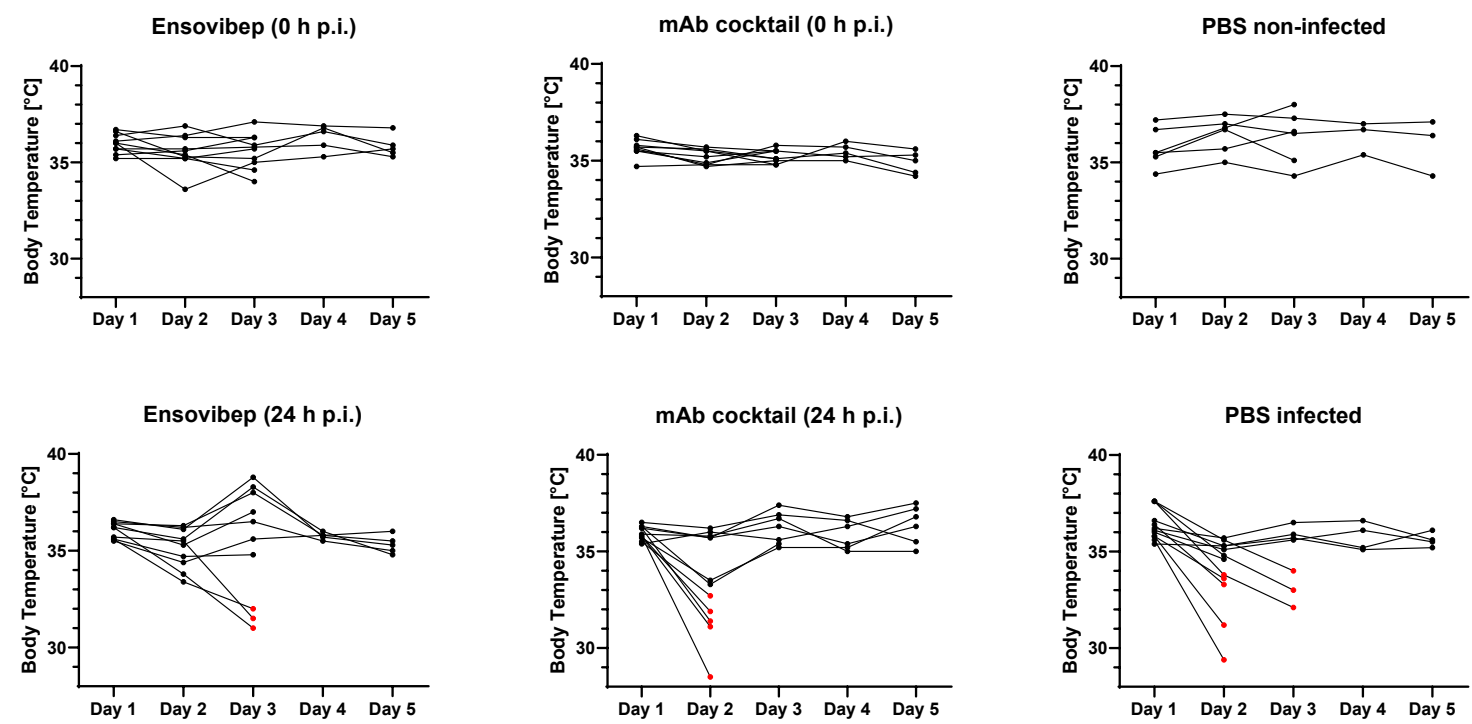

1127

1128

Supplementary Figure 8: Clinical Parameters of individuals over the course of

1129 infection, (mean +/- SD presented in Figure 5C) A) Body weight changes of individual hamsters B) Body temperatures of individual hamsters. Animals that had to be euthanized based on score sheet criteria are marked in red. 


\section{Pharmacokinetics in Roborovski dwarf hamster}

following i.p. administration of $10 \mathrm{mg} / \mathrm{kg}$

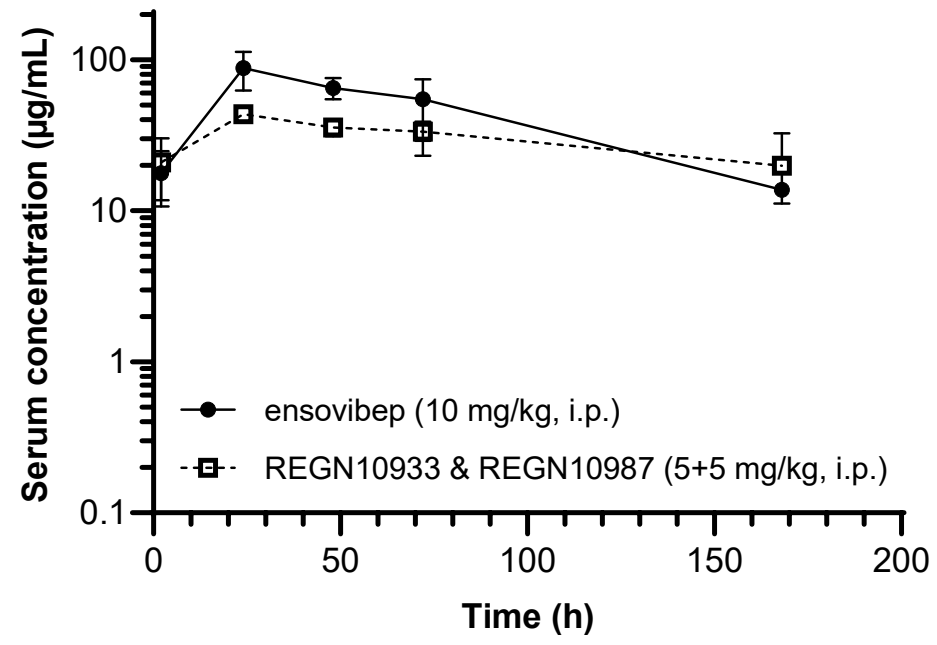

1133 Supplementary Figure 9: Pharmacokinetics profiles of non-infected Roborovski dwarf

1134 hamsters injected i.p. with either $10 \mathrm{mg} / \mathrm{kg}$ of ensovibep or the cocktail of REGN10933 and

1135 REGN10987 at $5 \mathrm{mg} / \mathrm{kg}$ for each of the monoclonal antibodies. Three animals were

1136 sacrificed for determination of the therapeutic concentration in the serum of the terminal

1137 bleeds. Obvious outliers due to likely a failure of the intraperitoneal injection were removed

1138 from the evaluation. Pharmacokinetic parameters for ensovibep: $T_{1 / 2}: 52.0 \mathrm{~h} ; C_{\max }: 87.8$

$1139 \mu \mathrm{g} / \mathrm{mL} ; T_{\max }: 24 \mathrm{~h}$. Pharmacokinetic parameters for the cocktail of REGN10933 and

1140 REGN10987: $T_{1 / 2}: 139$ h; $C_{\max }: 43.5 \mu \mathrm{g} / \mathrm{mL}$; $T_{\max }: 24 \mathrm{~h}$. 
Supplementary Table 1: Cryo-EM data collection and image processing information.

\begin{tabular}{|c|c|c|c|}
\hline Incubation time (seconds) & 60 & 60 & 15 \\
\hline Magnification & 75,000 & 75,000 & 92,000 \\
\hline Voltage $^{94}$ & 300 & 300 & 200 \\
\hline Electron exposure (e-/ $\left.\AA^{2}\right)$ & 40 & 40 & 40 \\
\hline Defocus range $(\mu \mathrm{m})$ & $1.25-2.5$ & $1.25-2.5$ & $1.25-2.5$ \\
\hline Pixel size $(\AA)$ & 1.045 & 1.045 & 1.1 \\
\hline Symmetry imposed & C3 & $\mathrm{C} 1$ & N/A \\
\hline Initial particle images (no.) & 123,833 & 123,833 & 46,140 \\
\hline Final particle images (no.) & 46,762 & 21,612 & 6,888 \\
\hline Map resolution $(\AA)$ & 4.2 & 9.6 & $\mathrm{~N} / \mathrm{A}$ \\
\hline FSC threshold & 0.143 & 0.143 & $\mathrm{~N} / \mathrm{A}$ \\
\hline Map resolution range $(\AA)$ & $3.6-14.1$ & $8.2-26$ & $N / A$ \\
\hline
\end{tabular}


bioRxiv preprint doi: https://doi.org/10.1101/2021.02 03.429164; this version posted December $17,2021$. The copyright holder for this preprint (which was not certified by peer review) is the author/funder, who has granted bioRxiv a license to display the preprint in perpetuity. It is made available under aCC-BY-NC-ND 4.0 International license.

Supplementary Table 2: In vitro protection against emerging SARS-CoV-2 variants for ensovibep

\begin{tabular}{|c|c|c|c|}
\hline Variant & Substitutions / Deletions & Assay Type & $\begin{array}{l}\text { Neutralizing } \mathrm{IC}_{50} \\
{[\mathrm{ng} / \mathrm{mL}]}\end{array}$ \\
\hline \multirow{3}{*}{ References } & Wuhan wild type & VSV pseudotype & 1 \\
\hline & D614G background & $\begin{array}{l}\text { Lentivirus } \\
\text { pseudotype }\end{array}$ & 1.1 \\
\hline & French isolate: V367F; E990A & Authentic virus & 1.3 \\
\hline \multirow{5}{*}{ Alpha / B.1.1.7 } & $\begin{array}{l}\text { 69-70 del, del145, N501Y, A570D, D614G, P681H, T716I, } \\
\text { S982A, D1118H }\end{array}$ & VSV & 1.7 \\
\hline & $\begin{array}{l}\text { 69-70 del, del145, E484K, N501Y, A570D, D614G, P681H, } \\
\text { T716I, S982A, D1118H }\end{array}$ & VSV & 3.2 \\
\hline & $\begin{array}{l}\text { 69-70 del, del145, N501Y, A570D, D614G, P681H, T716I, } \\
\text { S982A, D1118H }\end{array}$ & $\begin{array}{l}\text { Lentivirus } \\
\text { pseudotype }\end{array}$ & 0.9 \\
\hline & $\begin{array}{l}\text { 69-70 del, del145, S494P, N501Y, A570D, D614G, P681H, } \\
\text { T716I, S982A, D1118H }\end{array}$ & $\begin{array}{l}\text { Lentivirus } \\
\text { pseudotype }\end{array}$ & 0.8 \\
\hline & $\begin{array}{l}\text { H69_V70del, Y145del, N501Y, A570D, D614G, P681H, T716I, S982A, } \\
\text { D1118H }\end{array}$ & Authentic & 1.3 \\
\hline \multirow{4}{*}{ Beta / B.1.351 } & D80A, D215G, E484K, N501Y, A701V & VSV & 5.5 \\
\hline & $\begin{array}{l}\text { L18F, D80A, D215G, Del242-244, R246I, K417N, E484K, } \\
\text { N501Y, D614G, A701V }\end{array}$ & VSV & 5 \\
\hline & $\begin{array}{l}\text { L18F, D80A, D215G, Del242-244, K417N, E484K, N501Y, } \\
\text { D614G, A701V }\end{array}$ & $\begin{array}{l}\text { Lentivirus } \\
\text { pseudotype }\end{array}$ & 1.2 \\
\hline & $\begin{array}{l}\text { L18F, D80A, D215G, L242_L244del, T302T, K417N, E484K, } \\
\text { N501Y, D571D,D614G, A701V }\end{array}$ & Authentic & 7.5 \\
\hline \multirow{3}{*}{ Gamma / P.1 } & $\begin{array}{l}\text { L18F, T20N, P26S, D138Y, R190S, K417T, E484K, N501Y, } \\
\text { D614G, H655Y, T1027I }\end{array}$ & VSV & 1.2 \\
\hline & $\begin{array}{l}\text { L18F, T20N, P26S, D138Y, R190S, K417T, E484K, N501Y, } \\
\text { D614G, H655Y, T1027I, V1176F }\end{array}$ & $\begin{array}{l}\text { Lentivirus } \\
\text { pseudotype }\end{array}$ & 0.7 \\
\hline & $\begin{array}{l}\text { L18F, T20N, P26S, D138Y, R190S, K417T, E484K, N501Y, } \\
\text { D614G, H655Y, T1027I, V1176F }\end{array}$ & Authentic & 5.7 \\
\hline \multirow{2}{*}{$\begin{array}{l}\text { Delta/DeltaPlus } \\
\text { / B.1.617.2 }\end{array}$} & $\begin{array}{l}\text { T19R, G142D, E156Gl, F157del, R158del, L452R, T478K, } \\
\text { D614G, P681R, D950N }\end{array}$ & $\begin{array}{l}\text { Lentivirus } \\
\text { pseudotype }\end{array}$ & 2.4 \\
\hline & $\begin{array}{l}\text { T19R, T95I, G142D, E156G, F157del, R158del, W258L, } \\
\text { K417N, L452R, T478K, D614G, P681R, D950N }\end{array}$ & $\begin{array}{l}\text { Lentivirus } \\
\text { pseudotype }\end{array}$ & 2.6 \\
\hline \multirow{2}{*}{ Epsilon/B.1.429 } & S13I, W152C, L452R, D614G & $\begin{array}{l}\text { Lentivirus } \\
\text { pseudotype }\end{array}$ & 0.9 \\
\hline & S13I, P26S, W152C, L452R, D614G & $\begin{array}{l}\text { Lentivirus } \\
\text { pseudotype }\end{array}$ & 0.5 \\
\hline lota/B.1.526 & L5F, T95I, D253G, E484K, D614G, A701V & $\begin{array}{l}\text { Lentivirus } \\
\text { pseudotype }\end{array}$ & 3.0 \\
\hline \multirow{2}{*}{$\begin{array}{l}\text { Kappa I } \\
\text { B.1.617.1 }\end{array}$} & $\begin{array}{l}\text { T95I, G142D, E154K, L452R, E484Q, D614G, P681R, } \\
\text { Q1071H }\end{array}$ & $\begin{array}{l}\text { Lentivirus } \\
\text { pseudotype }\end{array}$ & 2.0 \\
\hline & $\begin{array}{l}\text { G142D, E154K, V382L, L452R, E484Q, D614G, P681R, } \\
\text { Q1071H, D1153Y }\end{array}$ & $\begin{array}{l}\text { Lentivirus } \\
\text { pseudotype }\end{array}$ & 1.9 \\
\hline Lambda / C37 & $\begin{array}{l}\text { G75V, T76I, R246del, S247-G252del, D253N, L452Q, F490S, } \\
\text { D614G, T859N }\end{array}$ & $\begin{array}{l}\text { Lentivirus } \\
\text { pseudotype }\end{array}$ & 0.4 \\
\hline
\end{tabular}


bioRxiv preprint doi: https://doi org/10.1101/2021.02.03.429164; this version posted December 17, 2021. The copyright holder for this preprint (which was not certified by peer review) is the author/funder, who has granted bioRxiv a license to display the preprint in perpetuity. It is made available under aCC-BY-NC-ND 4.0 International license.

\begin{tabular}{|c|c|c|c|}
\hline Mu / B.1.621 & $\begin{array}{l}\text { T95I, Y144S, Y145N, R346K, E484K, N501Y, D614G, P681H, } \\
\text { D950N }\end{array}$ & $\begin{array}{l}\text { Lentivirus } \\
\text { pseudotype }\end{array}$ & 6.1 \\
\hline \multirow{3}{*}{$\begin{array}{l}\text { Omicron I } \\
\text { B.1.1.529 }\end{array}$} & $\begin{array}{l}\text { A67V, } \Delta 69-70, \text { T95I, G142D, } \Delta 143-145, \Delta 211, \text { L212I, } \\
\text { ins214EPE, G339D, S371L, S373P, S375F, K417N, N440K, } \\
\text { G446S, S477N, T478K, E484A, Q493R, G496S, Q498R, } \\
\text { N501Y, Y505H, T547K, D614G, H655Y, N679K, P681H, } \\
\text { N764K, D796Y, N856K, N969K, L981F }\end{array}$ & VSV pseudotype & 2.2 \\
\hline & $\begin{array}{l}\text { A67V, } \Delta 69-70, \text { T95I, G142D, } \Delta 143-145, \Delta 211, \text { L212I, } \\
\text { ins214EPE, G339D, S371L, S373P, S375F, K417N, N440K, } \\
\text { G446S, S477N, T478K, E484A, Q493K, G496S, Q498R, } \\
\text { N501Y, Y505H, T547K, D614G, H655Y, N679K, P681H, } \\
\text { N764K, D796Y, N856K, Q954H, N969K, L981F }\end{array}$ & VSV pseudotype & 2.1 \\
\hline & $\begin{array}{l}\text { A67V, } \Delta 69-70, \text { T95I, G142D, } \Delta 143-145, \Delta 211, \mathrm{~L} 212 \mathrm{I}, \\
\text { ins214EPE, G339D, S371L, S373P, S375F, K417N, N440K, } \\
\text { G446S, S477N, T478K, E484A, Q493R, G496S, Q498R, } \\
\text { N501Y, Y505H, T547K, D614G, H655Y, N679K, P681H, } \\
\text { N764K, D796Y, N856K, Q954H, N969K, L981F }\end{array}$ & $\begin{array}{l}\text { Lentivirus } \\
\text { pseudotype }\end{array}$ & 3.6 \\
\hline R.1 & W152L, E484K, D624G, G769V & $\begin{array}{l}\text { Lentivirus } \\
\text { pseudotype }\end{array}$ & 2.4 \\
\hline A.23.1 & F157L, V367F, Q613H, D614G, P681R & $\begin{array}{l}\text { Lentivirus } \\
\text { pseudotype }\end{array}$ & 0.3 \\
\hline
\end{tabular}


1147 or deletions for ensovibep.

\begin{tabular}{|c|c|c|c|}
\hline $\begin{array}{l}\text { Amino } \\
\text { acid } \\
\text { position }\end{array}$ & $\begin{array}{l}\text { Substitution } \\
\text { I deletion }\end{array}$ & Assay Type & $\begin{array}{l}\text { Neutralizing } \mathrm{IC}_{50} \\
{[\mathrm{ng} / \mathrm{mL}]}\end{array}$ \\
\hline L18 & $\mathrm{F}$ & VSV & 3.5 \\
\hline T20 & $\mathrm{N}$ & VSV & 4.6 \\
\hline P26 & $S$ & VSV & 1.8 \\
\hline $69-70$ & del & VSV & 1.9 \\
\hline D80 & $A$ & VSV & 3.6 \\
\hline T95 & I & Lenti & 0.9 \\
\hline D138 & $\bar{Y}$ & VSV & 2.2 \\
\hline 145 & del & VSV & 2.1 \\
\hline W152 & $\mathrm{L}$ & Lenti & 1.2 \\
\hline R190 & $S$ & VSV & 1.7 \\
\hline A222 & $\mathrm{V}$ & VSV & 2.2 \\
\hline N234 & $\mathrm{Q}$ & VSV & 16.2 \\
\hline $242-244$ & del & VSV & 2.0 \\
\hline G339 & $\mathrm{D}$ & Lenti & 2.0 \\
\hline \multirow[t]{2}{*}{ E406 } & $Q$ & Lenti & 1.5 \\
\hline & $W$ & VSV & 2.7 \\
\hline Q409 & $E$ & VSV & 2.0 \\
\hline \multirow{4}{*}{ K417 } & $\mathrm{E}$ & VSV & 0.5 \\
\hline & $\mathrm{N}$ & VSV & 0.6 \\
\hline & $\mathrm{R}$ & VSV & 2.1 \\
\hline & $T$ & VSV & 0.5 \\
\hline D420 & $\mathrm{N}$ & VSV & 5.6 \\
\hline N439 & $\mathrm{K}$ & VSV & 1.3 \\
\hline \multirow{4}{*}{ K444 } & $\mathrm{E}$ & Lenti & 0.8 \\
\hline & $\mathrm{N}$ & VSV & 4.4 \\
\hline & $Q$ & Lenti & 1.3 \\
\hline & $T$ & VSV & 6.1 \\
\hline V445 & A & Lenti & 1.3 \\
\hline \multirow{2}{*}{ G446 } & $\mathrm{V}$ & VSV & 1.7 \\
\hline & $S$ & Lenti & 1.3 \\
\hline N450 & $\mathrm{D}$ & Lenti & 0.9 \\
\hline L452 & $\mathrm{R}$ & Lenti & 0.4 \\
\hline Y453 & $\mathrm{F}$ & VSV & 3.2 \\
\hline
\end{tabular}


bioRxiv preprint doi: https://doi.org/10.1101/2021.02.03.429164; this version posted December 17, 2021. The copyright holder for this preprint (which was not certified by peer review) is the author/funder, who has granted bioRxiv a license to display the preprint in perpetuity. It is made available under aCC-BY-NC-ND 4.0 International license.

\begin{tabular}{|c|c|c|c|}
\hline L455 & $F$ & Lenti & 1.1 \\
\hline \multirow{2}{*}{ N460 } & $S$ & VSV & 2.6 \\
\hline & $T$ & VSV & 0.6 \\
\hline A475 & $\mathrm{V}$ & Lenti & 0.9 \\
\hline G476 & $S$ & VSV & 1.5 \\
\hline S477 & $\mathrm{N}$ & VSV & 1.9 \\
\hline \multirow{2}{*}{ T478 } & I & VSV & 2.7 \\
\hline & $\mathrm{K}$ & Lenti & 1.5 \\
\hline P479 & $S$ & VSV & 2.1 \\
\hline V483 & A & VSV & 2.3 \\
\hline \multirow{3}{*}{ E484 } & A & Lenti & 2.4 \\
\hline & $\mathrm{K}$ & VSV & 2.7 \\
\hline & Q & Lenti & 2.3 \\
\hline G485 & D & VSV & 28.5 \\
\hline \multirow{2}{*}{ F486 } & $\mathrm{V}$ & VSV & $>100$ \\
\hline & $\mathrm{L}$ & VSV & $>100$ \\
\hline F490 & $S$ & VSV & 3.8 \\
\hline \multirow[t]{2}{*}{ Q493 } & $\bar{K}$ & VSV & 7.9 \\
\hline & $R$ & VSV & 2.2 \\
\hline S494 & $P$ & Lenti & 1.3 \\
\hline N501 & $\mathrm{Y}$ & VSV & 0.6 \\
\hline A570 & $\mathrm{D}$ & VSV & 1.2 \\
\hline D614 & G & VSV & 2.4 \\
\hline H655 & $\mathrm{Y}$ & VSV & 2.4 \\
\hline P681 & $\mathrm{H}$ & VSV & 1.5 \\
\hline A701 & V & VSV & 1.1 \\
\hline T716 & I & VSV & 0.6 \\
\hline S982 & $A$ & VSV & 2.0 \\
\hline T1027 & I & VSV & 3.3 \\
\hline D1118 & $\mathrm{H}$ & VSV & 2.6 \\
\hline
\end{tabular}


Supplementary Table 4: drug exposure levels in serum at day of euthanization.

Animals with drug exposure levels below $10 \%$ of the group average were removed from the study analysis (depicted in bold).

\begin{tabular}{|c|c|c|}
\hline \multicolumn{3}{|c|}{$\left(10 \begin{array}{c}\text { Ensovibep } \\
\text { mg/kg i.p.; 0 h p.i) }\end{array}\right.$} \\
\hline$\#$ & Animal ID & $\begin{array}{c}\text { Serum concentration } \\
{[\mu \mathrm{gg} / \mathrm{mL}]}\end{array}$ \\
\hline 1 & DN5_1 & 86.9 \\
\hline $\mathbf{2}$ & DN5_2 & $\mathbf{2 . 7}$ \\
\hline 3 & DN5_3 & 169.7 \\
\hline 4 & DN5_4 & 44.5 \\
\hline 5 & DN5_5 & 92.9 \\
\hline 6 & DN5_6 & 39.2 \\
\hline 7 & DN5_7 & 1.5 \\
\hline 8 & DN5_8 & 109.4 \\
\hline 9 & DN5_9 & 51.8 \\
\hline 10 & DN5_10 & 127.9 \\
\hline 11 & DN5_11 & 70.2 \\
\hline 12 & DN5_12 & 38.6 \\
\hline
\end{tabular}

\begin{tabular}{|c|c|c|}
\hline \multicolumn{3}{|c|}{$\left(10 \begin{array}{c}\text { Ensovibep } \\
\text { mg/kg i.p.; 24 h p.i) }\end{array}\right.$} \\
\hline$\#$ & Animal ID & $\begin{array}{c}\text { Serum concentration } \\
{[\mu \mathrm{gg} / \mathrm{mL}]}\end{array}$ \\
\hline 1 & DN5_25 & 17.0 \\
\hline $\mathbf{2}$ & DN5_26 & $\mathbf{1 . 8}$ \\
\hline 3 & DN5_27 & 39.1 \\
\hline 4 & DN5_28 & N/A \\
\hline 5 & DN5_29 & 48.0 \\
\hline $\mathbf{6}$ & DN5_30 & $\mathbf{5 . 7}$ \\
\hline 7 & DN5_31 & 225.1 \\
\hline 8 & DN5_32 & 27.3 \\
\hline 9 & DN5_33 & 66.6 \\
\hline 10 & DN5_34 & 109.5 \\
\hline 11 & DN5_35 & 128.4 \\
\hline 12 & DN5_36 & 78.3 \\
\hline
\end{tabular}

\begin{tabular}{|c|c|c|}
\hline \multicolumn{3}{|c|}{$\begin{array}{r}\text { REGN10933 \& REGN10987 } \\
(5+5 \mathrm{mg} / \mathrm{kg} \text { i.p.; 0 h p.i) }\end{array}$} \\
\hline$\#$ & Animal ID & $\begin{array}{r}\text { Serum concentration } \\
{[\mu \mathrm{mg} / \mathrm{mL}]}\end{array}$ \\
\hline 1 & DN5_13 & 29.0 \\
\hline $\mathbf{2}$ & DN5_14 & $\mathbf{0 . 3}$ \\
\hline 3 & DN5_15 & 26.5 \\
\hline $\mathbf{4}$ & DN5_16 & $\mathbf{1 . 1}$ \\
\hline 5 & DN5_17 & 34.0 \\
\hline $\mathbf{6}$ & DN5_18 & $\mathbf{1 . 4}$ \\
\hline 7 & DN5_19 & 41.9 \\
\hline 8 & DN5_20 & 30.3 \\
\hline 9 & DN5_21 & 43.5 \\
\hline 10 & DN5_22 & 38.0 \\
\hline 11 & DN5_23 & 28.1 \\
\hline 12 & DN5_24 & 32.7 \\
\hline
\end{tabular}

\begin{tabular}{|c|c|c|}
\hline \multicolumn{3}{|c|}{$\begin{array}{r}\text { REGN10933 \& REGN10987 } \\
(5+5 \mathrm{mg} / \mathrm{kg} \text { i.p.; 24 h p.i) }\end{array}$} \\
\hline$\#$ & Animal ID & $\begin{array}{c}\text { Serum concentration } \\
{[\mu \mathrm{mg} / \mathrm{mL}]}\end{array}$ \\
\hline 1 & DN5_37 & 72.0 \\
\hline 2 & DN5_38 & 60.9 \\
\hline 3 & DN5_39 & 42.8 \\
\hline 4 & DN5_40 & 32.6 \\
\hline 5 & DN5_41 & 46.7 \\
\hline 6 & DN5_42 & 41.9 \\
\hline 7 & DN5_43 & 43.7 \\
\hline 8 & DN5_44 & 45.3 \\
\hline 9 & DN5_45 & 46.1 \\
\hline 10 & DN5_46 & 61.9 \\
\hline 11 & DN5_47 & 37.2 \\
\hline 12 & DN5_48 & 41.8 \\
\hline
\end{tabular}

N/A: Not available due to low amount of serum extracted from terminal bleeds

Bold: animals removed from the study data due to low therapeutic exposure

Red: animals taken out at 2 dpi

Blue: animals taken out at 3 dpi

Green: animals taken out at 5dpi 
Supplementary Table 5: Identification of escape mutations by deep sequencing of SARS-CoV-2 Alpha variant B.1.1.7 in animals at day 5 p.i., which indicated remaining viral titers. As a control, three non-treated animals were also deep sequenced. Deep Sequencing was performed from either swab (S) or lung $(L)$ extracted RNA.

\begin{tabular}{|c|c|c|c|c|}
\hline Treatment group & $\begin{array}{c}\text { Animal } \\
\text { identifier }\end{array}$ & $\begin{array}{l}\text { Throat swab (S) or } \\
\text { lung homogenate (L) }\end{array}$ & $\begin{array}{l}\text { Identified spike protein } \\
\text { amino acid substitution }\end{array}$ & $\begin{array}{l}\text { Potential } \\
\text { Impact }\end{array}$ \\
\hline \multirow{4}{*}{$\begin{array}{l}\text { Ensovibep } \\
0 \text { dpi }\end{array}$} & \multirow{2}{*}{ DN5_2 } & L & - & - \\
\hline & & $\mathrm{s}$ & - & - \\
\hline & \multirow[b]{2}{*}{ DN5_4 } & $\mathrm{L}$ & - & - \\
\hline & & $\mathrm{S}$ & K1034M & $\begin{array}{c}\text { Neutral / outside } \\
\text { ensovibep epitope }\end{array}$ \\
\hline \multirow{4}{*}{$\begin{array}{l}\text { antibody cocktail } \\
0 \text { dpi }\end{array}$} & \multirow{2}{*}{ DN5_15 } & L & - & - \\
\hline & & $\mathrm{s}$ & - & - \\
\hline & \multirow{2}{*}{ DN5_24 } & $\mathrm{L}$ & - & - \\
\hline & & $\mathrm{S}$ & - & - \\
\hline \multirow{2}{*}{$\begin{array}{l}\text { Ensovibep } \\
1 \mathrm{dpi}\end{array}$} & \multirow{2}{*}{ DN5_30 } & $\mathrm{L}$ & - & - \\
\hline & & $S$ & - & - \\
\hline \multirow{6}{*}{ Placebo group } & \multirow{2}{*}{ DN5_50 } & $\mathrm{L}$ & - & - \\
\hline & & $S$ & R671L & At furin cleavage site \\
\hline & \multirow{2}{*}{ DN5_52 } & $\mathrm{L}$ & - & - \\
\hline & & $\mathrm{S}$ & $\mathrm{R} 671 \mathrm{~L}$ & At furin cleavage site \\
\hline & \multirow{2}{*}{ DN5_53 } & $\mathrm{L}$ & - & - \\
\hline & & $\mathrm{s}$ & - & - \\
\hline
\end{tabular}


bioRxiv preprint doi: https://doi.org/10.1101/2021.02 03 429164; this version posted December 17, 2021. The copyright holder for this

preprint (which was not certified by peer review) is the author/funder, who has granted bioRxiv a license to display the preprint in perpetuity. It is made available under aCC-BY-NC-ND 4.0 International license.

1153

1154

\section{Supplementary Table 6 : Histopathology data table}

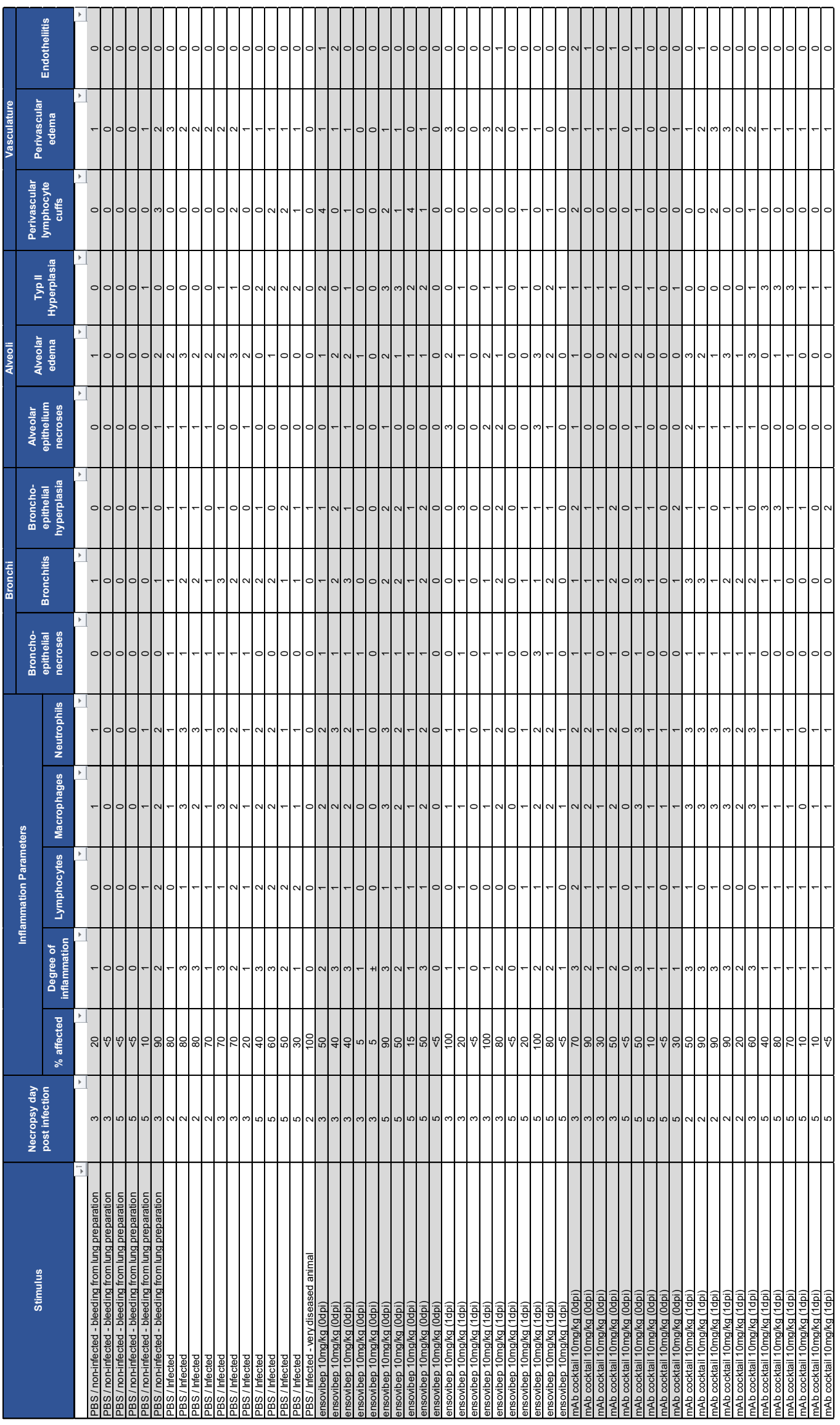




\section{References}

$1 \quad$ Zhou, P. et al. A pneumonia outbreak associated with a new coronavirus of probable bat origin. Nature 579, 270-273, doi:10.1038/s41586-020-2012-7 (2020).

2 Shang, J. et al. Structural basis of receptor recognition by SARS-CoV-2. Nature 581, 221-224, doi:10.1038/s41586-020-2179-y (2020).

3 Tortorici, M. A. \& Veesler, D. Structural insights into coronavirus entry. Adv Virus Res 105, 93-116, doi:10.1016/bs.aivir.2019.08.002 (2019).

$4 \quad$ Letko, M., Marzi, A. \& Munster, V. Functional assessment of cell entry and receptor usage for SARSCoV-2 and other lineage B betacoronaviruses. Nat Microbio/ 5, 562-569, doi:10.1038/s41564-020-0688y (2020).

$5 \quad$ Walls, A. C. et al. Structure, Function, and Antigenicity of the SARS-CoV-2 Spike Glycoprotein. Cell 181, 281-292 e286, doi:10.1016/j.cell.2020.02.058 (2020).

$6 \quad$ Walls, A. C. et al. Cryo-electron microscopy structure of a coronavirus spike glycoprotein trimer. Nature 531, 114-117, doi:10.1038/nature16988 (2016).

$7 \quad$ Walls, A. C. et al. Tectonic conformational changes of a coronavirus spike glycoprotein promote membrane fusion. Proc Natl Acad Sci U S A 114, 11157-11162, doi:10.1073/pnas.1708727114 (2017).

$8 \quad H o f f m a n n$, M. et al. SARS-CoV-2 Cell Entry Depends on ACE2 and TMPRSS2 and Is Blocked by a Clinically Proven Protease Inhibitor. Cell 181, 271-280 e278, doi:10.1016/j.cell.2020.02.052 (2020).

9 Jun Zhang1, Yongfei Cai1,2†, Tianshu Xiao1,2, Jianming Lu3, Hanqin Peng1, Sarah M. Sterling4,5, Richard M. Walsh Jr.4,5, Sophia Rits-Volloch1, Haisun Zhu6, Alec N. Woosley6, Wei Yang6, Piotr Sliz1,2,5, Bing Chen1,2*. Structural impact on SARS SoV-2 spike protein by D614G substitution. Science (2021).

10 Garcia-Beltran, W. F. et al. Multiple SARS-CoV-2 variants escape neutralization by vaccine-induced humoral immunity. Cell 184, 2372-2383 e2379, doi:10.1016/j.cell.2021.03.013 (2021).

11 Greaney, A. J. et al. Complete Mapping of Mutations to the SARS-CoV-2 Spike Receptor-Binding Domain that Escape Antibody Recognition. Cell host \& microbe 29, 44-57.e49, doi:10.1016/j.chom.2020.11.007 (2021).

12 Lusvarghi, S. et al. Key substitutions in the spike protein of SARS-CoV-2 variants can predict resistance to monoclonal antibodies, but other substitutions can modify the effects. bioRxiv, 2021.2007.2016.452748, doi:10.1101/2021.07.16.452748 (2021).

13 Starr, T. N. et al. Deep Mutational Scanning of SARS-CoV-2 Receptor Binding Domain Reveals Constraints on Folding and ACE2 Binding. Cell 182, 1295-1310.e1220, doi:10.1016/j.cell.2020.08.012 (2020).

14 Thomson, E. C. et al. Circulating SARS-CoV-2 spike N439K variants maintain fitness while evading antibody-mediated immunity. Cell 184, 1171-1187.e1120, doi:10.1016/j.cell.2021.01.037 (2021).

15 Wang, P. et al. Increased Resistance of SARS-CoV-2 Variants B.1.351 and B.1.1.7 to Antibody Neutralization. bioRxiv, doi:10.1101/2021.01.25.428137 (2021).

16 Yi, C. et al. Key residues of the receptor binding motif in the spike protein of SARS-CoV-2 that interact with ACE2 and neutralizing antibodies. Cell Mol Immunol 17, 621-630, doi:10.1038/s41423-020-0458-z (2020).

17 Liu, Z. et al. Identification of SARS-CoV-2 spike mutations that attenuate monoclonal and serum antibody neutralization. Cell host \& microbe 29, 477-488.e474, doi:10.1016/j.chom.2021.01.014 (2021).

18 Zhou, D. et al. Evidence of escape of SARS-CoV-2 variant B.1.351 from natural and vaccine-induced sera. Cell 184, 2348-2361.e2346, doi:https://doi.org/10.1016/j.cell.2021.02.037 (2021).

19 Gobeil, S. M.-C. et al. Effect of natural mutations of SARS-CoV-2 on spike structure, conformation, and antigenicity. Science 373, eabi6226, doi:doi:10.1126/science.abi6226 (2021).

20 Tegally, $H$. et al. Emergence and rapid spread of a new severe acute respiratory syndrome-related coronavirus 2 (SARS-CoV-2) lineage with multiple spike mutations in South Africa. medRxiv, doi:10.1101/2020.12.21.20248640 (2020).

21 Voloch, C. M. et al. Novel circulating lineage of SARS-CoV-2 in the state of Rio de Janeiro Brazil originated from B.1.1.28 lineage. medRxiv, doi:10.1101/2020.12.23.20248598 (2020).

22 Cele, S. et al. SARS-CoV-2 Omicron has extensive but incomplete escape of Pfizer BNT162b2 elicited neutralization and requires ACE2 for infection. medRxiv, 2021.2012.2008.21267417, doi:10.1101/2021.12.08.21267417 (2021).

23 Thomson, E. C. et al. The circulating SARS-CoV-2 spike variant N439K maintains fitness while evading antibody-mediated immunity. bioRxiv, doi:10.1101/2020.11.04.355842 (2020). 
bioRxiv preprint doi: https://doi.org/10.1101/2021.02.03.429164; this version posted December 17, 2021. The copyright holder for this preprint (which was not certified by peer review) is the author/funder, who has granted bioRxiv a license to display the preprint in perpetuity. It is made available under aCC-BY-NC-ND 4.0 International license.

24 Laffeber, C., de Koning, K., Kanaar, R. \& Lebbink, J. H. G. Experimental Evidence for Enhanced Receptor Binding by Rapidly Spreading SARS-CoV-2 Variants. Journal of Molecular Biology 433, 167058, doi:10.1016/j.jmb.2021.167058 (2021).

25 Planas, D. et al. Reduced sensitivity of SARS-CoV-2 variant Delta to antibody neutralization. Nature 596, 276-280, doi:10.1038/s41586-021-03777-9 (2021).

26 Ledford, H. The race to make COVID antibody therapies cheaper and more potent. Nature 587, 18, doi:10.1038/d41586-020-02965-3 (2020).

27 Baum, A. et al. Antibody cocktail to SARS-CoV-2 spike protein prevents rapid mutational escape seen with individual antibodies. Science 369, 1014-1018, doi:10.1126/science.abd0831 (2020).

28 Copin, R. et al. The monoclonal antibody combination REGEN-COV protects against SARS-CoV-2 mutational escape in preclinical and human studies. Cell 184, 3949-3961.e3911, doi:10.1016/j.cell.2021.06.002 (2021).

$29 \mathrm{Ku}, \mathrm{Z}$. et al. Molecular determinants and mechanism for antibody cocktail preventing SARS-CoV-2 escape. Nat Commun 12, 469, doi:10.1038/s41467-020-20789-7 (2021).

30 Binz, H. K. et al. High-affinity binders selected from designed ankyrin repeat protein libraries. Nat Biotechnol 22, 575-582, doi:10.1038/nbt962 (2004).

31 Walser, M. et al. Highly potent anti-SARS-CoV-2 multivalent DARPin therapeutic candidates. bioRxiv (2020).

32 Stumpp, M. T., Dawson, K. M. \& Binz, H. K. Beyond Antibodies: The DARPin((R)) Drug Platform. BioDrugs 34, 423-433, doi:10.1007/s40259-020-00429-8 (2020).

33 Binz, H. K. et al. Design and characterization of MP0250, a tri-specific anti-HGF/anti-VEGF DARPin(R) drug candidate. MAbs 9, 1262-1269, doi:10.1080/19420862.2017.1305529 (2017).

34 Fiedler, U. et al. MP0250, a VEGF and HGF neutralizing DARPin((R)) molecule shows high anti-tumor efficacy in mouse xenograft and patient-derived tumor models. Oncotarget 8, 98371-98383, doi:10.18632/oncotarget.21738 (2017).

35 Steiner, D. et al. Half-life extension using serum albumin-binding DARPin(R) domains. Protein Eng Des Sel 30, 583-591, doi:10.1093/protein/gzx022 (2017).

36 Copin, R. et al. In vitro and in vivo preclinical studies predict REGEN-COV protection against emergence of viral escape in humans. bioRxiv, doi:10.1101/2021.03.10.434834v3 (2021).

37 Cathcart, A. et al. The dual function monoclonal antibodies VIR-7831 and VIR-7832 demonstrate potent in vitro and in vivo activity against SARS-CoV-2. bioRxiv, doi:10.1101/2021.03.09.434607v1 (2021).

38 Trimpert, J. et al. The Roborovski Dwarf Hamster Is A Highly Susceptible Model for a Rapid and Fatal Course of SARS-CoV-2 Infection. Cell reports 33, 108488, doi:10.1016/j.celrep.2020.108488 (2020).

39 Walls, A. C. et al. Unexpected Receptor Functional Mimicry Elucidates Activation of Coronavirus Fusion. Cell 176, 1026-1039 e1015, doi:10.1016/j.cell.2018.12.028 (2019).

40 Corti, D., Purcell, L. A., Snell, G. \& Veesler, D. Tackling COVID-19 with neutralizing monoclonal antibodies. Cell 184, 3086-3108, doi:10.1016/j.cell.2021.05.005 (2021).

41 Falsey, A. R. et al. SARS-CoV-2 Neutralization with BNT162b2 Vaccine Dose 3. N Engl J Med, doi:10.1056/NEJMc2113468 (2021).

42 Hoffmann, M. et al. SARS-CoV-2 variants B.1.351 and P.1 escape from neutralizing antibodies. Cell 184, 2384-2393.e2312, doi:10.1016/j.cell.2021.03.036 (2021).

43 Pulliam, J. R. C. et al. Increased risk of SARS-CoV-2 reinfection associated with emergence of the Omicron variant in South Africa. medRxiv, 2021.2011.2011.21266068, doi:10.1101/2021.11.11.21266068 (2021).

44 Casalino, L. et al. Beyond Shielding: The Roles of Glycans in the SARS-CoV-2 Spike Protein. ACS Cent Sci 6, 1722-1734, doi:10.1021/acscentsci.0c01056 (2020).

45 Andreano, E. et al. SARS-CoV-2 escape in vitro from a highly neutralizing COVID-19 convalescent plasma. bioRxiv, doi:10.1101/2020.12.28.424451 (2020).

46 Osterrieder, N. et al. Age-Dependent Progression of SARS-CoV-2 Infection in Syrian Hamsters. Viruses 12, doi:10.3390/v12070779 (2020).

$47 \quad$ Nouailles, G. et al. Temporal omics analysis in Syrian hamsters unravel cellular effector responses to moderate COVID-19. Nat Commun 12, 4869, doi:10.1038/s41467-021-25030-7 (2021).

$48 \quad$ Kumari, P. et al. Neuroinvasion and Encephalitis Following Intranasal Inoculation of SARS-CoV-2 in K18hACE2 Mice. Viruses 13, doi:10.3390/v13010132 (2021).

49 Schoof, M. et al. An ultrapotent synthetic nanobody neutralizes SARS-CoV-2 by stabilizing inactive Spike. Science 370, 1473-1479, doi:10.1126/science.abe3255 (2020). 
126750 Cao, L. et al. De novo design of picomolar SARS-CoV-2 miniprotein inhibitors. Science 370, 426-431,

51 Linsky, T. W. et al. De novo design of potent and resilient hACE2 decoys to neutralize SARS-CoV-2. Science 370, 1208-1214, doi:10.1126/science.abe0075 (2020).

52 Walter, J. D., Hutter, C. A. J., Garaeva, A. A., Scherer, M. \& Zimmermann, I. Highly potent bispecific sybodies neutralize SARS-CoV-2. bioRxiv (2020).

53 Hunt, A. C. et al. Multivalent designed proteins protect against SARS-CoV-2 variants of concern. bioRxiv, doi:10.1101/2021.07.07.451375 (2021).

54 Jones, B. E. et al. LY-CoV555, a rapidly isolated potent neutralizing antibody, provides protection in a non-human primate model of SARS-CoV-2 infection. bioRxiv, doi:10.1101/2020.09.30.318972 (2020). Pinto, D. et al. Cross-neutralization of SARS-CoV-2 by a human monoclonal SARS-CoV antibody. Nature 583, 290-295, doi:10.1038/s41586-020-2349-y (2020).

56 Shi, R. et al. A human neutralizing antibody targets the receptor-binding site of SARS-CoV-2. Nature 584, 120-124, doi:10.1038/s41586-020-2381-y (2020).

57 Starr, T. N. et al. Deep Mutational Scanning of SARS-CoV-2 Receptor Binding Domain Reveals Constraints on Folding and ACE2 Binding. Cell 182, 1295-1310 e1220, doi:10.1016/j.cell.2020.08.012 (2020).

58 Zahradnik, J. et al. SARS-CoV-2 RBD in vitro evolution follows contagious mutation spread, yet generates an able infection inhibitor. bioRxiv, doi:10.1101/2021.01.06.425392v3 (2021).

59 Cao, Y. et al. B.1.1.529 escapes the majority of SARS-CoV-2 neutralizing antibodies of diverse epitopes. bioRxiv, 2021.2012.2007.470392, doi:10.1101/2021.12.07.470392 (2021).

60 Zivanov, J. et al. New tools for automated high-resolution cryo-EM structure determination in RELION3. Elife 7, doi:10.7554/eLife.42166 (2018).

61 Zheng, S. Q. et al. MotionCor2: anisotropic correction of beam-induced motion for improved cryoelectron microscopy. Nat Methods 14, 331-332, doi:10.1038/nmeth.4193 (2017). Zhang, K. Gctf: Real-time CTF determination and correction. J Struct Biol 193, 1-12, doi:10.1016/j.jsb.2015.11.003 (2016).

63 Pettersen, E. F. et al. UCSF Chimera--a visualization system for exploratory research and analysis. J Comput Chem 25, 1605-1612, doi:10.1002/jcc.20084 (2004).

64 Wrapp, D. et al. Cryo-EM structure of the 2019-nCoV spike in the prefusion conformation. Science 367, 1260-1263, doi:10.1126/science.abb2507 (2020).

65 Sanchez-Garcia, R. et al. DeepEMhancer: a deep learning solution for cryo-EM volume post-processing. bioRxiv, doi:10.1101/2020.06.12.148296 (2020).

66 Cianfrocco, M. A., Wong, M., Youn, C. \& Wagner, R. in The Practice and Experience in Advanced Research Computing (New Orleans, LA 2017).

67 Chaudhury, S. et al. Benchmarking and analysis of protein docking performance in Rosetta v3.2. PLoS One 6, e22477, doi:10.1371/journal.pone.0022477 (2011).

68 Huang, P. S. et al. RosettaRemodel: a generalized framework for flexible backbone protein design. PLoS One 6, e24109, doi:10.1371/journal.pone.0024109 (2011).

69 Leaver-Fay, A. et al. ROSETTA3: an object-oriented software suite for the simulation and design of macromolecules. Methods Enzymol 487, 545-574, doi:10.1016/B978-0-12-381270-4.00019-6 (2011). Laskowski, R. A. \& Swindells, M. B. LigPlot+: multiple ligand-protein interaction diagrams for drug discovery. J Chem Inf Model 51, 2778-2786, doi:10.1021/ci200227u (2011).

71 Goddard, T. D. et al. UCSF ChimeraX: Meeting modern challenges in visualization and analysis. Protein Sci 27, 14-25, doi:10.1002/pro.3235 (2018).

72 Berger Rentsch, M. \& Zimmer, G. A vesicular stomatitis virus replicon-based bioassay for the rapid and sensitive determination of multi-species type I interferon. PLoS One 6, e25858, doi:10.1371/journal.pone.0025858 (2011).

73 Torriani, G. et al. Macropinocytosis contributes to hantavirus entry into human airway epithelial cells. Virology 531, 57-68, doi:10.1016/j.virol.2019.02.013 (2019).

74 Torriani, G. et al. Identification of Clotrimazole Derivatives as Specific Inhibitors of Arenavirus Fusion. J Virol 93, doi:10.1128/JVI.01744-18 (2019).

75 Matsuyama, S. et al. Enhanced isolation of SARS-CoV-2 by TMPRSS2-expressing cells. Proc Natl Acad Sci U S A 117, 7001-7003, doi:10.1073/pnas.2002589117 (2020).

$76 \quad$ Nao, N. et al. Consensus and variations in cell line specificity among human metapneumovirus strains. PLoS One 14, e0215822, doi:10.1371/journal.pone.0215822 (2019). 
bioRxiv preprint doi: https://doi.org/10.1101/2021.02.03.429164; this version posted December 17, 2021. The copyright holder for this

preprint (which was not certified by peer review) is the author/funder, who has granted bioRxiv a license to display the preprint in perpetuity. It is made available under aCC-BY-NC-ND 4.0 International license.

77 Neerukonda, S. N. et al. Establishment of a well-characterized SARS-CoV-2 lentiviral pseudovirus neutralization assay using 293T cells with stable expression of ACE2 and TMPRSS2. PLoS One 16, e0248348, doi:10.1371/journal.pone.0248348 (2021).

78 Wollscheid, B. et al. Mass-spectrometric identification and relative quantification of N-linked cell surface glycoproteins. Nat Biotechnol 27, 378-386, doi:10.1038/nbt.1532 (2009).

$79 \mathrm{Li}, \mathrm{H}$. et al. The Sequence Alignment/Map format and SAMtools. Bioinformatics 25, 2078-2079, doi:10.1093/bioinformatics/btp352 (2009).

80 Bolger, A. M., Lohse, M. \& Usadel, B. Trimmomatic: a flexible trimmer for Illumina sequence data. Bioinformatics 30, 2114-2120, doi:10.1093/bioinformatics/btu170 (2014).

81 Li, H. \& Durbin, R. Fast and accurate short read alignment with Burrows-Wheeler transform. Bioinformatics 25, 1754-1760, doi:10.1093/bioinformatics/btp324 (2009).

82 Wilm, A. et al. LoFreq: a sequence-quality aware, ultra-sensitive variant caller for uncovering cellpopulation heterogeneity from high-throughput sequencing datasets. Nucleic Acids Res 40, 1118911201, doi:10.1093/nar/gks918 (2012).

83 Cingolani, P. et al. A program for annotating and predicting the effects of single nucleotide polymorphisms, SnpEff: SNPs in the genome of Drosophila melanogaster strain w1118; iso-2; iso-3. Fly (Austin) 6, 80-92, doi:10.4161/fly.19695 (2012).

84 Gu, Z., Eils, R. \& Schlesner, M. Complex heatmaps reveal patterns and correlations in multidimensional genomic data. Bioinformatics 32, 2847-2849, doi:10.1093/bioinformatics/btw313 (2016).

85 Copin, R. et al. In vitro and in vivo preclinical studies predict REGEN-COV protection against emergence of viral escape in humans. doi:10.1101/2021.03.10.434834 (2021).

86 Corman, V. M. et al. Detection of 2019 novel coronavirus (2019-nCoV) by real-time RT-PCR. Euro Surveill 25, doi:10.2807/1560-7917.ES.2020.25.3.2000045 (2020).

87 Gruber, A. D. et al. Standardization of Reporting Criteria for Lung Pathology in SARS-CoV-2-infected Hamsters: What Matters? Am J Respir Cell Mol Biol 63, 856-859, doi:10.1165/rcmb.2020-0280LE (2020).

88 Danecek, P. et al. Twelve years of SAMtools and BCFtools. GigaScience 10, doi:10.1093/gigascience/giab008 (2021).

89 Robinson, J. T. et al. Integrative genomics viewer. Nat Biotechnol 29, 24-26, doi:10.1038/nbt.1754 (2011).

90 Duvaud, S. et al. Expasy, the Swiss Bioinformatics Resource Portal, as designed by its users. Nucleic Acids Res 49, W216-w227, doi:10.1093/nar/gkab225 (2021).

91 Choi, Y., Sims, G. E., Murphy, S., Miller, J. R. \& Chan, A. P. Predicting the functional effect of amino acid substitutions and indels. PLoS One 7, e46688, doi:10.1371/journal.pone.0046688 (2012). Choi, Y. in Proceedings of the ACM Conference on Bioinformatics, Computational Biology and Biomedicine 414-417 (Association for Computing Machinery, Orlando, Florida, 2012).

$93 \mathrm{Sim}$, N. L. et al. SIFT web server: predicting effects of amino acid substitutions on proteins. Nucleic Acids Res 40, W452-457, doi:10.1093/nar/gks539 (2012).

94 Friedrich, M. et al. Preclinical characterization of AMG 330, a CD3/CD33-bispecific T-cell-engaging antibody with potential for treatment of acute myelogenous leukemia. Mol Cancer Ther 13, 1549-1557, doi:10.1158/1535-7163.MCT-13-0956 (2014). 